\title{
Localization of Orphanin FQ (Nociceptin) Peptide and Messenger RNA in the Central Nervous System of the Rat
}

\author{
CHARLES R. NEAL, JR., $1,2 *$ ALFRE D MANSOUR, ${ }^{3}$ RAINER REINSCHEID, ${ }^{4}$ \\ HANS-PETER NOTHACKER, ${ }^{5}$ OLIVIER CIVELLI, ${ }^{5}$ AND STANLEY J . WATSON, J R. ${ }^{1,6}$ \\ ${ }^{1}$ Mental Health Research Institute, University of Michigan Medical Center, \\ Ann Arbor, Michigan 48109-0720 \\ 2Department of Pediatrics, University of Michigan Medical Center, \\ Ann Arbor, Michigan 48109-0720 \\ 3P harmaco Genesis Corporation, West Bloomfield, Michigan 48322 \\ ${ }^{4}$ University Hospital Eppendorf, Hamburg, Germany \\ ${ }^{5}$ Department of Pharmacology, College of Medicine, University of California-Irvine, \\ I rvine, California 92697-4625 \\ ${ }^{6}$ Department of Psychiatry, University of Michigan Medical Center, \\ Ann Arbor, Michigan 48109-0720
}

\begin{abstract}
Orphanin FQ (OFQ) is the endogenous agonist of the opioid receptor-like receptor (ORL-1). It and its precursor, prepro-OF Q, exhibit structural features suggestive of the opioid peptides. A cDNA encoding the OFQ precursor sequence in the rat recently has been cloned, and the authors recently generated a polyclonal antibody directed against the OF Q peptide. In the present study, the authors used in situ hybridization and immunohistochemistry to examinethe distribution of OF Q peptide and mRNA in the central nervous system of the adult rat. OFQ immunoreactivity and prepro-OFQ mRNA expression correlated virtually in all brain areas studied. In the forebrain, OFQ peptide and mRNA were prominent in the neocortex endopiriform nucleus, claustrum, lateral septum, ventral forebrain, hypothalamus, mammillary bodies, central and medial nuclei of the amygdala, hippocampal formation, paratenial and reticular nuclei of the thalamus, medial habenula, and zona incerta. No OFQ was observed in the pineal or pituitary glands. In the brainstem, OFQ was prominent in the ventral tegmental area, substantia nigra, nucleus of the posterior commissure, central gray, nucleus of Darkschewitsch, peripeduncular nucleus, interpeduncular nucleus, tegmental nuclei, locus coeruleus, raphe complex, lateral parabrachial nucleus, inferior ol ivary complex, vestibular nudlear complex, prepositus hypoglossus, solitary nucleus, nucleus ambiguous, caudal spinal trigeminal nucleus, and reticular formation. In the spinal cord, OFQ was observed throughout the dorsal and ventral horns. The wide distribution of this peptide provides support for its rolein a multitude of functions, including not only nociception but also motor and balance control, special sensory processing, and various autonomic and physiologic processes. J . Comp. Neurol. 406:503-547, 1999. ๑ 1999 Wiley-Liss, Inc.
\end{abstract}

Indexing terms: immunohistochemistry; in situ hybridization; mapping; mRNA; polyclonal antibody

Following the cloning of the $\mathrm{mu}(\mu)$, delta $(\delta)$, and kappa (к) receptors, a novel clone also was isolated (Marchese et al., 1994). This cDNA encoded a putative membrane receptor with homology to the $\mu, \delta$, and $\kappa$ opioid receptors (Bunzow et al., 1994; Wick et al., 1994). Early studies of this new clone demonstrated that it is homologous to opioid receptors in rat, mouse, and human but is distinct in its structure and distribution (Chen et al., 1994; Fukuda et al., 1994; Lachowic et al., 1994). This orphan clone has been isolated and named opioid receptor-like(ORL 1) recep- tor to emphasize its relationship to the known opioid receptors (Mollereau et al., 1994). Splice variants and

Grant sponsor: National Institute of Mental Health; Grant number: 5 T32 MH15794; Grant sponsor: National Institute of Drug Abuse; Grant number: RO1 DA08920.

*Correspondence to: Charles R. Neal, J r., M.D., Ph.D., Mental Health Research Institute, 205 Zina Pitcher Place, Ann Arbor, MI 48109-0720. E-mail: crnj@umich.edu

Received 15A pril 1998; Revised 16 October 1998; Accepted 23 October 1998. 


\begin{tabular}{|c|c|c|c|}
\hline \multicolumn{4}{|c|}{ Abbreviations } \\
\hline $3 \mathrm{~V}$ & third ventricle & $\mathrm{Cl}$ & claustrum \\
\hline $4 \mathrm{~V}$ & fourth ventricle & $\mathrm{CL}$ & centrolateral thalamic nucleus \\
\hline 6 & abducens nucleus & CLi (B8) & caudal linear nucleus of the raphe \\
\hline $6 n$ & root of the abducens nerve & CM & central medial thalamic nucleus \\
\hline 7 & facial nucleus & $\mathrm{CnF}$ & cuneiform nucleus \\
\hline $7 n$ & facial nerve & $\mathrm{cp}$ & cerebral peduncle \\
\hline $8 n$ & vestibulocochlear nerve & CPO & caudal periolivary nucleus \\
\hline $9 n$ & glossopharyngeal nerve & $\mathrm{CPu}$ & caudate putamen (striatum) \\
\hline 10 & dorsal motor nucleus of the vagal nerve & CSC & commissure of the superior colliculus \\
\hline 12 & hypoglossal nucleus & $\mathrm{ctg}$ & central tegmental tract \\
\hline $12 n$ & root of the hypoglossal nerve & $\mathrm{Cu}$ & cuneate fasciculus \\
\hline A5 & A5 noradrenaline cells & $\mathrm{Cu}$ & cuneate nucleus \\
\hline A7 & A7 noradrenaline cells & DA & dorsal hypothalamic area \\
\hline AAA & anterior amygdaloid area & $\mathrm{DC}$ & dorsal cochlear nucleus \\
\hline ac & anterior commissure & $\mathrm{DCIC}$ & dorsal cortex of the inferior colliculus \\
\hline $\mathrm{Acb}$ & accumbens nucleus & dcs & dorsal corticospinal tract \\
\hline $\mathrm{AcbC}$ & accumbens nucleus, core & DEn & dorsal endopiriform nucleus \\
\hline AcbSh & accumbens nucleus, shell & df & dorsal fornix \\
\hline ACo & anterior cortical amygdaloid nucleus & DG & dentate gyrus \\
\hline$A D$ & anterodorsal thalamic nucleus & DGgr & dentate gyrus, granule cell layer \\
\hline $\mathrm{AHA}$ & anterior hypothalamic area & DGhi & dentate gyrus, hilum \\
\hline $\mathrm{AHIA}$ & amygdalohippocampal area & DGmo & dentate gyrus, molecular layer \\
\hline $\mathrm{Al}$ & agranular insular cortex & DGpo & dentate gyrus, polymorph layer \\
\hline$A L$ & anterior lobe, pituitary gland & $\mathrm{DH}$ & dorsal horn of the spinal cord \\
\hline alv & alveus & $\mathrm{Dk}$ & nucleus of Darkschewitsch \\
\hline AM & anteromedial thalamic nucleus & dlf & dorsal longitudinal fasciculus \\
\hline Amb & nucleus ambiguous & DLL & dorsal nucleus of the lateral lemniscus \\
\hline AMPO & anterior medial preoptic nucleus & $\mathrm{DM}$ & dorsomedial hypothalamic nucleus \\
\hline AOD & anterior ol factory nucleus, dorsal & DMSp5 & dorsomedial spinal trigeminal nucleus \\
\hline $\mathrm{AOL}$ & anterior ol factory nucleus, lateral & DMTg & dorsomedial tegmental area \\
\hline AOM & anterior ol factory nucleus, medial & DP & dorsal peduncular cortex \\
\hline AOP & anterior olfactory nucleus, posterior & DPGi & dorsal paragigantocellular nucleus \\
\hline AOV & anterior olfactory nucleus, ventral & DpMe & deep mesencephalic nucleus \\
\hline APir & amygdal opiriform transition area & DPO & dorsal periolivary nucleus \\
\hline $\mathrm{APT}$ & anterior pretectal nucleus & $\mathrm{DR}(\mathrm{B} 6, \mathrm{~B} 7)$ & dorsal raphe \\
\hline APTD & anterior pretectal nucleus, dorsal part & DRG & dorsal root ganglion \\
\hline APTV & anterior pretectal nucleus, ventral part & DTg & dorsal tegmental nucleus \\
\hline $\mathrm{Aq}$ & aqueduct & $\mathrm{ECIC}$ & external cortex of the inferior colliculus \\
\hline Arc & arcuate nucleus & $\mathrm{ECu}$ & external cuneate nucleus \\
\hline ATg & anterior tegmental nucleus & Ent & entorhinal cortex \\
\hline AV & anteroventral thalamic nucleus & $\mathrm{EP}$ & entopeduncular nucleus \\
\hline AVPO & anteroventral preoptic nucleus & EW & E dinger-Westphal nucleus \\
\hline B & basal nucleus of M eynert & $f$ & fornix \\
\hline BAOT & bed nucleus of the accessory ol factory tract & $\mathrm{F}$ & nucleus of the fields of F orel \\
\hline bas & basilar artery & $\mathrm{fr}$ & fasciculus retroflexus \\
\hline bic & brachium of the inferior colliculus & $\mathrm{Fr}$ & frontal cortex \\
\hline $\mathrm{BIC}$ & nucleus of the brachium of the inferior colliculus & FStr & fundus striati \\
\hline $\mathrm{BL}$ & basolateral amygdaloid nucleus & $\mathrm{Gi}$ & gigantocellular reticular nucleus \\
\hline BM & basomedial amygdaloid nucleus & $\mathrm{Gl}$ & granular insular cortex \\
\hline BSTIA & bed nudeus of thestria terminalis, intraamygdaloid division & GiA & gigantocellular reticular nucleus, alpha \\
\hline BSTI & bed nucleus of the stria terminalis, Iateral division & GiV & gigantocellular reticular nucleus, ventral \\
\hline BSTId & bed nudeus of the stria terminalis, lateral division, dorsal part & GP & globus pallidus \\
\hline BSTIj & bed nucleus of the stria terminalis, lateral juxtacapsular part & $\mathrm{gr}$ & gracile fasciculus \\
\hline BSTIp & bed nucleus of the stria terminalis, lateral posterior part & $\mathrm{Gr}$ & gracile nucleus \\
\hline BSTIV & bed nucleus of the stria terminalis, lateral ventral part & HDB & nucleus of the horizontal limb of the diagonal band of Broca \\
\hline BSTma & bed nucleus of the stria terminalis, medial anterior part & hi & hilum of the dentate gyrus \\
\hline BSTmpl & bed nudeus of the stria terminalis, medial posterolateral part & $\mathrm{I}-\mathrm{X}$ & laminae $(I-X)$ of the spinal cord \\
\hline BSTmpm & bed nudeus of thestria terminalis, medial posteromedial part & 1 & intercalated nuclei of the amygdala \\
\hline BSTmv & bed nucleus of the stria terminalis, medial ventral part & IAD & interanterodorsal thalamic nucleus \\
\hline & $\mathrm{Cl}$ adrenaline cells & $\mathrm{ICj}$ & islands of Calleja \\
\hline $\mathrm{C} 2$ & C2 adrenaline cells & icp & inferior cerebellar peduncle \\
\hline C3 & C3 adrenaline cells & IG & indusium griseum \\
\hline CA3sl & field CA3 of Ammon's horn, stratum lucidum & 11 & intermediate lobe, pituitary gland \\
\hline CA1-3so & fiel ds CA1-CA3 of Ammon's horn, stratum oriens & IL & infralimbic cortex \\
\hline CA1-3sp & fiel ds CA1-CA3 of Ammon's horn, stratum pyramidal & ILL & intermediate nucleus of the lateral lemniscus \\
\hline CA1-3sr & fiel ds CA1-CA3 of Ammon's horn, stratum radiatum & IML & intermediolateral cell column \\
\hline CC & corpus callosum & IMLF & interstitial nucleus of the medial Iongitudinal fasciculus \\
\hline $\mathrm{CC}$ & central canal & IMM & intermediomedial cell column \\
\hline $\mathrm{Ce}$ & central amygdaloid nucleus & InCo & intercollicular nucleus \\
\hline CeL & central amygdaloid nucleus, lateral & IntA & interposed cerebellar nucleus, anterior part \\
\hline CeM & central amygdaloid nucleus, medial & IntDL & interposed cerebellar nucleus, dorsolateral part \\
\hline Cer & cerebellum & IntDM & interposed cerebellar nucleus, dorsomedial part \\
\hline $\mathrm{Cg}$ & cingulate gyrus & IntP & interposed cerebellar nucleus, posterior part \\
\hline CG & central gray & 10 & inferior olive \\
\hline CGD & central gray, dorsal & IOA & inferior olive, medial subnucleus A \\
\hline CGPn & pontine central gray & $\mathrm{IOB}$ & inferior olive, medial subnucleus B \\
\hline $\mathrm{Cl}$ & caudal interstitial nucleus, medial longitudinal fasciculus & IOD & inferior olive, dorsal \\
\hline cic & commissure of the inferior colliculus & IODM & inferior olive, dorsomedial \\
\hline $\mathrm{ClC}$ & central nucleus of the inferior colliculus & IOM & inferior olive, medial \\
\hline
\end{tabular}


$\begin{array}{ll}\text { IOPr } & \text { inferior olive, principal } \\ \text { IPC } & \text { interpeduncular nucleus, caudal }\end{array}$

IPD interpeduncular nucleus, dorsal

IPL interpeduncular nucleus, lateral

IPN interpeduncular nucleus

IPR interpeduncular nucleus, rostral

IPRL interpenduncular nucleus, rostrolateral

IRt intermediate reticular nucleus

KF Kolliker-Fuse nucleus

La lateral amygdaloid nucleus

LA lateroanterior hypothalamic nucleus

Lat lateral (dentate) cerebellar nucleus

LatC lateral cervical nucleus

LatPC lateral cerebellar nucleus, parvocellular part

LC locus coeruleus

Ld lambdoid septal zone

LD laterodorsal thalamic nucleus

LDTg laterodorsal tegmental nucleus

Ifp Iongitudinal fasciculus of the pons

Ifu lateral funiculus of the spinal cord

LGN lateral geniculate nucleus

LH lateral hypothalamic area

LHb lateral habenula

II lateral lemniscus

LM Iateral mammillary nucleus

lo lateral olfactory tract

LO Iateral orbital cortex

LOT nucleus of the lateral olfactory tract

LP Iateral posterior thalamic nucleus

LPB lateral parabrachial nucleus

LPGi lateral paragigantocellular nucleus

LPO Iateral preoptic area

LRt Iateral reticular nucleus

LS lateral septal nucleus

LSD lateral septal nucleus, dorsal

LSI Iateral septal nucleus, intermediate

LSO lateral superior olive

LSp lateral spinal nucleus

LSV lateral septal nucleus, ventral

LV lateral ventricle

LVe lateral vestibular nucleus

LVPO lateroventral periolivary nucleus

MA3 medial accessory oculomotor nucleus

MCPC magnocellular nucleus of the posterior commissure

MCPO magnocellular preoptic nucleus

MD mediodorsal thalamic nucleus

MdD medullary reticular nucleus, dorsa

MdV medullary reticular nucleus, ventral

ME medial eminence

Me5 mesencephalic trigeminal nucleus

MeAD medial amygdaloid nucleus, anterodorsal

MeAV medial amygdaloid nucleus, anteroventral

Med medial (fastigial) cerebellar nucleus

MedDL medial cerebellar nucleus, dorsolateral protuberance

MePD medial amygdaloid nucleus, posterodorsal

MePV medial amygdaloid nucleus, posteroventral

MGN medial geniculate nucleus

$\mathrm{MHb} \quad$ medial habenula

MiTg microcellular tegmental nucleus

$\mathrm{ml}$ medial lemniscus

ML medial mammillary nucleus, lateral part

mlf medial longitudinal fasciculus

MM medial mammillary nucleus, medial part

MMn medial mammillary nucleus, median part

MnR (B5) median raphenucleus

MO medial orbital cortex

mo molecular layer of the dentategyrus

Mo5 motor trigeminal nucleus

$\mathrm{mp} \quad$ mammillary peduncle

MPA medial preoptic area

MPB medial parabrachial nucleus

MPO medial preoptic nucleus

MS medial septal nucleus

MSO medial superior olive

$\mathrm{mt}$ mammillothalamic tract

MTu medial tuberal nucleus

MVe medial vestibular nucleus

$\mathrm{MVeV} \quad$ medial vestibular nucleus, ventral

MVPO medioventral periolivary nucleus
Abbreviations

Oc

occipital cortex
optic tract

OPT

OT

ox

Pa4

Pa5

Par

PaS

PBG

PC

PC

PCRt

PDTg

$\mathrm{Pe}$

$\mathrm{PeF}$

$\mathrm{PH}$

Pin

Pir

Pit

$\mathrm{PL}$

PLCo

PLd
PLi

PMCO

PMD

PMR

PMV

Pn

PN
PnC

PnC

PnR

PnV

Po

PP

PPT

PPTg

PR

Pr5

PrC

PrH

PrS

PT

PVA

PVNm

PVNp

PVP

RAmb

Rbd

$\mathrm{RCh}$

$\mathrm{Re}$

$\mathrm{Rh}$

RI

RLi
RMC

RMg (B3)

ROb (B2)

$\mathrm{RPa}$ (B1)

RPC

RPO

RR

RRF

rS

RSA

RSG

Rt

RtTg

$\mathrm{S}$

s5

SC(DpG)

$\mathrm{SC}(\mathrm{DpWh})$

SC(InG)

SC(InWh)

$\mathrm{SC}(\mathrm{Op})$

SC(SuG)

optic chiasm

pineal gland

pontine nuclei

prerubral field

presubiculum

subiculum olivary pretectal nucleus

nucleus of the optic tract

paratrochlear nucleus

paratrigeminal nucleus

parietal cortex

parasubiculum

parabigeminal nucleus

posterior commissure

paracentral thalamic nucleus

nucleus of the posterior commissure

parvocellular reticular nucleus

posterodorsal tegmental nucleus

periventricular hypothalamic nucleus

perifornical nucleus

posterior hypothalamus

piriform cortex

pituitary gland

paralemniscal nucleus

posterolateral cortical amygdaloid nucleus

paralambdoid septal nucleus

posterior limitans thalamic nucleus

posteromedial cortical amygdaloid nucleus

premammillary nucleus, dorsal

paramedian raphe nucleus

premammillary nucleus, ventral

paranigral nucleus

pontine reticular nucleus, caudal

pontine reticular nucleus, oral

pontine raphe nucleus

pontine reticular nucleus, ventral

posterior thalamic nucleus group

peripeduncular nucleus

posterior pretectal nucleus

pedunculopontinetegmental nucleus

principal sensory trigeminal nucleus

precommissural nucleus

prepositus hypoglossal nucleus

paratenial nucleus

paraventricular thalamic nucleus, anterior

paraventricular hypothalamic nucleus, magnocellular

paraventricular hypothalamic nucleus, parvocellular

paraventricular thalamic nucleus, posterior

pyramidal tract

retroambiguous nucleus

rhabdoid nucleus

retrochiasmatic area

reunions thalamic nucleus

rhomboid thalamic nucleus

rostral interstitial nucleus, medial longitudinal fasciculus

rostral linear nucleus of the raphe

red nucleus, magnocellular

raphe magnus nucleus

raphe obscurus nucleus

raphe pallidus nucleus

red nucleus, parvocellular

rostral periolivary region

retrorubral nucleus

retrorubral field

rubrospinal tract

retrosplenial agranular cortex

retrosplenial granular cortex

reticular thalamic nucleus

reticulotegmental nucleus of the pons

sensory root of the trigeminal nerve

superior colliculus

superior colliculus, deep gray layer

superior colliculus, deep whitelayer

superior colliculus, intermediate gray layer

superior colliculus, intermediate white layer

superior colliculus, optic nervelayer

superior colliculus, superficial gray layer 
possible brain heterogeneity of this receptor have been reported (Wang et al., 1994; Mathis et al., 1997) as well as its presence outside of the central nervous system (CNS; Halford et al., 1995). Functional studies of this receptor have demonstrated that, similar to opioid receptors, its activation stimulates GTP $\gamma$ S binding and inhibits adenylate cyclase (Wu et al., 1997). However, the expressed ORL 1 receptor has a poor affinity for the known opioid ligands (Meng et al., 1996; Sim et al., 1996; Ma et al., 1997). Binding and mutation analyses have established that ORL 1 has features that specifically exclude known opioids and promote the high-affinity binding of its own endogenous ligand (Standifer et al., 1994; Meng et al., 1996; Mollereau et al., 1996a).

In the pursuit to identify a neuropeptide that activates the ORL 1 receptor, orphanin FQ (OFQ), a novel heptadecapeptide al so referred to as nociceptin, recently was discovered. OF Q exhi bits structural features suggestive of endogenous opioid peptides (Civelli et al., 1997) and has been shown to be an endogenous agonist of the ORL 1 receptor (Meunier et al., 1995; Reinscheid et al., 1995; Saito et al., 1995, 1996, 1997). This novel peptide demonstrates specific binding characteristics with the ORL 1 receptor (Dool ey and Houghten, 1996; Reinscheid et al., 1996; Shimohigashi et al., 1996; Ardati et al., 1997; Butour et al., 1997; Guerrini et al., 1997). In addition, high-affinity binding of OFQ peptide fragments with the ORL 1 receptor recently has been reported (Dooley et al., 1997). Orphanin FQ has been shown to depend on peptidase metabolism (Montiel et al., 1997; Noble and Roques, 1997), to stimulate ORL1induced $\mathrm{Ca}^{2+}$ and $\mathrm{K}^{+}$conductance changes (Connor et al., 1996, 1997; Knoflach et al., 1996; Nicol et al., 1996; Vaughan and Christie, 1996; Abdulla and Smith, 1997;
Ikeda et al., 1997; Vaughan et al., 1997; Yu et al., 1997; Wagner et al., 1998) and protein kinase C activation (Lou et al., 1997), and to effect function of other neurotransmitter systems (Faber et al., 1996; Giuliani and Maggi, 1996; Murphy et al., 1996; Wang et al., 1996; Gintzler et al, 1997; Liebel et al., 1997). Unlike other opioid peptides, OFQ fails to produce cross tolerance with morphine (Hao et al., 1997) or conditioned place preference (Devine et al., 1996b). However, it has been implicated subsequently in many other physiologic and behavioral processes, including cardiac and vascular control (Champion and Kadowitz, 1997a,b; Champion et al., 1997; Gumusel et al., 1997), diuresis (Kapusta et al., 1997), feeding (Pomonis et al., 1996), learning (Sandin et al., 1997), locomotion (Devine et al., 1996a; Florin et al., 1996, 1997a), and nociception (Grisel et al., 1996; M ogil et al., 1996a,b; Rossi et al., 1996, 1997; Stanfa et al., 1996; Xu et al., 1996; Dawson-Basoa and Gintzler, 1997; Heinricher et al., 1997; King et al., 1997; Liebel et al., 1997; Morgan et al, 1997; Nishi et al., 1997; Tian et al., 1997a,b; Yamamoto et al., 1997; Zhu et al., 1997). I ts possible role as an anxiolytic also has been reported (Moreau et al., 1997).

OFQ is derived from a larger precursor, prepro-OFQ, which shares structural homology to the opioid peptide precursors, prodynorphin and preproenkephalin, and it has been suggested recently that a coordinated mechanism of evolution has separated the OF Q system from the opioid system (Reinscheid et al., 1998). The primary structure of the rat and human OFQ precursor has recently been reported, as has tissue distribution of preproorphanin mRNA in rat (Mollereau et al., 1996b; Nothacker et al., 1996) and mouse (Houtani et al., 1996; Pan et al., 1996). Antisera to OFQ have been produced, and detection
Abbreviations

\begin{tabular}{|c|c|}
\hline $\mathrm{SC}(\mathrm{Zo})$ & superior colliculus, zonal layer \\
\hline $\mathrm{SCh}$ & suprachiasmatic area \\
\hline scp & superior cerebellar peduncle \\
\hline Sd & subiculum, dorsal \\
\hline SFO, SF & subfornical organ \\
\hline SG & suprageniculate nucleus \\
\hline SGe & supragenual nucleus \\
\hline $\mathrm{SHi}$ & septohippocampal nucleus \\
\hline $\mathrm{SHy}$ & septohypothalamic nucleus \\
\hline SI & substantia innominata \\
\hline sm & stria medullaris of the thalamus \\
\hline SNC & substantia nigra, pars compacta \\
\hline SNL & substantia nigra, pars lateralis \\
\hline SNR & substantia nigra, pars reticulata \\
\hline so & stratum oriens \\
\hline SO & supraoptic nucleus \\
\hline sol & solitary tract \\
\hline Sol & nucleus of the solitary tract \\
\hline SolC & nucleus of the solitary tract, commissural \\
\hline SolL & nucleus of the solitary tract, lateral \\
\hline SolM & nucleus of the solitary tract, medial \\
\hline SOR & supraoptic nucleus, retrochiasmatic (diffuse) \\
\hline sp & stratum pyramidal \\
\hline sp5 & spinal trigeminal tract \\
\hline Sp5C & spinal trigeminal nucleus, caudal \\
\hline Sp5l & spinal trigeminal nucleus, interpolar \\
\hline Sp50 & spinal trigeminal nucleus, oral \\
\hline SPFPC & subparafascicular thalamic nucleus, parvocellular \\
\hline SPO & superior paraolivary nucleus \\
\hline SPTg & subpeduncular tegmental nucleus \\
\hline SpVe & spinal vestibular nucleus \\
\hline $\mathrm{sr}$ & stratum radiatum \\
\hline st & stria terminalis \\
\hline STh & subthalamic nucleus \\
\hline
\end{tabular}

supraoculomotor central gray

subcoeruleus nucleus

subgeniculate nucleus

supramammillary nucleus

supramammillary decussation

superior vestibular nucleus

temporal cortex

tuber cinereum

terete hypothalamic nucleus

tuberomammillary nucleus

tuberal magnocellular nucleus

tenia tecta

ol factory tubercle

trapezoid body

nucleus of the trapezoid body

ventral cochlear nucleus, anterior

ventral cochlear nucleus, posterio

nucleus of the vertical limb of the diagonal band of Broca ventral endopiriform nucleus

ventral funiculus of the spinal cord

ventral horn of the spinal cord

ventrolateral thalamic nucleus

ventral nucleus of the lateral lemniscus

ventrolateral tegmental nucleus

ventromedial thalamic nucleus

ventromedial hypothalamic nucleus

ventral orbital cortex

ventral pallidum

ventral posterolateral thalamic nucleus

ventral posteromedial thalamic nucleus

ventral tegmental area

ventral tegmental nucleus

zona incerta 
of OFQ-like immunoreactivity has been reported in the spinal cord (Riedl et al., 1996; Lai et al., 1997; Schuligoi et al., 1997) and other structures within pain-modulatory regions in the rat (Schulz et al., 1996), and the hypothalamus of the rodent and monkey (Quigley et al., 1998).

Autoradiographic analysis of ${ }^{3} \mathrm{H}-\mathrm{OFQ}$ receptor binding and immunohistochemical analysis of the ORL 1 receptor have been reported in rat, mouse, and human (Anton et al ., 1996; Florin et al., 1997b; Makman et al., 1997), as has agonist-stimulated binding of ${ }^{35} \mathrm{~S}-$ labeled GTP $\gamma \mathrm{S}$ to the ORL 1 receptor in the guinea pig brain (Sim and Childers, 1997). No such critical anatomic analysis of OF Q has been reported to date. In this study, by using antisera that were generated against the orphanin heptadecapeptide, and ${ }^{35}$ S-labeled CRNA corresponding to the 5' portion of the prepro-OFQ precursor sequence, we performed in situ hybridization and immunohistochemistry to analyze the distribution of prepro-OFQ mRNA expression and OFQ peptideimmunoreactivity in the adult rat forebrain, brainstem, and spinal cord.

\section{MATERIALS AND METHODS Animals}

Adult male Sprague-Dawley rats (Charles River, Portage, MI; 250-300 g) were used for all in situ and immunocytochemistry studies. Handling and use of all animals strictly conformed to National Institutes of Health guidelines. In addition, protocols for animal use in this study were approved by the University Unit for Laboratory Animal Medicine (ULAM) at the University of Michigan Medical Center.

\section{Tissue preparation}

For in situ hybridization, adult male Sprague-Dawley rats were killed by decapitation, and their brains were removed and immediately frozen in isopentane at $-30^{\circ} \mathrm{C}$. In addition to whole brains, the pituitary gland and a portion of the cervical and thoracic spinal cord were dissected from each animal and similarly frozen. Brain, pituitary, and spinal cord tissue were stored at $-80^{\circ} \mathrm{C}$ until sectioning. All CNS material was sectioned coronally on a Bright cryostat at $15 \mu \mathrm{m}$, thaw mounted on polylysinesubbed microscope slides, and then stored at $-80^{\circ} \mathrm{C}$ until use.

For immunohistochemistry, adult male Sprague-Dawley rats were deeply anesthetized with $75 \mathrm{mg} / \mathrm{kg}$ of sodium pentobarbital i.p. and transcardially perfused with approximately $50-75 \mathrm{ml}$ of $0.9 \% \mathrm{NaCl}$ containing $2.2 \%$ sodium nitrite. This was followed with approximately $400 \mathrm{ml}$ of Zamboni's fixative (Zamboni and De Martino, 1967). Seven animals were injected with colchicine $(300 \mu \mathrm{g}$ in $7.5 \mu \mathrm{l}$ of sterile saline, i.c.v.) 48 hours prior to transcardiac perfusion. After perfusion was completed, the brain, pituitary, and portions of the thoracic and cervical spinal cord were removed and postfixed in Zamboni's fixative for 1 hour. Tissue was then transferred to a solution of $10 \%$ sucrose in $50 \mathrm{mM}$ potassium phosphate-buffered saline, pH 7.2 (KPBS), for 24-48 hours. Brains were frozen in liquid isopentane at $-30^{\circ} \mathrm{C}$, then stored at $-80^{\circ} \mathrm{C}$ until sectioning. All material was sectioned coronally on a Leica CM1800 cryostat at $30 \mu \mathrm{m}$ and stored in cryoprotectant (sodium phosphate buffer, pH 7.4, with $0.9 \%$ saline, 30\% sucrose, and $30 \%$ ethylene glycol) at $-20^{\circ} \mathrm{C}$ until use.

\section{cRNA probe}

Hybridization of CNS tissue was performed by using ${ }^{35} \mathrm{~S}$-UTP and ${ }^{35} \mathrm{~S}$-CTP-label ed riboprobes generated against the rat prepro-OFQ mRNA sequence. A polymerase chain reaction fragment corresponding to the $5^{\prime}$ portion of the prepro-OFQ sequence was used to prepare a ${ }^{35} \mathrm{~S}$-labeled cRNA probe. This CDNA fragment spans 580 base pairs (bases 106-686) and contains the entire open reading frame of the prepro-OFQ precursor molecule (Houtani et al., 1996; Mollereau et al., 1996b; Nothacker et al., 1996).

\section{Antibody production}

The entire OFQ heptadecapeptide (FGGFTGARKSARKLANQ) was used for polyclonal antibody production. The purity of this peptide and its activity at the ORL-1 receptor have been reported previously (Reinscheid et al., 1995). By using glutaraldehyde, OFQ was conjugated to thyroglobulin, and additional free aldehyde sites were blocked by saturating the solution with glycine. OFQ thyroglobulin conjugates were then divided into aliquots and delivered to HRP Inc. (Denver, PA), where rabbit anti-OF Q antiserum was produced.

At HRP Inc., antisera was generated by inoculating rabbits (New Zealand White; $\mathrm{n}=2$ ) with $350 \mu \mathrm{g}$ of the thyroglobulin-conjugated OFQ peptide suspended in complete Freund's adjuvant. Rabbits were injected initially once a week for 3 weeks, given 2 weeks rest, and then bled on week 6 . On week 7 , the animals were inoculated with $190 \mu \mathrm{g}$ of conjugated peptide suspended in incomplete Freund's adjuvant. They were allowed to rest on week 8 and were bled on week 9. This second inoculation-restbleed procedure was continued until a total of eight bleeds were obtained, after which the rabbits were exsanguinated. Sera obtained from each rabbit were tested immunohistochemically for each bleed. Based on initial results, antisera from animal 217, bleeds 5 and 6, were affinity purified by using the OFQ heptadecapeptide coupled to a sepharose-4B-cyanogen bromide column. After final analysis, affinity-purified antiserum from animal number 217, bleed 6 , was used in this study.

\section{I mmunohistochemistry}

The immunohistochemistry technique employed in this study has been described previously for detection of the $\mu$ and $\kappa$ opioid receptors in the rat CNS (Mansour et al., 1995a, 1996). Floating rat brain and spinal cord sections were washed in $50 \mathrm{mM}$ KPBS to remove cryoprotectant. Sections were then incubated for 30 minutes in $0.3 \% \mathrm{H}_{2} \mathrm{O}_{2}$ and rinsed in $50 \mathrm{mM}$ KPBS. Next, tissue was incubated with an avidin-D blocking agent for 15 minutes, rinsed with $50 \mathrm{mM}$ KPBS, and followed with a 15-minute incubation with a biotin-blocking solution (blocking agents obtained from Vector Laboratories, Burlingame, CA). Prior to the addition of primary antibody, sections were incubated for 60 minutes in bovine serum albumin (BSA) diluent (50 $\mathrm{mM}$ KPBS with $0.9 \% \mathrm{NaCl}, 1 \% \mathrm{BSA}, 1 \%$ normal goat serum, and $0.4 \%$ Triton $X-100$ ), then transferred to a solution containing affinity-purified OFQ antibody diluted to $1: 1,500$ with BSA diluent, and incubated at $-4^{\circ} \mathrm{C}$ for 36- 48 hours. After primary antibody incubation, the sections were washed in KPBS and incubated with biotinylated goat anti-rabbit immunoglobulin G (I gG; 1:1,000) for 60 minutes at room temperature, followed by an avidinbiotin complex $(A B C)$ coupled to horseradish peroxidase 
(1:1,000; Vector Elite; Vector Laboratories) for 60 minutes, also at room temperature. I mmunostaining was visualized with a $0.04 \%$ solution of 3,3'-diaminobenzidine tetrahydrochloride (DAB) containing 2.5\% nickel chloride and 0.01\% $\mathrm{H}_{2} \mathrm{O}_{2}$ dissolved in $0.1 \mathrm{M}$ sodium acetate. After 6 minutes in $\mathrm{DAB}$, the reaction was terminated by two consecutive washes in $0.9 \% \mathrm{NaCl}$. Sections were mounted from $0.9 \%$ $\mathrm{NaCl}$ onto polylysine-subbed microscope slides, dehydrated with graded alcohols followed by xylene, and coverslipped with Permount. Tissue sections adjacent to those that were stained immunohistochemically were mounted onto polylysine-subbed slides and Nissl counterstained with cresyl violet to aid in anatomic localization. I mmunohistochemical brightfield staining was viewed with a Zeiss Axiphot microscope (Thornwood, NY) and a Leitz DM RD microscope (Wetzlar, Germany) with camera attachment. Representative sections were photographed, and images from negatives were generated on high-quality Kodak photographic paper for illustrations (Rochester, NY) for illustrations. Processing of all photomicrographs was performed under identical darkroom conditions.

\section{In situ hybridization}

The in situ hybridization technique employed in this study has been described previously for detection of opioid receptor mRNA in the rat CNS (Mansour et al., 1993, 1994). Adjacent sections of frozen brain, pituitary, and spinal cord with dorsal root ganglia were removed from storage $\left(-80^{\circ} \mathrm{C}\right)$ and placed into $4 \%$ paraformal dehyde for 60 minutes at room temperature. Sections were next given three 5-minute rinses in a solution of $300 \mathrm{mM}$ sodium chloride and $30 \mathrm{mM}$ sodium citrate, $\mathrm{pH} 7.2$ (SSC; $2 \times \mathrm{SSC}$ ), followed by treatment with proteinase $\mathrm{K}[1 \mu \mathrm{g} / \mathrm{ml}$ in 100 $\mathrm{mM}$ Tris and $50 \mathrm{mM}$ ethylenediamine tetraacetic acid (EDTA), pH 8.0] for 10 minutes at $37^{\circ} \mathrm{C}$. Sections were rinsed once in water then treated with $0.1 \mathrm{M}$ triethanolamine and acetic anhydride (400:1 volume/volume), $\mathrm{pH}$ 8.0, for 10 minutes at room temperature. Sections were rinsed again in water, dehydrated in graded alcohols, and air dried.

Prepared tissue was hybridized with a $35 \mathrm{~S}$-UTP- and ${ }^{35} \mathrm{~S}$-CTP-labeled riboprobe generated to the rat OFQ peptide precursor as described above. The cRNA probe was diluted by using a hybridization buffer composed of $75 \%$ formamide, $10 \%$ dextran sulfate, $3 \times \mathrm{SSC}, 0.1 \mathrm{mg} / \mathrm{ml}$ yeast tRNA, $1 \times$ Denhardt's, and $10 \mathrm{mM}$ dithiothreitol in $50 \mathrm{mM}$ $\mathrm{Na}_{2} \mathrm{PO}_{4}, \mathrm{pH}$ 7.4. The activity of $35 \mathrm{~S}$-labeled cRNA used for hybridization was in the range of $1-2 \times 10^{6} \mathrm{cpm} / 35 \mu$. Volumes of $35 \mu \mathrm{l}$ of diluted probe were applied to tissue sections, and glass coverslips were placed, keeping the hybridization buffer in contact with tissue. Slides were placed in sealed humidifying chambers containing $50 \%$ formamide and hybridized overnight in a VRW Scientific 1535 incubator (Cornelius, OR) at $55^{\circ} \mathrm{C}$.

On day 2, glass coversl ips were removed, and slides were rinsed twice in $2 \times \mathrm{SSC}$ for 5 minutes, then treated with RNase A for 60 minutes at $37^{\circ} \mathrm{C}(200 \mu \mathrm{g} / \mathrm{ml}$ RNase $A$ and $0.5 \mathrm{M} \mathrm{NaCl}$ in $100 \mathrm{mM}$ Tris, $\mathrm{pH}$ 8.0). Following RNase $A$ treatment, sections were washed in $2 \times$ SSC for 5 minutes, followed by $1 \times$ SSC for 5 minutes, and $0.5 \times$ SSC for 5 minutes, all at room temperature. Low salt wash was completed with incubation in $0.1 \times$ SSC for 60 minutes at $65^{\circ} \mathrm{C}$. Sections were then rinsed in water, dehydrated through graded al cohols, and air dried.
On completion of hybridization, slide-mounted sections were opposed to Kodak XAR- 5 x-ray film for 5 days then dipped in NTB2 film emulsion. Brain sections were then devel oped following a 30-day exposure to NTB2 emulsion. The exposuretime was chosen to maximize the detection of in situ hybridization grains and was determined empirically by periodic development of test slides of tissue sections dipped in the NTB2 emulsion. Following development of the NTB2 film emulsion, all slides were rinsed in running water at room temperature for 30 minutes and Nissl counterstained with cresyl violet, dehydrated in graded alcohols followed by xylene, and coverslipped with Permount. Hybridized tissue was analyzed by using a "Dark-Lite" darkfield stage light on a Leitz DM RD microscope with camera attachment. Representative sections were photographed, and images from negatives were generated on high-quality Kodak photographic paper for illustrations. Like the immunohistochemical images, all processing was done under identical darkroom conditions.

\section{Controls}

For immunohistochemical controls, the OFQ antibody was preabsorbed by incubating the primary antiserum with $25 \mu \mathrm{M}$ of the OFQ heptadecapeptide overnight prior to the addition of floating tissue sections. Preabsorption controls and normal immunohistochemical studies were performed on adjacent tissues from both normal and colchicine-treated animals.

The specificity of the $5^{\prime}$ portion of the prepro-OFQ sequence used for in situ hybridization was determined with two separate control conditions. After the 60-minute incubation in $4 \%$ paraformal dehyde, sections from representative brain regions were incubated in RNase A for 60 minutes at $37^{\circ} \mathrm{C}(200 \mu \mathrm{g} / \mathrm{ml}$ RNase $A$ and $0.5 \mathrm{M} \mathrm{NaCl}$ in $100 \mathrm{mM}$ Tris, $\mathrm{pH}$ 8.0). They were then run through the entire hybridization procedure with ${ }^{35} \mathrm{~S}$-labeled CRNA, as described above. A separate set of adjacent, representative brain regions was run through the entire hybridization procedure as described above, with the exception that a ${ }^{35} \mathrm{~S}$-labeled mRNA (sense strand) was used for the hybridization. Other than the alterations described above (RNase A and sense controls), all control tissue was treated identically and ran along side adjacent sections under normal conditions for comparison.

\section{RE SULTS Colchicine treatment}

Colchicine injection into the lateral ventricle markedly altered OF Q immunohistochemical staining in all animals studied. Brains of untreated animals contained more robust fiber staining than what was observed in colchicinetreated animals, but they also demonstrated very few immunolabel ed cell bodies. Areas of heaviest immunolabeling (e.g., lateral septum, bed nudeus of the stria terminalis, central nucleus of the amygdala, arcuate nucleus, central gray, nucleus of Darkschewitsch, solitary nucleus) did contain some labeled perikarya in untreated animals. Untreated (normal) animals provided an added source of information concerning the distribution of OFQ fiber and terminal immunoreactivity, complimenting fiber and cell staining observed in colchicine-treated animals. Descriptions presented here are a synthesis of immunolabeling observed in both colchicine-treated and normal animals, with descriptions of cell labeling derived primarily from 
colchicine-treated animals, and fiber/terminal labeling derived primarily from untreated animals (Fig. 1).

\section{Controls}

No mRNA expression was detected in tissues pretreated with RNase A prior to in situ hybridization using ${ }^{35} \mathrm{~S}-$ labeled CRNA directed to the 5' portion of the prepro-OFQ CDNA sequence (antisense). Messenger RNA levels in these tissues were negligible in all levels of the forebrain, brainstem, and spinal cord. In addition, no mRNAexpressing cells were detected in tissues hybridized with a ${ }^{35} \mathrm{~S}$-labeled mRNA directed to the $5^{\prime}$ portion of the preproOFQ CDNA sequence (sense strand). Like the RNase A treatment, these tissues contained no mRNA-expressing cells at all levels studied (Fig. 2).

Unanticipated, nonspecific background staining noted during initial immunohistochemical trials was found to be due to impurities in the $\mathrm{ABC}$-horseradish peroxidase reaction kit obtained from Vector Laboratories (Vector Elite kit). Nonspecific background staining was removed completely by using an avidin-D and biotin-blocking solution, also provided by Vector Laboratories. Therefore, these blocking agents were used in all immunohistochemical studies reported below.

Preabsorption of the primary OF Q antibody with OFQ heptadecapeptide virtually el iminated all immunolabeling (Fig. 3). However, there were two notable exceptions. A densely stained group of cell bodies was observed clustered lateral to the paraventricular nucleus of the hypothalamus in a perifornical distribution dorsal to the anterior hypothaIamic area. Within this prominently immunolabeled cell group, a very small population of these neurons was not blocked completely in preabsorption controls. Unblocked perikarya were visible but were labeled very lightly. Within the forebrain, the neurons within this cell group were the only perikarya that were not blocked completely in preabsorption controls. Preabsorption of the OF Q antibody with the OF Q peptide completely blocked immunoreactivity in every other forebrain region. In the cerebellum, dense staining of perikarya was observed throughout the Purkinje cell layer in preabsorption controls. These immunolabeled cells, which were confined to the cerebellum, were considered to be nonspecific because 1) they were present equally in both colchicinetreated and untreated animals, 2) this cell population was confined to the Purkinje layer and remained completely unblocked in all preabsorption control studies, and 3) no mRNA expression was observed in this cell layer at any brainstem level. Therefore, in the cerebellum, the Purkinje cell layer was considered to be void of specific immunolabeling. In contrast, immunolabeling in the granular layer and deep cerebellar nudei is treated as specific, because cerebellar labeling in these areas was blocked completely in preabsorption control studies.

Immunohistochemical and in situ hybridization controls demonstrated high specificity of the OFQ antiserum and the ${ }^{35} \mathrm{~S}-$ labeled prepro-OF $\mathrm{Q}$ riboprobe used in this study. A detailed description of the distribution of prepro-OFQ mRNA and OFQ peptide is presented below. Anatomic descriptions and nomenclature are based on those described for the rat CNS by Paxinos and Watson (1986). A summary of OFQ mRNA and peptide distribution is provided in Table 1. An overview of OF Q mRNA expression in the brain and spinal cord is presented in Figures 4 and 5.
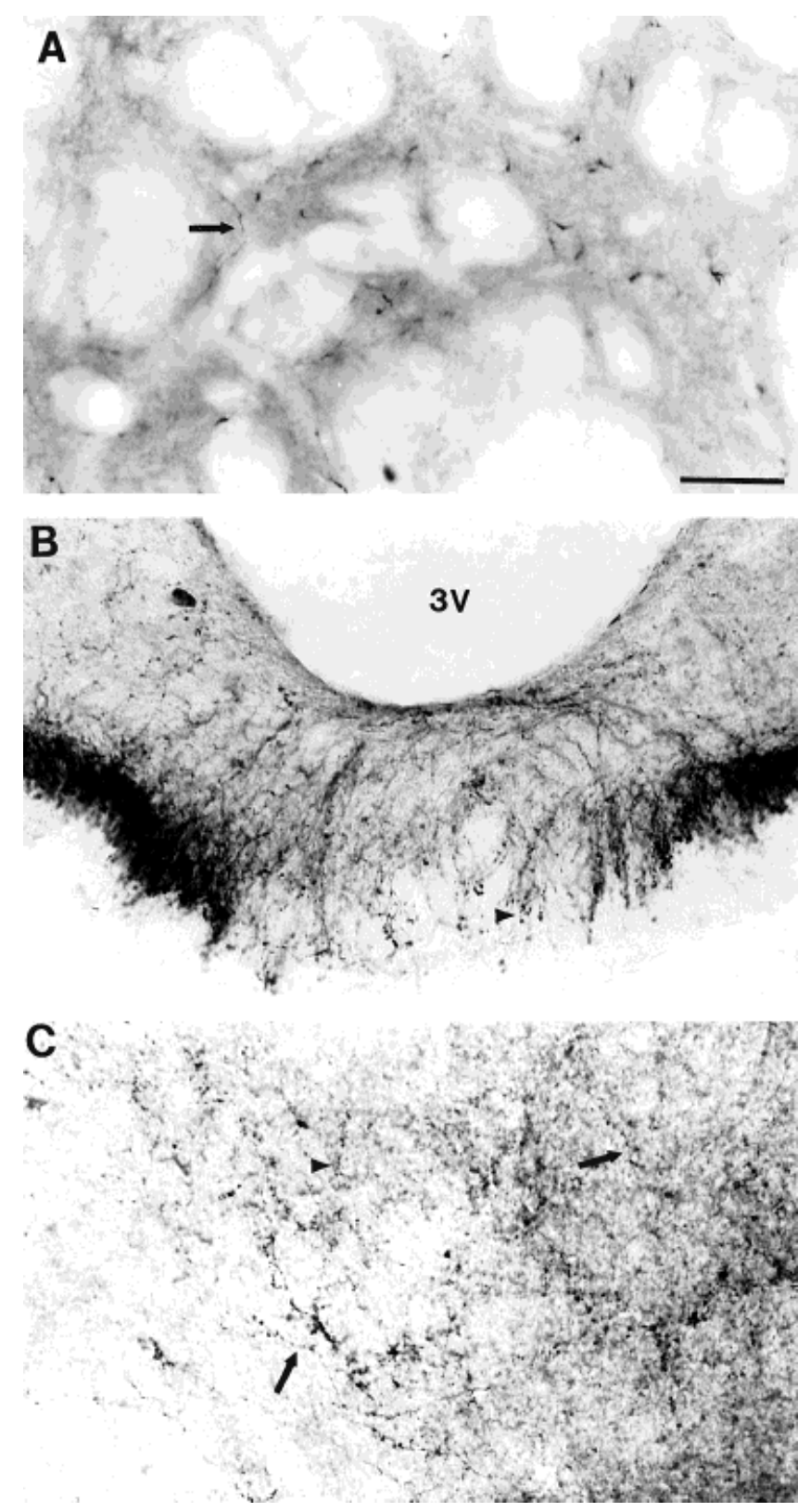

Fig. 1. Brightfield photomicrographs demonstrating orphanin $F Q$ (OFQ)-containing fibers (arrows) and terminal-like structures (arrowheads) in noncolchicine-treated tissue. A: High-power image of the striatum demonstrating the fine immunoreactive fibers found scattered throughout this structure. B: High-power photomicrograph of dense OFQ-containing fibers in the median eminence. C: High-power photomicrograph of OFQ immunoreactivity in the posteroventral part of the medial nucleus of the amygdala demonstrating immunolabeled fibers and terminal-like structures in this region. For abbreviations, see list. Scale bar $=50 \mu \mathrm{m}$.

\section{Cortex}

In situ hybridization. Prepro-OFQ mRNA expression is found throughout the rostral-to-caudal extent of the neocortex. Cells containing OFQ mRNA are scattered primarily in layers II, III, V, and $\mathrm{VI}$, with the strongest expression in layer VI. Prepro-OFQ mRNA-expressing cells are most numerous in the frontal cortex (Fig. 2A), 

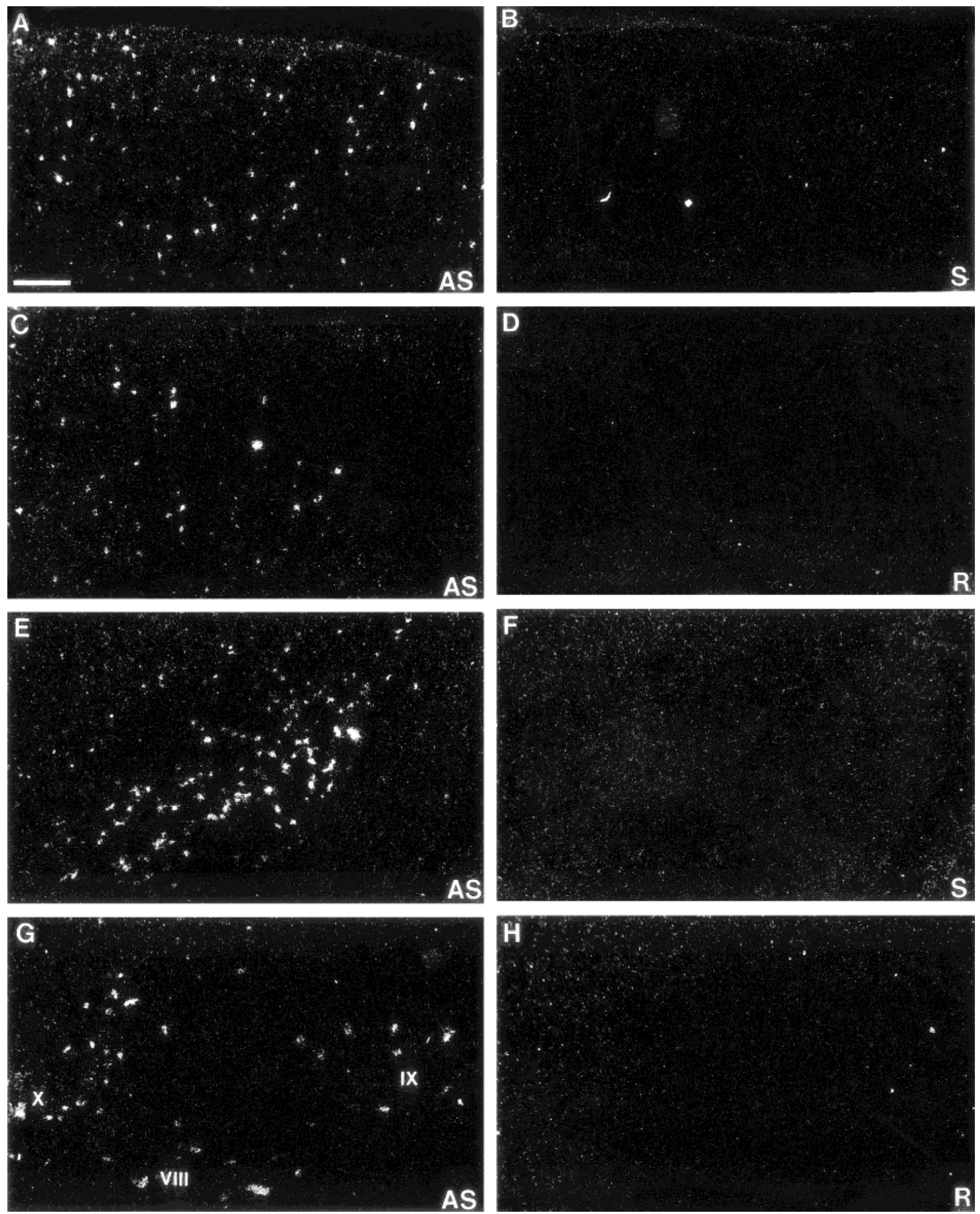

Fig. 2. Darkfield autoradiograms of in situ hybridization controls. A: mRNA expression obtained after hybridization with a ${ }^{35} \mathrm{~S}$-labeled CRNA (antisense strand) generated against the $5^{\prime}$ portion of the preproorphanin sequence in the frontal cortex (AS). B: mRNA expression is absent in an adjacent section hybridized with a ${ }^{35} \mathrm{~S}$-labeled mRNA (sense strand) generated against the same region of the preproorphanin sequence (S). C: Photomicrograph of mRNA-expressing neurons in the rostral claustrum. D: Labeling is absent in an

adjacent section treated with RNase A prior to hybridization (R). E: Antisense signal generated in the peripeduncular nucleus of the mesencephalon. $\mathbf{F}$ : Labeling is absent in an adjacent section following hybridization with sense strand. G: mRNA-expressing neurons in laminae VIII and IX of the ventral horn of the cervical spinal cord. In $\mathbf{H}$, labeling is absent in an adjacent section that was treated with RNase A prior to hybridization. Scale bar $=200 \mu \mathrm{m}$ in A-F, $100 \mu \mathrm{m}$ in $\mathrm{G}, \mathrm{H}$. 

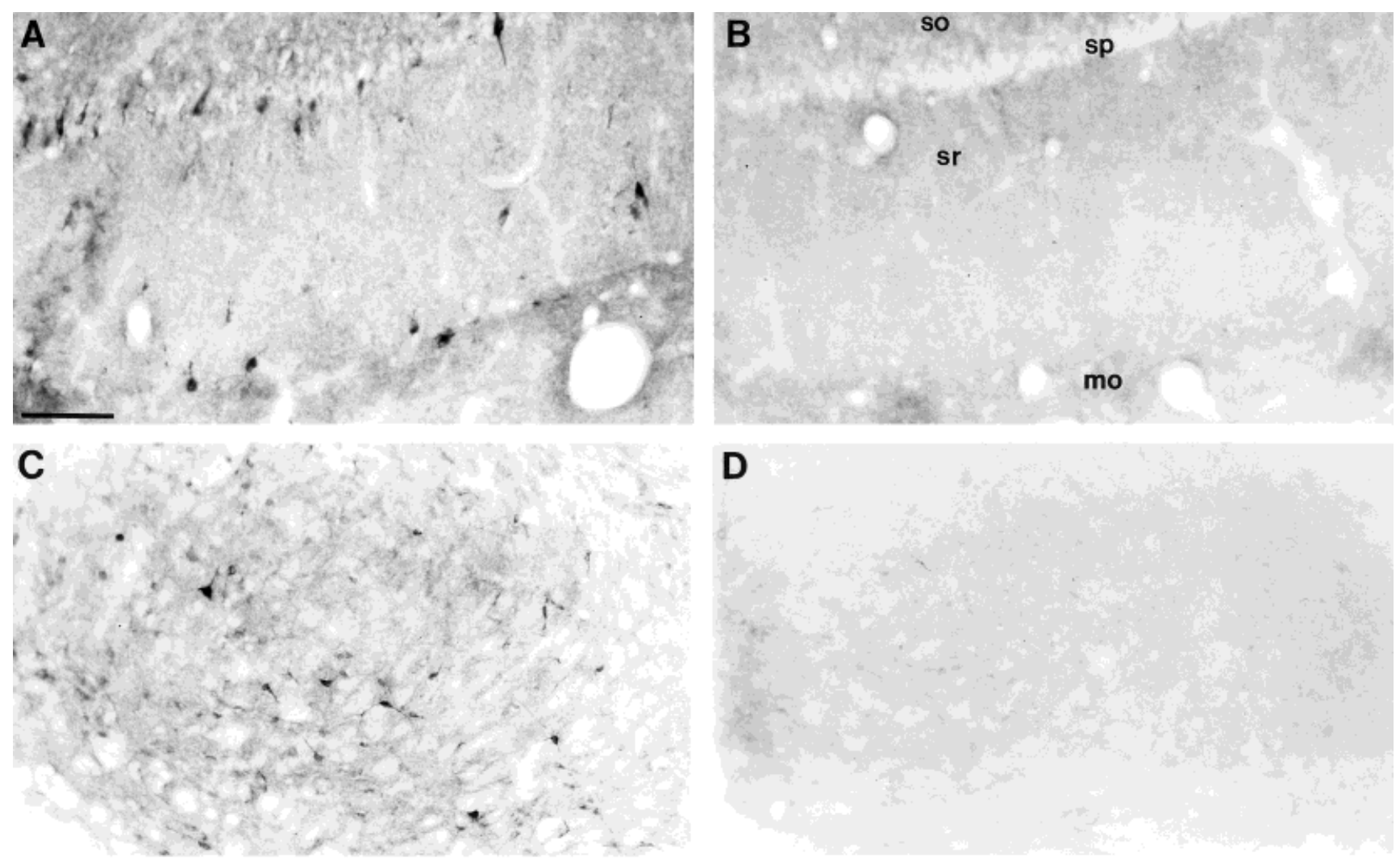

$\mathbf{E}$

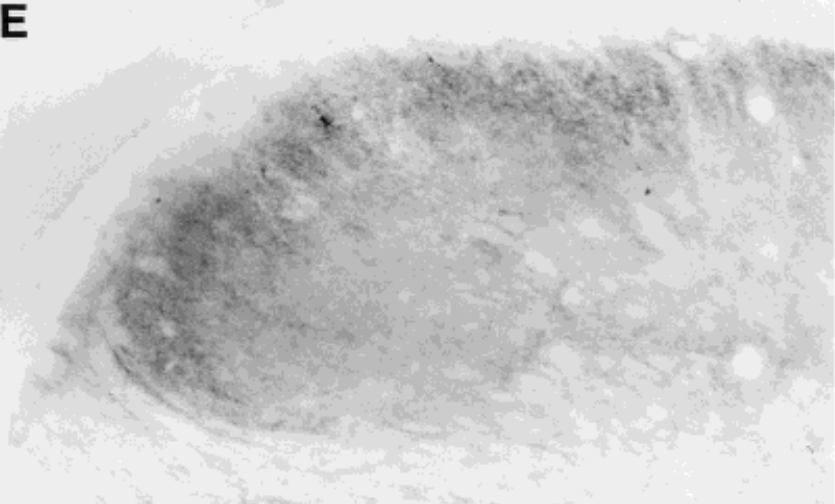

$\mathbf{F}$
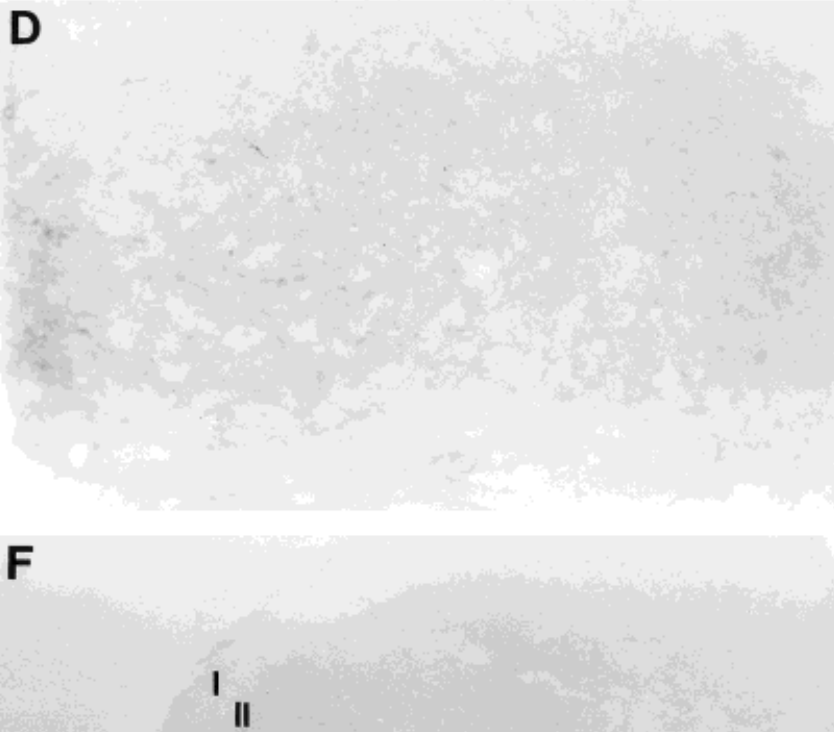

III

IV

Fig. 3. Brightfield photomicrographs demonstrating immunohistochemistry controls in colchicine-treated animals: I mmunolabeling in area CA1 of Ammon's horn in the hippocampal formation after incubation with primary OFQ antiserum (A) is absent in the same region when incubated in primary antiserum after preabsorption with

with mRNA expression in the temporal cortex weakest of all regions. No mRNA expression is observed within the corpus callosum.

Messenger RNA expression is also strong in other cortical regions. Rostrally, moderate mRNA expression is seen in medial, lateral, and ventral orbital cortices, primarily in layer II. Expression levels are strongest in the rostral pole of the orbital cortex, tapering off at caudal levels. In the rostral agranular insular cortex, mRNA-containing neurons are numerous and are found mostly in layers II, III, and $\mathrm{V}$. This mRNA expression becomes most intense in caudal insular regions, with adjacent granular cortex

$25 \mathrm{mM}$ OFQ peptide (B). Densely immunolabeled neurons within the substantia nigra, pars reticulata (C) are unlabeled in adjacent control tissue (D). Cell and fiber immunolabeling within the dorsal horn of the spinal cord (E) also is blocked completely in adjacent control tissue (F). For abbreviations, see list. Scale bar $=75 \mu \mathrm{m}$ in A,B, $200 \mu \mathrm{m}$ in C-F.

maintaining a more moderate distribution of prepro-OF Qcontaining neurons. In therostral forebrain, mRNA expression is strong in the prefrontal cortical regions. Messenger RNA-containing neurons are numerous in the infralimbic and dorsal peduncular cortical regions ventrally and in the rostral cingulate cortex dorsally, mostly in layers II, III, and V. Rostral cingulate expression is strongest in area 1 , but mRNA expression intensity is strongest in area 2 caudally, into the retrosplenial cortices. Messenger RNA levels throughout the retrosplenial cortex remain heavy in the agranular part, primarily in layers II and V rostral, and in layers II and III caudal. In the rostral tenia tecta, 
TABLE 1. Distribution of Orphanin FQ Peptide and mRNA in the Rat Central Nervous System

\begin{tabular}{llll}
\hline CNS region & \multicolumn{2}{c}{ Orphanin FQ peptide } & $\begin{array}{c}\text { Preproorphanin } \\
\text { FQ mRNA } \\
\text { expression }\end{array}$ \\
\cline { 2 - 3 } & Cells $\quad F / T$ &
\end{tabular}

Neocortex

Frontal 1

Layer II

Layer III

Layer IV

Layer V
Layer VI

Parietal

Layer I

Layer III

Layer IV

Layer $\mathrm{V}$

Temporal

Layer I

Layer II

Layer III

Layer $V$

Layer $V$

Occipital

Layer I

Layer II

Layer I

Layer IV

Layer $\mathrm{VI}$

Other cortical regions

Al

$\stackrel{\mathrm{cc}}{\mathrm{Cg}}$

$\mathrm{Cg}$
$\mathrm{DP}$

Ent

GI

LO

MO

RSA

RSG

TT
VO

Ventral forebrain

ac

AcbC

AcbSh

AOD

AOL

AOP

AOV

HDB

ICj

SI

Tu
VDB

VP

Septum
Ld
Ld

Ld

LSD

LSI

MS

PLd

$\mathrm{SHi}$

Basal ganglia

B

$\mathrm{CPu}$

Den
EP

EP

SNC

SNL

SNR
STh

Basal telencephalon

AMPO

AVPO

BSTI
TABLE 1. (continued)

\begin{tabular}{llll}
\hline CNS region & \multicolumn{2}{c}{ Orphanin FQ peptide } & $\begin{array}{c}\text { Preproorphanin } \\
\text { FQ mRNA } \\
\text { expression }\end{array}$ \\
\cline { 2 - 2 } & Cells $\quad F / T$ &
\end{tabular}

Basal telencephalon

BSTld

BSTIP

BSTIV

BSTma

BSTmpl
BSTmpm

BSTmv

LOT

(1)

LPO

MCPO

MPA

$\mathrm{Pe}$

st

Hypothalamus

AHA

Arc

DM

LA

LH

ME

$M L$

MMn

$\mathrm{mp}$

MTu

$\mathrm{Pe}$
$\mathrm{PeF}$
$\mathrm{PH}$

Pin

Pit

PMD

PVNm

PVNm
PVNp

RCh

SCh

SO

SOR
SuM

SuM

sumx

TC

Te
TM

TMC

VMH

Amygdala

AAA

ACO

AHiA

APir

BAOT

$B L$
$B M$

BSTIA

Cel
CeM

I

La

MeAD

MeAV

MePV

PLCo

PMCO

Hippocampal formation

CAlso

CAlsp

CAlsr

CA2so

CA2sp

CA2sr

CA3SI

CA3so

CA3sp

CA3sr

DGgr

DGmo $+++\quad++++$

1
+++
++

+1
+++
+++

$++++$

$++$

$+2+1$
++
+++

$++++$

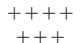

$-$

++
++

++
++
++

$\begin{array}{ccc}2 & c \\ +++ & +2 & +2 \\ +++ & +++\end{array}$

$\begin{array}{lll}+ & ++ \\ + & ++\end{array}$

$\begin{array}{cccc}++ & + & 2 \\ ++ & + & +++ & ++ \\ ++ & +2 & ++\end{array}$

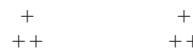

$++$

++
+++
+++

-

$-$

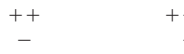

$++$

-
++

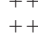

+
++

$+++$

$-$

$+$

-
++

$++$

++
+
+

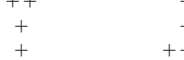

$+++$

$++$

$+$

++
++

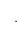

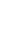

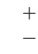

$+$

+2
+
+
+

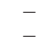

-
++
++

$+$

$+$

$+$

+
++
+

+
$-/+$

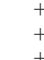

$+$

$++$

$\stackrel{2+}{+}+$

$++$

2
++
++

+++
+++

$++++$

$\begin{array}{ll}++ & ++++\end{array}$

$\begin{array}{lll}- & - \\ + & + & +\end{array}$

$-$

+
+++
+++

$+++$

-
++

++
+

$+++++$

$++$

$-$
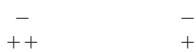

$++$

$+$

$+$

$+$

$+$

$++$

$-1+$
++

+
+++

$+$ 
TABLE 1. (continued)

\begin{tabular}{|c|c|c|c|}
\hline \multirow[b]{2}{*}{ CNS region } & \multicolumn{2}{|c|}{ Orphanin FQ peptide } & \multirow{2}{*}{$\begin{array}{l}\text { Preproorphanin } \\
\text { FQ mRNA } \\
\text { expression }\end{array}$} \\
\hline & Cells & $F / T$ & \\
\hline $\begin{array}{l}\text { Hippocampal fo } \\
\text { (continued) }\end{array}$ & & & \\
\hline DGpo & + & + & + \\
\hline IG & +++ & + & +++ \\
\hline PaS & + & - & ++ \\
\hline $\operatorname{PrS}$ & + & - & + \\
\hline $\mathrm{s}$ & +++ & + & +++ \\
\hline SFO & + & ++ & ++ \\
\hline $\mathrm{SHi}$ & ++ & ++ & ++ \\
\hline Thalamus & & & \\
\hline$A D$ & - & ++ & - \\
\hline AM & - & - & - \\
\hline $\mathrm{AV}$ & - & + & ++ \\
\hline $\mathrm{CL}$ & - & - & - \\
\hline CM & - & - & - \\
\hline $\mathrm{F}$ & - & - & - \\
\hline IAD & - & +++ & - \\
\hline LD & - & - & + \\
\hline LGN & - & - & + \\
\hline $\mathrm{LHb}$ & - & ++ & ++ \\
\hline LP & - & - & - \\
\hline MD & - & - & + \\
\hline MGN & - & - & - \\
\hline $\mathrm{MHb}$ & ++ & +++ & + \\
\hline $\mathrm{mt}$ & - & - & - \\
\hline PC & - & ++ & - \\
\hline PLi & + & - & ++ \\
\hline Po & + & - & ++ \\
\hline PR & - & - & + \\
\hline $\operatorname{PrC}$ & ++ & +++ & ++ \\
\hline PT & - & +++ & +++ \\
\hline PVA & + & +++ & ++ \\
\hline PVP & - & + & ++ \\
\hline $\mathrm{Re}$ & - & + & + \\
\hline $\mathrm{Rh}$ & - & + & - \\
\hline $\mathrm{RI}$ & - & - & + \\
\hline Rt & ++++ & ++ & +++++ \\
\hline SG & +++ & - & ++ \\
\hline SPFPC & ++ & +++ & +++ \\
\hline SubG & - & - & ++ \\
\hline $\mathrm{VL}$ & - & - & - \\
\hline VM & - & - & - \\
\hline VPL & - & - & - \\
\hline VPM & - & - & - \\
\hline $\mathrm{ZI}$ & ++ & ++ & +++ \\
\hline Mesencephalon & & & \\
\hline APT & +++ & ++ & ++ \\
\hline APTD & ++ & ++ & ++ \\
\hline APTV & +++ & + & +++ \\
\hline ATg & + & + & - \\
\hline bic & - & - & - \\
\hline $\mathrm{BIC}$ & - & ++ & - \\
\hline CG & ++++ & +++ & ++++ \\
\hline CGD & + & + & ++ \\
\hline cic & - & - & - \\
\hline $\mathrm{CIC}$ & + & - & - \\
\hline CLi (B8) & ++ & + & ++ \\
\hline $\mathrm{CnF}$ & - & - & - \\
\hline $\mathrm{cp}$ & - & - & - \\
\hline CSC & - & - & - \\
\hline $\mathrm{ctg}$ & - & - & - \\
\hline $\mathrm{DClC}$ & + & + & + \\
\hline $\mathrm{Dk}$ & ++++ & ++ & +++++ \\
\hline dlf & - & - & - \\
\hline DLL & - & - & - \\
\hline $\mathrm{DpMe}$ & + & + & ++ \\
\hline DR (B7) & ++ & ++ & ++ \\
\hline DTg & +++ & + & ++++ \\
\hline $\mathrm{ECIC}$ & ++ & + & +++ \\
\hline $\mathrm{EW}$ & - & - & - \\
\hline $\mathrm{fr}$ & - & - & - \\
\hline Ifp & - & - & - \\
\hline ILL & - & - & - \\
\hline IMLF & ++ & + & +++ \\
\hline InCo & - & - & - \\
\hline IPC & + & + & ++ \\
\hline IPD & ++ & +++ & ++++ \\
\hline IPL & - & + & +++ \\
\hline IPR & +++ & + & +++ \\
\hline LC & ++ & ++ & +++ \\
\hline LDTg & +++ & ++ & +++ \\
\hline LGN & - & - & + \\
\hline II & - & - & - \\
\hline MA3 & - & - & - \\
\hline MCPC & + & - & ++ \\
\hline $\mathrm{Me} 5$ & - & - & - \\
\hline MGN & - & - & - \\
\hline
\end{tabular}

TABLE 1. (continued)

\begin{tabular}{|c|c|c|c|}
\hline \multirow[b]{2}{*}{ CNS region } & \multicolumn{2}{|c|}{ Orphanin FQ peptide } & \multirow{2}{*}{$\begin{array}{l}\text { Preproorphanin } \\
\text { FQ mRNA } \\
\text { expression }\end{array}$} \\
\hline & Cells & $\mathrm{F} / \mathrm{T}$ & \\
\hline \multicolumn{4}{|c|}{$\begin{array}{l}\text { Mesencephalon } \\
\text { (continued) }\end{array}$} \\
\hline MiTg & - & - & - \\
\hline $\mathrm{ml}$ & - & ++ & - \\
\hline MnR (B8) & +++ & + & ++ \\
\hline $\begin{array}{l}\mathrm{mp} \\
\mathrm{OPT}\end{array}$ & $\begin{array}{c}- \\
++\end{array}$ & - & - \\
\hline OT & $\begin{array}{l}++ \\
++\end{array}$ & + & $\begin{array}{l}+ \\
++\end{array}$ \\
\hline $\mathrm{Pa} 4$ & - & - & - \\
\hline PBG & - & - & - \\
\hline $\mathrm{pc}$ & - & - & - \\
\hline PCom & +++ & - & +++ \\
\hline $\mathrm{PL}$ & + & - & - \\
\hline $\mathrm{PLi}$ & + & - & ++ \\
\hline PMR & ++ & - & + \\
\hline $\mathrm{Pn}$ & - & + & - \\
\hline PN & +++ & + & ++++ \\
\hline $\mathrm{PnO}$ & + & ++ & ++ \\
\hline $\mathrm{PP}$ & +++ & ++ & $\begin{array}{l}++ \\
++++\end{array}$ \\
\hline PPT & ++ & - & ++ \\
\hline PPTg & ++ & + & +++ \\
\hline $\mathrm{PR}$ & - & - & - \\
\hline $\mathrm{Rbd}$ & - & - & - \\
\hline $\mathrm{RLi}$ & ++ & + & ++ \\
\hline RMC & + & + & ++ \\
\hline RPC & - & + & + \\
\hline RPO & + & - & - \\
\hline $\mathrm{RR}$ & ++ & - & + \\
\hline RRF & ++ & + & ++ \\
\hline rs & - & - & - \\
\hline RtTg & - & - & - \\
\hline $\mathrm{SC}(\mathrm{DpG})$ & - & - & + \\
\hline SC(DpWh) & - & - & - \\
\hline $\mathrm{SC}(\operatorname{InG})$ & +++ & + & +++ \\
\hline $\mathrm{SC}(\mathrm{InWh})$ & - & - & - \\
\hline SC(Op) & ++ & + & ++ \\
\hline SC(SuG) & + & + & + \\
\hline SC(Zo) & - & + & - \\
\hline scp & - & - & - \\
\hline SG & ++ & - & +++ \\
\hline SNC & ++ & + & +++ \\
\hline SNL & ++ & + & ++ \\
\hline SNR & +++ & ++ & +++ \\
\hline $\mathrm{sp} 5$ & - & - & - \\
\hline SPTg & - & - & - \\
\hline $\mathrm{Su} 3{ }^{\circ}$ & ++ & + & ++ \\
\hline $\mathrm{tz}$ & - & - & - \\
\hline $\mathrm{Tz}$ & ++ & - & +++ \\
\hline VLL & - & - & - \\
\hline VLTg & - & - & - \\
\hline VTA & +++ & ++ & +++ \\
\hline $\mathrm{VTg}$ & + & + & ++ \\
\hline $\mathrm{Zl}$ & ++ & ++ & +++ \\
\hline Cerebellum & & & \\
\hline Lobules & + & - & + \\
\hline IntA & - & - & - \\
\hline IntDL & - & - & - \\
\hline IntDM & - & - & - \\
\hline IntP & - & - & - \\
\hline Lat & - & - & - \\
\hline LatPC & - & - & - \\
\hline Med & +++ & ++ & ++ \\
\hline MedDL & ++ & ++ & ++ \\
\hline Metencephalor & & & \\
\hline 6 & - & - & - \\
\hline $6 n$ & - & - & - \\
\hline 7 & - & - & - \\
\hline $7 \mathrm{n}$ & - & - & - \\
\hline $8 \mathrm{n}$ & - & - & - \\
\hline A5 & ++ & - & ++ \\
\hline A7 & - & - & - \\
\hline CGPn & ++ & + & ++ \\
\hline CPO & - & + & - \\
\hline $\mathrm{DC}$ & ++ & + & + \\
\hline DMTg & + & - & ++ \\
\hline DPO & + & - & ++ \\
\hline DR (B6) & ++ & ++ & ++ \\
\hline DTg & ++ & - & ++ \\
\hline $\mathrm{Gi}$ & + & - & ++ \\
\hline $\mathrm{GiA}$ & ++ & - & ++ \\
\hline GiV & +++ & - & +++ \\
\hline $\mathrm{Gr}$ & - & - & - \\
\hline icp & - & - & - \\
\hline $\mathrm{KF}$ & - & - & - \\
\hline LC & ++ & ++ & +++ \\
\hline LDTg & + & - & ++ \\
\hline LPB & ++ & + & +++ \\
\hline
\end{tabular}


TABLE 1. (continued)

\begin{tabular}{|c|c|c|c|}
\hline \multirow[b]{2}{*}{ CNS region } & \multicolumn{2}{|c|}{ Orphanin FQ peptide } & \multirow{2}{*}{$\begin{array}{l}\text { Preproorphanin } \\
\text { FQ mRNA } \\
\text { expression }\end{array}$} \\
\hline & Cells & $\mathrm{F} / \mathrm{T}$ & \\
\hline $\begin{array}{l}\text { Metencephalor } \\
\text { (continued }\end{array}$ & & & \\
\hline LPGi & ++ & - & ++++ \\
\hline LRt & + & - & ++ \\
\hline LSO & + & ++ & ++ \\
\hline LVe & ++ & + & +++ \\
\hline LVPO & ++ & + & ++ \\
\hline mlf & - & - & - \\
\hline MnR (B5) & +++ & + & ++ \\
\hline Mo5 & - & - & - \\
\hline MPB & - & - & - \\
\hline MSO & - & - & - \\
\hline MVeV & ++ & + & ++ \\
\hline MVe & ++ & ++ & ++ \\
\hline MVPO & ++ & + & +++ \\
\hline $\mathrm{Pa} 5$ & + & - & ++ \\
\hline PCRt & - & ++ & + \\
\hline PDTg & + & - & +++ \\
\hline $\mathrm{PnC}$ & ++ & + & ++ \\
\hline PnR & ++ & + & +++ \\
\hline $\mathrm{PnV}$ & ++ & + & + \\
\hline PPTg & +++ & - & +++ \\
\hline Pr5 & - & - & - \\
\hline py & - & - & - \\
\hline RMg & +++ & ++ & ++++ \\
\hline $\mathrm{RPa}$ (B1) & ++ & + & ++ \\
\hline RPO & + & ++ & ++ \\
\hline Sp5O & - & + & + \\
\hline SPO & ++ & ++ & ++ \\
\hline SpVe & + & + & ++ \\
\hline Subc & - & - & - \\
\hline SuVe & +++ & + & ++ \\
\hline $\mathrm{Tz}$ & ++ & - & +++ \\
\hline VCA & - & - & - \\
\hline VCP & - & - & - \\
\hline Mylencephal on & & & \\
\hline $9 n$ & - & - & - \\
\hline 10 & - & - & - \\
\hline 12 & - & - & - \\
\hline A5 & ++ & - & ++ \\
\hline A7 & - & - & - \\
\hline Amb & +++ & ++ & ++++ \\
\hline $\mathrm{Cl}$ & - & - & - \\
\hline $\mathrm{C} 2$ & - & - & - \\
\hline $\mathrm{C} 3$ & - & - & - \\
\hline $\mathrm{Cl}$ & ++ & - & +++ \\
\hline $\mathrm{Cu}$ & - & - & - \\
\hline DMSp5 & +++ & +++ & +++++ \\
\hline $\mathrm{DPGi}$ & + & - & + \\
\hline $\mathrm{ECu}$ & - & - & + \\
\hline $\mathrm{Gr}$ & - & - & - \\
\hline IOA & + & - & ++ \\
\hline IOB & - & - & ++ \\
\hline IOD & +++ & ++ & ++ \\
\hline IODM & - & - & - \\
\hline IOM & - & - & - \\
\hline IOPr & +++ & + & +++ \\
\hline IRt & ++ & - & +++ \\
\hline LVe & ++ & + & +++ \\
\hline $\mathrm{MdD}$ & ++ & - & ++ \\
\hline $\mathrm{MdV}$ & ++ & - & ++ \\
\hline $\mathrm{mlf}$ & - & - & - \\
\hline MVeV & - & - & - \\
\hline MVe & ++ & + & ++ \\
\hline $\mathrm{Pa} 5$ & + & - & ++ \\
\hline $\mathrm{PrH}$ & ++++ & +++ & ++++ \\
\hline py & - & - & - \\
\hline RAmb & +++ & - & +++++ \\
\hline RMg (B3) & +++ & ++ & ++++ \\
\hline ROb (B2) & + & + & ++ \\
\hline $\mathrm{SGe}$ & ++ & +++ & +++ \\
\hline sol & - & - & - \\
\hline Sol & ++ & ++ & ++++ \\
\hline SolC & +++ & ++ & ++ \\
\hline SolL & +++ & +++ & +++ \\
\hline SolM & ++ & +++ & +++ \\
\hline Sp5C & +++ & ++++ & +++++ \\
\hline Sp5l & - & +++ & + \\
\hline SpVe & ++ & + & + \\
\hline SuVe & ++ & + & ++ \\
\hline $\mathrm{Tz}$ & +++ & - & +++ \\
\hline VCA & - & - & - \\
\hline VCP & - & - & - \\
\hline Spinal cord & & & \\
\hline Cervical & & & \\
\hline I & - & ++ & - \\
\hline II & ++ & ++++ & ++++ \\
\hline
\end{tabular}

TABLE 1. (continued)

\begin{tabular}{|c|c|c|c|}
\hline \multirow[b]{2}{*}{ CNS region } & \multicolumn{2}{|c|}{ Orphanin FQ peptide } & \multirow{2}{*}{$\begin{array}{l}\text { Preproorphanin } \\
\text { FQ mRNA } \\
\text { expression }\end{array}$} \\
\hline & Cells & $F / T$ & \\
\hline \multirow{2}{*}{\multicolumn{4}{|c|}{$\begin{array}{l}\text { Spinal cord } \\
\text { Cervical (continued) }\end{array}$}} \\
\hline & & & \\
\hline III & ++ & +++ & +++ \\
\hline IV & - & +++ & - \\
\hline $\mathrm{v}$ & - & + & + \\
\hline $\mathrm{VI}$ & - & + & + \\
\hline VII & + & + & ++ \\
\hline VIII & + & + & + \\
\hline IX & ++ & - & ++ \\
\hline \multirow{2}{*}{\multicolumn{4}{|c|}{ Thoracic }} \\
\hline & & & \\
\hline 1 & - & + & - \\
\hline 11 & ++ & +++ & ++++ \\
\hline III & - & ++ & +++ \\
\hline IV & - & ++ & - \\
\hline $\mathrm{v}$ & - & ++ & + \\
\hline VII & - & ++ & - \\
\hline VIII & & ++ & + \\
\hline IX & + & - & ++ \\
\hline $\mathrm{x}$ & ++ & +++ & ++ \\
\hline $\mathrm{cu}$ & - & - & \\
\hline dcs & - & - & 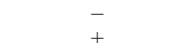 \\
\hline DRG & & & + \\
\hline $\begin{array}{l}\mathrm{gr} \\
\mathrm{IML}\end{array}$ & $\begin{array}{l}- \\
-\end{array}$ & $\begin{array}{l}- \\
-\end{array}$ & $\begin{array}{l}- \\
-\end{array}$ \\
\hline IMM & + & - & +++ \\
\hline LatC & +++ & +++ & + \\
\hline Ifu & - & - & - \\
\hline LSp & ++ & +++ & - \\
\hline vfu & - & - & - \\
\hline
\end{tabular}

Distribution of orphanin FQ immunoreactivity and preproorphanin mRNA in the central nervous system (CNS) of the adult male rat. Degree of immunoreactivity and mRNA expression was graded arbitrarily based on density and intensity of immunostaining, and intensity of microscopic mRNA expression was assessed based on emulsiondipped sections. $F / T$, fibers/terminals. Gradations used were +++++ , highest signal intensity (used for mRNA expression); ++++ , intense; +++ , moderate; ++ , light to moderate; +, light or sparse; - , undetectable. For abbreviations, see list.

scattered neurons expressing OF Q mRNA emerge in layer III at the level of the rostral accumbens. Caudally, more intense labeling is observed in its dorsal part in layers II and III. The piriform cortex maintains persistent cell labeling throughout its rostral-to-caudal extent. Messenger RNA levels in this cortical region are light to moderate, primarily in layer III, with occasional scattered neurons in layer II. In the entorhinal cortex, mRNA expression is moderate throughout but is observed mostly in layers II and III.

Immunohistochemistry. Moderately immunostained cells are scattered throughout the rostral-to-caudal extent of both the neocortex and the allocortex. Fiber labeling is minimal, with occasional fibers noted primarily in layers $\mathrm{V}$ and VI in untreated animals. These fibers are seen in all cortical regions and are sparse. Fibers in layer VI maintain a parallel orientation, whereas those in other layers maintain a perpendicular orientation. I mmunolabeling in the frontal cortex is light to moderate to its caudal extent, with most immunolabeled neurons within layers II, III, and VI rostral and with occasional scattered neurons noted in layer $\mathrm{V}$ caudally. Rostral parietal regions demonstrate sparse immunolabeling, but OF Q-containing neurons are slightly more numerous and are stained more moderately in its middleto-caudal regions. These perikarya are scattered mostly in layers II, III, V, and VI. In thetemporal cortex, theweakest OF Q neocortical immunolabeling is observed. Perikarya are observed occasionally in layer VI and are stained moderately. Occipital immunolabeling is confined to scattered, moderately labeled neurons in layers $\mathrm{V}$ and $\mathrm{VI}$, primarily in its dorsal part. Throughout its extent, the corpus callosum is devoid of immunolabeling. 

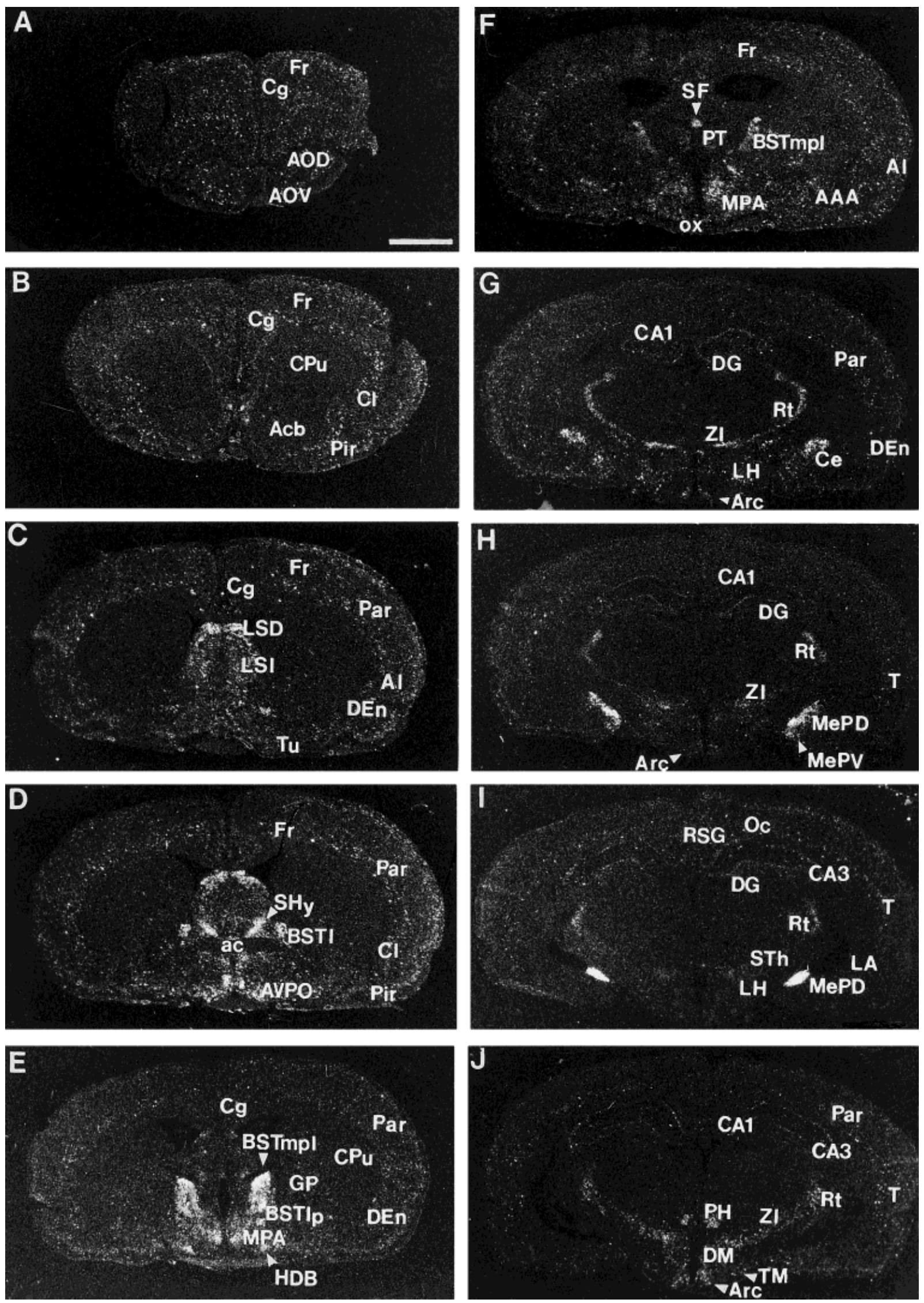

Fig. 4. A-J : Distribution of prepro-OFQ mRNA in the rat brain at representative coronal sections through the forebrain. For abbreviations, see list. Scale bar $=500 \mu \mathrm{m}$. 

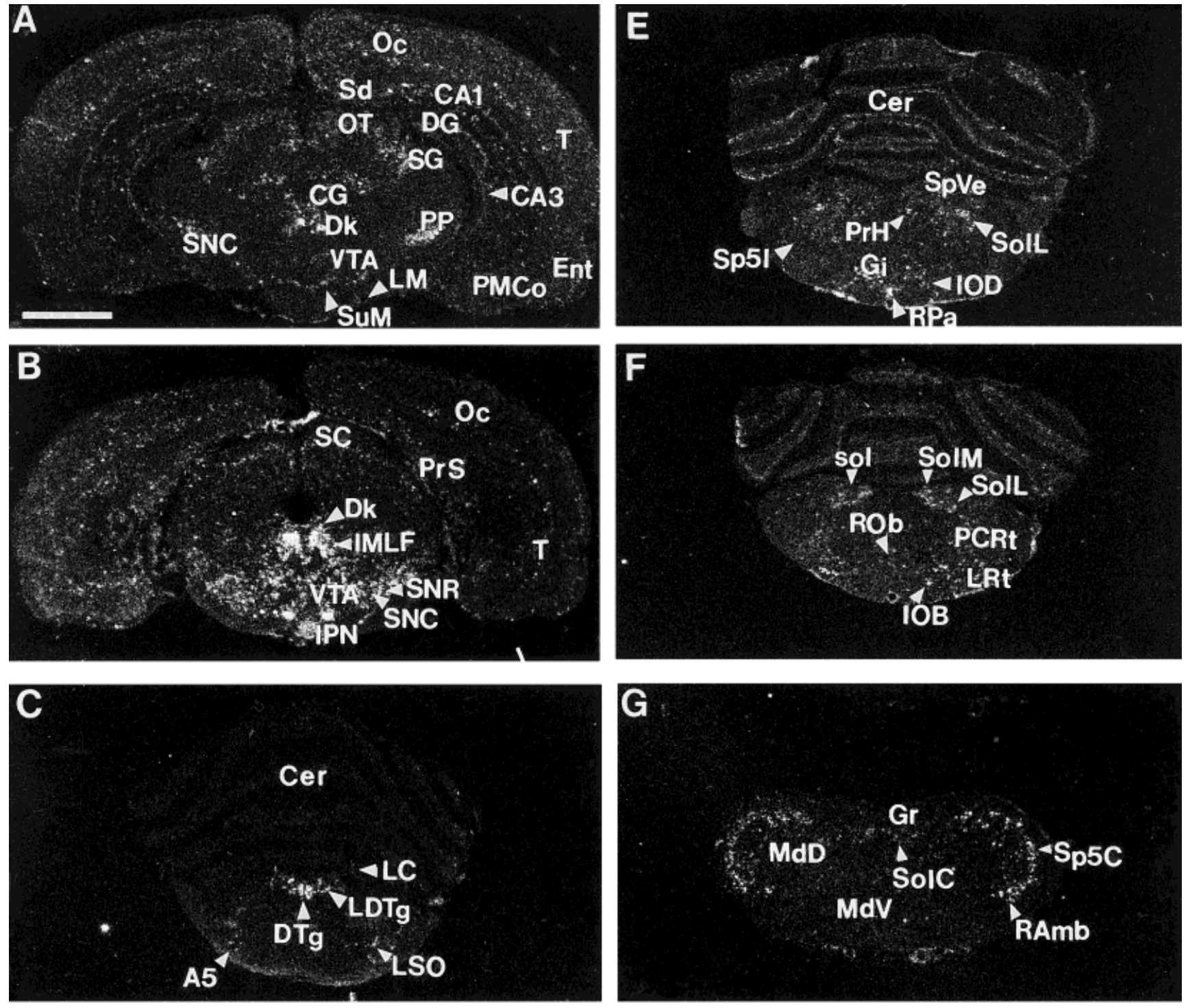

G
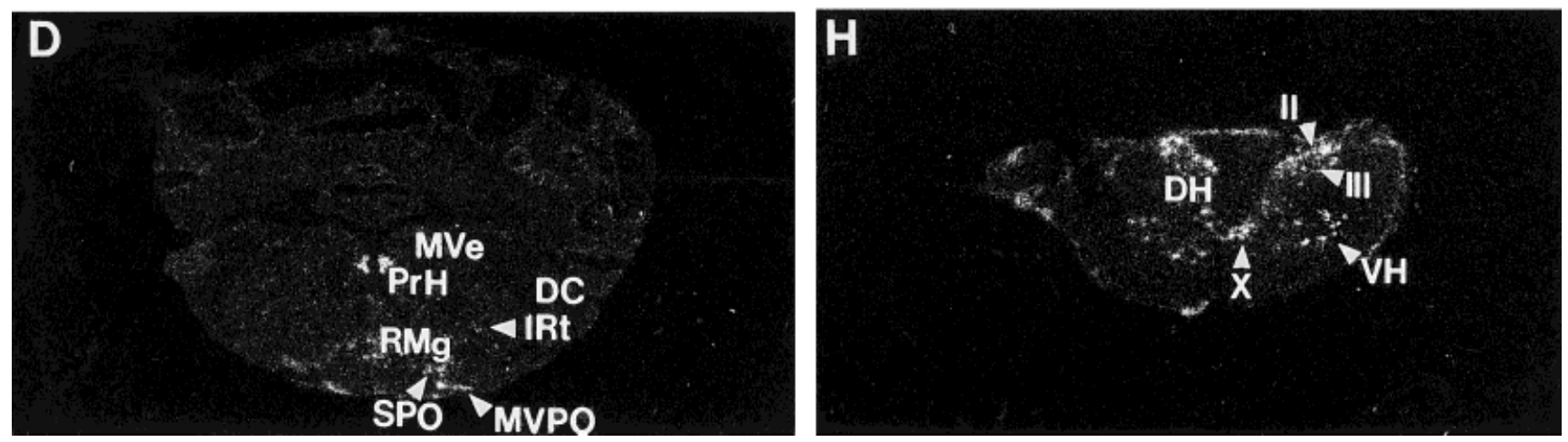

Fig. 5. A-H: Distribution of prepro-OFQ mRNA in the rat brain at representative coronal sections through the brainstem and spinal cord. For abbreviations, see list. Scale bar $=500 \mu \mathrm{m}$.

Scattered, lightly labeled cells are noted in the ventral orbital cortex, with moderately labeled immunoreactive cells noted in layers I and II of the dorsal peduncular and infralimbic cortices. I mmunolabeling in the insular cortex is confined to scattered, lightly labeled neurons in layers II and III, mostly in its granular part. Immunolabeled neurons are observed throughout the tenia tecta, mostly in layer II (Fig. 6B), and in the indusium griseum, where 

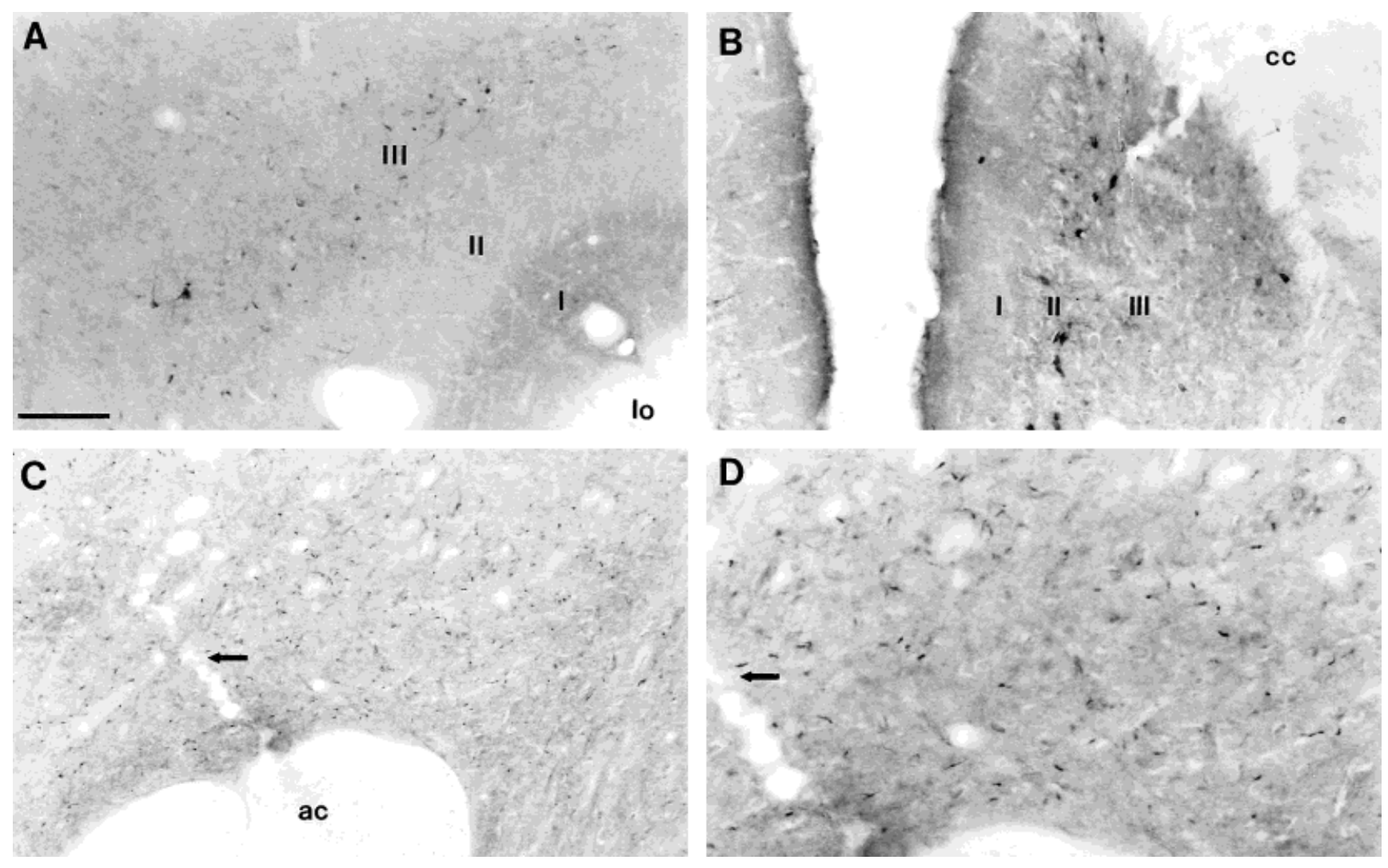

Fig. 6. Brightfield photomicrographs of OFQ immunolabeling in rostral forebrain structures. A: Fiber and neuronal immunolabeling within layer III of the piriform cortex. B: Photomicrograph illustrating OF Q-containing neurons within layer II of the tenia tecta. C,D: Low-

darkly stained cells are seen throughout its rostral-tocaudal extent. In the piriform cortex, scattered, moderately stained cells are dispersed throughout layer III, with a moderate network of fibers and puncta observed in layer III in untreated animals (Fig. 6A). No immunolabeling is observed in layer I. Lightly immunolabeled neurons and minimal fibers are observed in the amygdalopiriform transition area, and the entorhinal and perirhinal cortices exhibit no immunolabeling. OF Q-containing cells are dark and are most prominent in layers II and III throughout the cingulate cortex, with darkly immunolabeled neurons noted in layer VI in its caudal extent. This pattern persists into the retrosplenial cortex, where darkly stained cells are observed in its agranular and granular parts to its caudal extent.

\section{Ventral forebrain}

In situ hybridization. Messenger RNA expression is weak in the rostral anterior ol factory nucleus, particularly in its lateral and dorsal parts. M ore caudally, mRNA levels increase, with scattered mRNA-expressing neurons observed mostly in the medial, lateral, and posterior parts. Caudally, mRNA expression in the ventral division is the strongest of the entire anterior olfactory nucleus. No immunolabeled neurons are observed in the rostral pole of nucleus accumbens. As the accumbens differentiates into core and shell components, only scattered OF Q-containing neurons are observed in the shell throughout its rostral-to-

and high-power images, respectively, of immunolabeled fibers in the core of nucleus accumbens in untreated animals. For abbreviations, see list. Scale bar $=100 \mu \mathrm{m}$ in A-C, $50 \mu \mathrm{m}$ in D.

caudal extent. Throughout the accumbens core, mRNA expression is very light, with mRNA-containing neurons localized to the lateral part of the nucleus and extending into the substantia innominata. Medial to the accumbens shell, the major island of Calleja is devoid of mRNA expression. Throughout the ventral forebrain, the islands of Calleja and fundus striati contain no OFQ mRNA expression. Orphanin-containing neurons are lightly scattered in the medial ventral pallidum and are more numerous in its lateral aspect. Messenger RNA expression in the olfactory tubercle is moderate, with neurons scattered primarily throughout layer III. Moderate numbers of OF Q-containing neurons are observed in the vertical limb of the diagonal band of Broca (Fig. 9B). Heavy mRNA expression is observed in the horizontal limb to its caudal boundary, where a cluster of prepro-OFQ-containing neurons is present dorsal to the supraoptic nucleus in the rostral hypothalamus. No mRNA expression is present in the anterior commissure at any level.

Immunohistochemistry. I mmunolabeling in theanterior olfactory nucleus is confined to sparse, lightly stained neurons ventrally and to more numerous neurons in its posterior division, where cells are stained more moderately. In untreated animals, diffuse fibers and puncta are observed in the more caudal aspect of this nucleus extending into the rostral pole of the accumbens. I mmunolabeling in the rostral pole of the nucleus accumbens is limited to diffuse, fine, moderately labeled fibers that are observed 

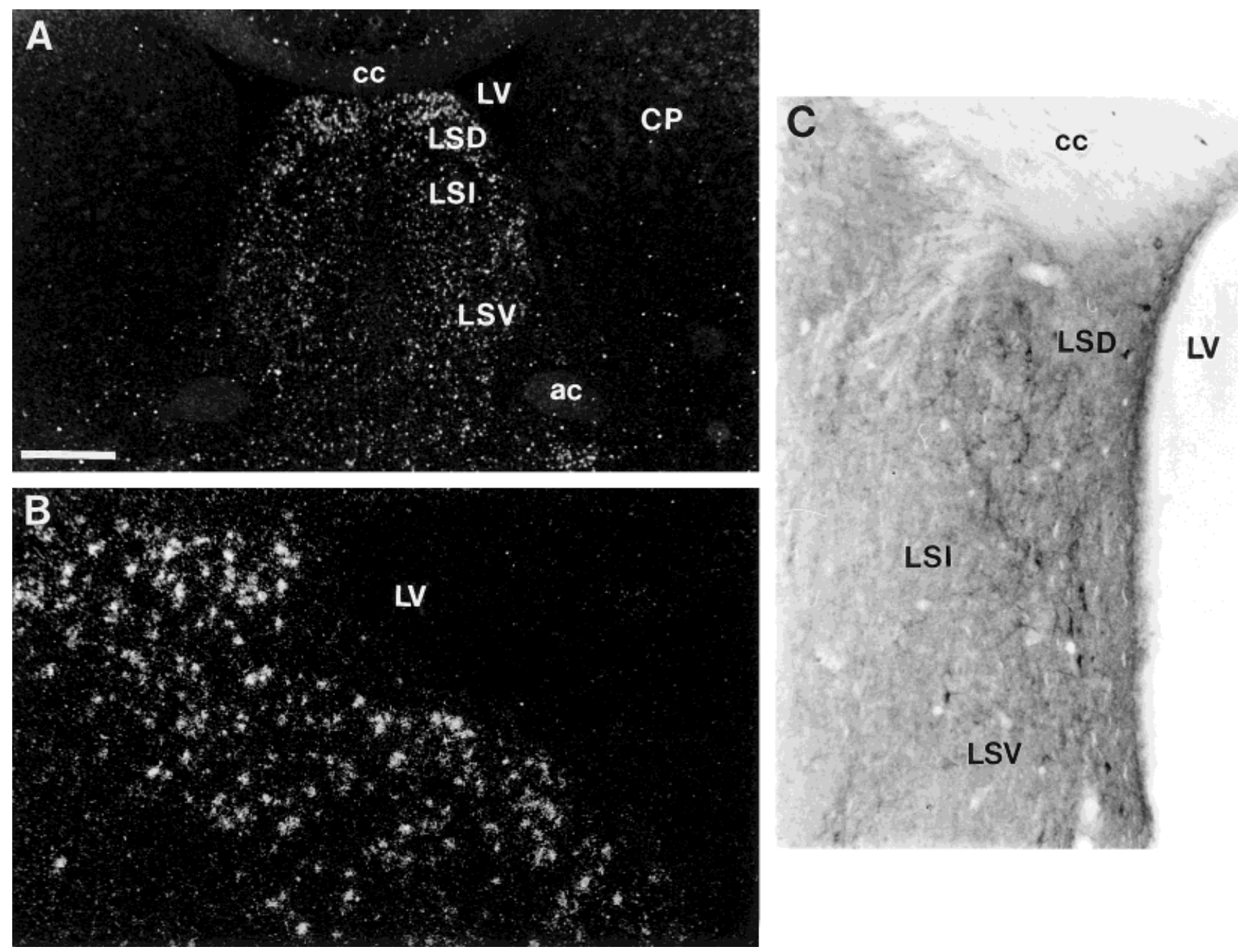

Fig. 7. Photomicrographs of mRNA expression and immunolabeling in the lateral septal nucleus. A: Low-power photomicrograph of mRNA expression in the dorsal, intermediate, and ventral divisions of the lateral septum. B: High-power photomicrograph of the dorsal

lateral septum demonstrating numerous mRNA-containing neurons within this region. C: Brightfield photomicrograph of immunolabeling in the lateral septum in a colchicine-treated animal. For abbreviations, see list. Scale bar $=800 \mu \mathrm{m}$ in A, $200 \mu \mathrm{m}$ in B, $100 \mu \mathrm{m}$ in C.

best in untreated animals. As the shell emerges, it contains scattered fibers and puncta with occasional darkly stained cells. F ine, immunoreactive fibers extend medially into the vertical limb of the diagonal band of Broca and caudally as a continuum with the ventral division of the bed nucleus of the stria terminalis. The accumbens core contains only occasional lightly stained neurons, whereas diffuse fibers are spread throughout this nucleus. Fiber immunolabeling intensifies caudally in its dorsal part, adjacent to the striatum (F ig. 6C,D), and extends ventrally with less intensity into the ventral pallidum. In the ventral pallidum, lightly immunolabeled neurons are scattered throughout the region, with a prominent fiber plexus observed to its caudal extent. A similar network of dense fibers and puncta is observed in the fundus striati with no immunoreactive neurons. This pattern of fiber immunolabeling, which is observed best in untreated animals, is similar to that seen in the ventral pallidum.

Several moderately stained neurons are found in layers II and III of the olfactory tubercle, with dark fibers and puncta distributed primarily in layer II. No immunostain- ing is observed in the islands of Calleja. The vertical limb of the diagonal band of B roca contains moderately immunolabeled fibers and puncta but only occasional lightly immunolabeled neurons. At the emergence of the horizontal limb, darkly labeled OFQ-containing neurons appear and remain to its caudal pole as a cluster of densely stained neurons ventrolateral to the preoptic area. Adjacent to the fundus striati caudally, several large, darkly stained, OFQ-containing neurons and fibers are observed in the substantia innominata. Scattered fibers present in the substantia innominata extend dorsally into the basal nudeus of Meynert, where large, moderately stained neurons are observed also in its caudal region. The anterior commissure is devoid of immunolabeling.

\section{Septum}

In situ hybridization. OF Q mRNA expression in this entire region is very strong (Figs. 7A, 9A). I nitially, light OF Q expression is observed in the most rostral pole of the lateral septum in its ventral and intermediate parts. At this level, the septohippocampal nucleus has moderate 
mRNA expression, which persists to its caudal extent. In the lateral septal nucleus, light OFQ expression is seen initially in the anterior portion of its ventral part. At the emergence of the dorsal lateral septum, mRNA expression becomes very intense, filling this division throughout its extent (Fig. 7B). The intermediate lateral septum also is labeled heavily but not as intensely as the dorsal part. The ventral part contains moderate mRNA expression. Scattered OFQ mRNA-containing neurons in the ventral lateral septum are observed primarily al ong the dorsal aspect of the accumbens shell, persisting caudally to the bed nucleus of the stria terminalis. At this level, intense mRNA expression is observed intensifying and stretching out from the lateral septal region into the septohypothaIamic nucleus (Fig. 9A). The medial septal nucleus has scattered OFQ-containing cells. No mRNA expression is observed in the lambdoid zone, the paralambdoid septal nucleus, or the dorsal fornix.

Immunohistochemistry. In contrast to the intense mRNA expression observed in this region, immunolabeling in the lateral septum is modest (Fig. 7C). A plexus of scattered fibers and terminals and numerous darkly stained cells resides in the dorsolateral portion of this nudeus, remaining consistently immunolabeled throughout. Moderately labeled OFQ-containing neurons in the intermediate lateral septal nucleus reside mostly along its lateral boundary, with more numerous immunolabeled neurons in the ventral part. In untreated animals, fiber and terminal staining in the intermediate division is moderate to intense, and the ventral lateral septum contains scattered, light neurons among a moderate fiber and terminal plexus located primarily along the ventrolateral border. Scattered, lightly labeled neurons are observed in the medial septum, where fiber labeling is negligible. No immunolabeling is noted in the lambdoid septal zone or the paralambdoid septal nucleus. The septohippocampal region contains a moderate number of densely stained neurons and fibers. I mmunolabeling in the septohypothalamic nucleus is prominent, with moderately stained fibers and dark cells extending ventral to the bed nucleus of the stria terminalis. The dorsal fornix is devoid of immunolabeling.

\section{Basal ganglia}

In situ hybridization. In therostral forebrain, prominent numbers of OF Q-containing neurons are observed in the claustrum scattered throughout the nucleus (Fig. 2C). At the emergence of the striatum, mRNA-containing neurons in the claustrum become much more numerous, with light-to-moderate mRNA expression extending ventrally into the dorsal and ventral endopiriform nuclei. The striatum contains little prepro-OFQ mRNA expression. Only scattered OFQ-containing neurons are identified throughout this nucleus, with mRNA-containing neurons more numerous in its mediodorsal part. Messenger RNA expression is intense throughout the globus pallidus. Neurons within this structure are not dense in number, but intensity of mRNA expression is strong, and labeled neurons are large. Near the caudal striatum, the basal nucleus of Meynert contains a moderate number of neurons expressing OFQ mRNA. The adjacent entopeduncular nucleus has numerous large, mRNA-expressing neurons, mostly in its ventromedial aspect. At the caudal extent of the entopeduncular nucleus, the subthalamic nucleus contains scattered, light mRNA expression.
Caudal to the subthalamic nucleus, preproorphanin mRNA is very prominent in the substantia nigra. In its rostral pole, scattered neurons are present in the pars reticulata. From its midrostral to midcaudal region, the pars reticulata contains heavy mRNA expression (Fig. 8C), falling off somewhat caudally, with scattered OFQcontaining neurons mostly in its dorsal part. The pars compacta contains lightly scattered, large, mRNA-containing neurons in its rostral portion, with mRNA expression becoming quite intense into the caudal half of this region (Fig. 8D) and persisting into the pars lateralis.

Immunohistochemistry. I n therostral for ebrain, moderately labeled neurons and occasional scattered fibers are noted in the most rostral extent of the claustrum. This pattern persists throughout the nucleus. Thedorsal endopiriform nucleus contains scattered, moderately labeled neurons and fibers, with most neurons residing medially. In the ventral endopiriform nucleus, immunolabeling consists of scattered neurons with no fibers. The striatum contains sparse, darkly stained fibers noted throughout its rostral-to-caudal extent. These diffuse fibers are observed equally in both colchicine-treated and untreated animals (Fig. 1A). Although these fibers can be seen in all regions of the striatum, there is a predominance in its ventromedial aspect. Occasional small, lightly immunolabeled neurons are observed but are very few in number. At the emergence of the globus pallidus, darkly immunolabeled neurons appear and remain throughout its extent (Fig. 8A). These neurons, although they are not numerous, are large and intensely stained. Medial to the globus pallidus at more caudal levels, large, darkly labeled neurons are observed throughout the basal nucleus of Meynert (Fig. 8B). There is moderate fiber staining in this structure, with lightly labeled puncta extending into the substantia innominata. The entopeduncular nucleus contains scattered, darkly immunolabeled neurons with sparse fibers and terminals.

Immediately caudal to the entopeduncular nucleus, sparse, lightly labeled fibers and neurons are observed in the subthalamic nucleus, confined primarily to its ventromedial part. The pars reticulata of the substantia nigra emerges with numerous, moderately labeled perikarya and fibers that are most numerous in its ventromedial part and that extend dorsally in caudal regions (Fig. 3C). Although the pars compacta has significantly fewer perikarya than are seen in the pars reticulata, neurons are intensely immunolabeled. Caudally, the darkly stained, large neurons in the pars compacta extend dorsolaterally into the pars lateralis.

\section{Basal telencephalon}

In situ hybridization. Within the forebrain, mRNA expression is highest within the basal telencephalon ( $F$ ig. 9A). In the rostral bed nucleus of the stria terminalis, mRNA expression is observed throughout the entire medial and lateral parts. Heavy mRNA levels are seen generally throughout the lateral division, with very light mRNA expression observed in its juxtacapsular part and with heavy expression in its dorsal and ventral parts. The medial division has a moderate-to-strong mRNA expression in its ventral part (Fig. 9B), increasing dramatically in its caudal aspect. Intensity of mRNA expression in the posterolateral part of the medial division is the strongest of the entire bed nudeus of the stria terminalis. Intense mRNA expression persists to the caudal pole of this 

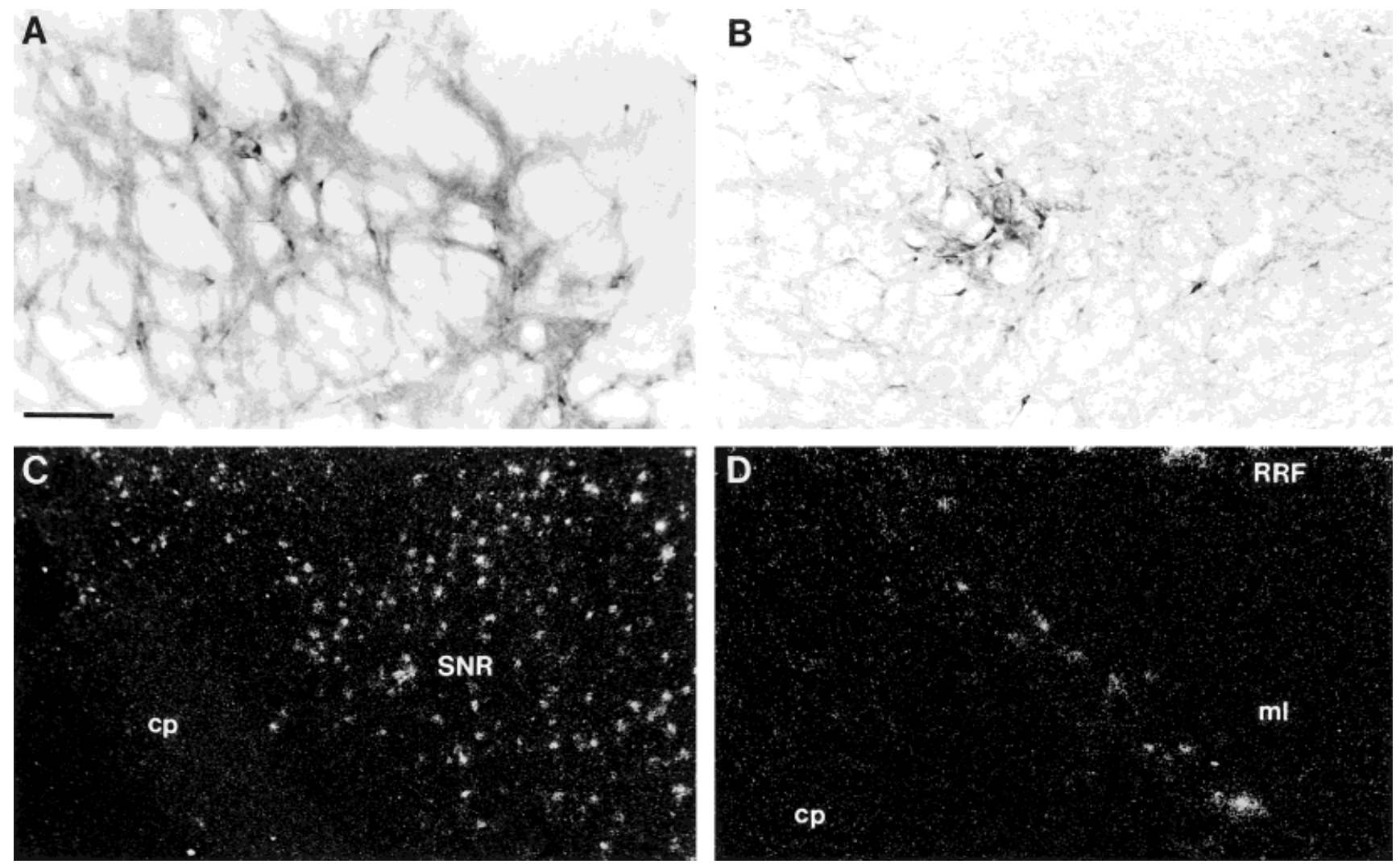

Fig. 8. Photomicrographs of mRNA expression and immunolabeling in basal ganglia-related structures. A: Brightfield photomicrograph of OFQ immunoreactivity in the gl obus pallidus demonstrating OF Q-immunoreactive fibers and cell bodies. B: Cell and fiber immunolabeling in the basal nucleus of Meynert (colchicine treated). C,D: In

nudear complex, surrounding the fornix in the anterior hypothalamus. In this region, scattered, mRNA-expressing neurons extend medially from this nucleus into the region of the paraventricular nudleus of the hypothalamus. No prepro-OFQ mRNA expression is observed in the fornix or the stria terminalis.

In the preoptic region, heavy mRNA expression is seen in the anteroventral preoptic nucleus, contrasting sharply with that of the anteromedial preoptic nucleus, in which mRNA levels are much lighter. The adjacent medial preoptic area is filled with mRNA-containing neurons throughout its rostral-to-caudal extent (Fig. 9E), with expression heaviest in its dorsal part rostrally and in the lateral aspect of this region more caudally. This expression pattern extends into the lateral preoptic area, where it remains strong. The medial preoptic nucleus contains a dense accumulation of cells expressing OFQ mRNA (Fig. 9E). J ust caudal to the horizontal limb of the diagonal band, moderate mRNA levels are observed in neurons within the magnocellular preoptic nucleus. In the caudal basal telencephalon, the nucleus of the lateral olfactory tract contains scattered neurons expressing mRNA. These OF Q-containing neurons are light to moderate in number and are confined mostly to layer II, with an occasional neuron observed in layer III. No OF Q mRNA expression is seen in the lateral ol factory tract.

Immunohistochemistry. Paralleling its mRNA expression pattern, immunolabeling in this region is quite

the substantia nigra, orphanin mRNA expression is heavy in midrostral to caudal levels of the pars reticulata (C) and in the caudal part of the pars compacta (D). For abbreviations, see list. Scale bar $=100 \mu \mathrm{m}$ in $A, B, D, 200 \mu \mathrm{m}$ in $C$.

intense. In the rostral bed nucleus of the stria terminalis, dense fibers, terminals, and immunolabeled neurons extend from the septohypothalamic nucleus and fill the anterior and ventral parts of the medial division. Farther caudally, a plexus of neurons, fibers, and puncta fill the posteromedial part of the medial division and most of the posterolateral part (Fig. 9C,D). This dense, immunolabeled plexus lies adjacent to the lateral ventricle and spreads ventrally toward the preoptic area. In the caudal posterolateral part of the medial division, a unique distribution pattern emerges. At the level of the anterior hypothalamus, numerous darkly stained neurons surround the fornix. This cell group extends medially as a continuum to the lateral boundary of the magnocellular part of the paraventricular nucleus of the hypothalamus, remaining outside of its boundaries and extending into the lateral hypothalamic area. Fiber and terminal labeling in the lateral subdivision is slightly more intense than in the medial subdivision at rostral levels, but drops off in posterior regions. The juxtacapsular part of the lateral subdivision contains only occasional cell bodies with lightto-moderate fiber and terminal staining (Fig. 9C). Perikarya are not observed in the posterior part of the lateral division, and fiber labeling drops off dramatically to its caudal extent, where immunolabeling in the medial division is most intense. Fiber staining is prominent in the stria terminalis, particularly dorsally, adjacent to the lateral ventricle. Occasional darkly stained neurons are 

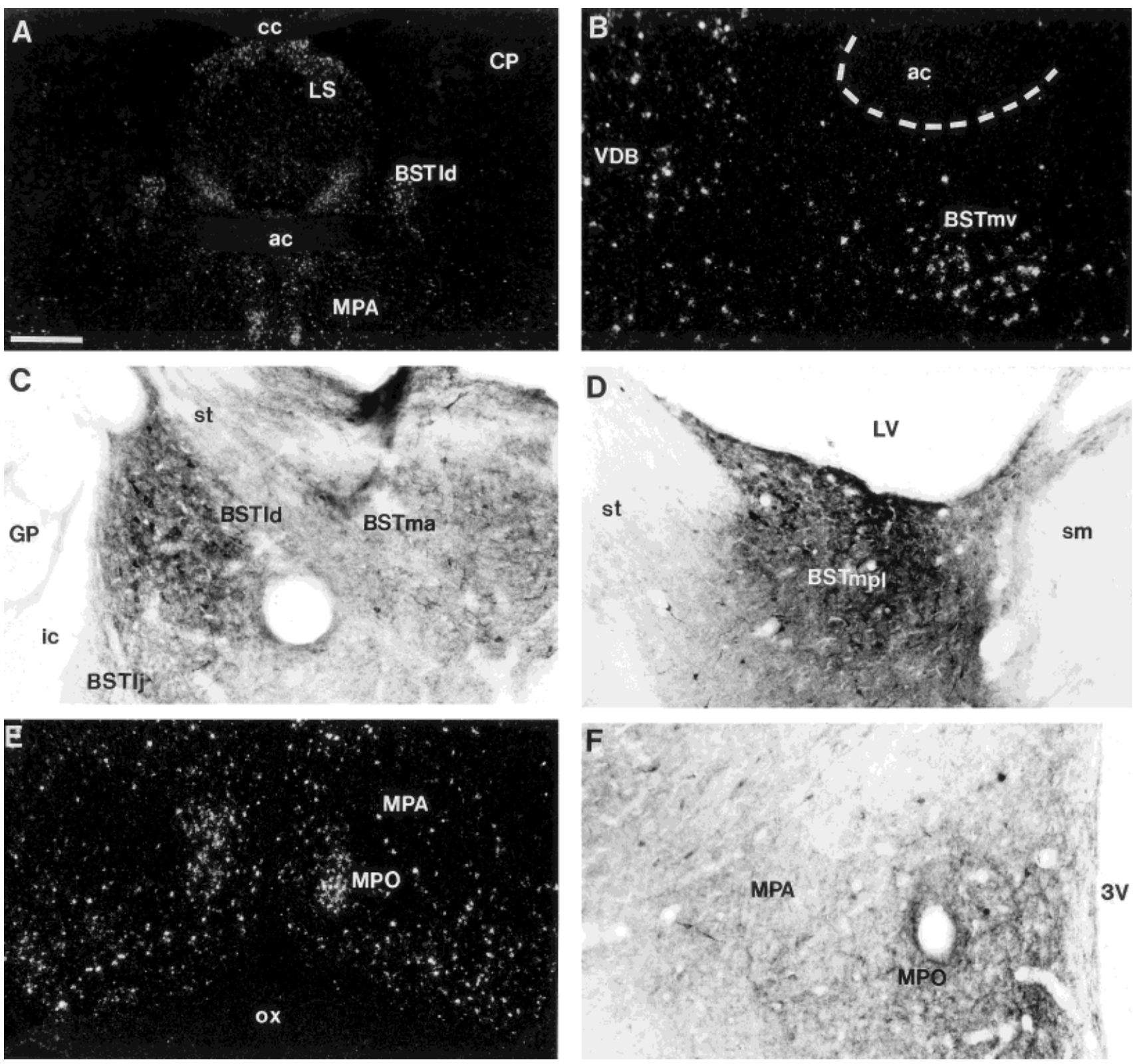

Fig. 9. Photomicrographs of OFQ mRNA and protein expression in the medial preoptic area and the bed nucleus of the stria terminalis. A: Low-power image of the rostral basal telencephal on demonstrating strong mRNA signal in the lateral septum, bed nucleus of the stria terminalis, and medial preoptic area. B: High-power photomicrograph demonstrating OFQ-containing neurons in the ventral part of the medial bed nucleus of the stria terminalis. Several neurons with robust OFQ mRNA signal in the ventral diagonal band are also present. Dashed line outlines the boundary of the anterior commissure. C: OFQ immunoreactivity in the dorsal part of the lateral bed

present in this structure as well. The fornix is devoid of immunolabeling.

The medial preoptic area contains scattered, darkly stained neurons and moderate-to-heavy fibers throughout its extent (Fig. 9F). Fewer immunolabeled neurons are seen in the medial preoptic nucleus and the magnocellular preoptic nucleus, and only scattered, lightly stained cells are seen in the anteromedial preoptic nud eus. A cluster of

nucleus of the stria terminalis, the juxtacapsular part of the lateral division, and the anterior part of the medial division (colchicine treated). D: OF Q-immunoreactivefibers and neurons in the posterol ateral medial division of the bed nucleus (colchicine treated). E: Orphanin expression in the midpreoptic region demonstrates moderate mRNA signal intensity, with a cluster of intense mRNA signal in the medial preoptic nucleus. F: OFQ-containing fibers and light cells in the medial preoptic area and the medial preoptic nucleus (untreated). For abbreviations, seelist. Scale bar $=850 \mu \mathrm{m}$ in A, $200 \mu \mathrm{m}$ in B,F, 100 $\mu \mathrm{m}$ in $\mathrm{C}, 150 \mu \mathrm{m}$ in $\mathrm{D}, 400 \mu \mathrm{m}$ in $\mathrm{E}$.

darkly stained neurons is observed in the anteroventral preoptic nucleus, continuing laterally with the caudal part of the horizontal limb of the diagonal band. Fiber and terminal labeling is very strong in the anteroventral and anteromedial nuclei and throughout the medial preoptic nucl eus. I mmunol abel ed fibers and terminals are sparsein the magnocellular preoptic nucleus, which contains a cluster of moderately immunolabeled neurons. The lateral 
preoptic area contains scattered, darkly stained neurons among moderate fibers and light terminal labeling, mostly in its medial aspect. Ventrally in this region, the nucleus of the lateral olfactory tract contains moderate numbers of lightly stained cells that are confined to layers II and III. Sparsely immunolabeled fibers and no puncta are observed in this nucleus.

\section{Hypothalamus}

In situ hybridization. In analyzing the nuclei of the hypothalamus by regions, based on a parcellation scheme that has been described previously by Swanson (1992), it becomes evident that the majority of OF Q in the hypothalamic region lies primarily in the medial zone. In the ventral hypothalamus, the suprachiasmatic and supraoptic nuclei are devoid of mRNA expression. Farther caudally, scattered cells are observed in the tuber cinereum, with strong expression observed within the medial tuberal nudeus and dorsal into the magnocellular part of the lateral hypothalamus. Occasional scattered neurons containing OF Q mRNA are noted within the retrochiasmatic area, just caudal to the suprachiasmatic nucleus. Orphanin mRNA expression is more moderate in the arcuate nudeus, persisting throughout its rostral-to-caudal extent, with heaviest expression in more ventral regions. No mRNA expression is seen in the median eminence. The ventromedial hypothalamic nucleus is devoid of mRNA expression, with only an occasional OF Q-containing neuron noted in the shell region.

In the dorsal region of the hypothalamus, there is a decrease in mRNA levels in the transition from the posterior bed nucleus of the stria terminalis into the anterior and lateral hypothalamic areas rostrally, where expression remains moderately strong. An occasional OFQcontaining neuron is observed in the lateroanterior hypothalamic area. A moderate cluster of mRNA-expressing cells is observed in the parvocellular part of the paraventricular nucleus. Although several orphanin-containing neurons are observed at the lateral border of this nucleus, the magnocellular part itself has only occasional, scattered mRNA-expressing cells. Caudal to the paraventricular nucleus, cells expressing mRNA are lightly scattered in the dorsal hypothalamic area, moderately scattered in the tuberal magnocellular nucleus, and numerous in the dorsomedial hypothalamic nucleus. Lateral to the dorsal hypothalamic area, the perifornical nucleus contains only scattered neurons expressing OFQ mRNA, with intensity increasing into the posterior hypothalamus. At the midline, the periventricular nucleus contains scattered mRNAexpressing neurons, persisting to its caudal extent. There is no mRNA expression detected in the terete hypothalamic nucleus.

In the mammillary region, OF Q mRNA expression in the ventral premammillary nucleus is moderate and increases into the dorsal premammillary region. The supramammillary (Fig. 11A) and lateral mammillary nuclei contain moderate mRNA expression throughout their rostral-tocaudal extents. In contrast, the medial mammillary nudeus has very low mRNA levels and is devoid of mRNA expression in its lateral and medial divisions. The median division of the medial mammillary nucleus contains only lightly scattered mRNA-expressing cells. The mammillary peduncle and supramammillary decussation are devoid of mRNA expression. The pituitary (Fig. 11C) and pineal
(Fig. 11D) glands also are devoid of OFQ mRNA expression.

Immunohistochemistry. A cluster of large, darkly stained neurons fills a region just lateral to the paraventricular nudeus. These large, OFQ-containing neurons extend laterally and surround the fornix in the posterolateral part of the medial division of the bed nucleus of the stria terminalis (Fig. 10C). The parvocellular part of the paraventricular nucleus contains a modest number of lightly stained neurons and fibers, mostly in its medial aspect, adjacent to the third ventricle. Scattered, darkly stained fibers and occasional neurons are present also within the magnocellular part of this nucleus (Fig. 10C). The lateroanterior hypothal amic nucleus, Iateral hypothalamic area, and anterior hypothalamic area contain moderate numbers of large, OF Q-containing neurons. Caudally, this cell duster extends into the tuber cinereum. In all of these regions, sparse, lightly stained fibers are present, except for the tuber cinereum, where moderate fiber staining is observed in untreated animals. The supraoptic and retrochiasmatic supraoptic nuclei contain no immunolabeled neurons, but both regions contain darkly immunolabeled fibers throughout their rostrocaudal extent. No immunolabeling is noted in the suprachiasmatic nucleus. Caudally, the retrochiasmatic area contains numerous darkly labeled neurons and fibers.

Throughout the rostral half of the hypothalamus, the periventricular nucleus contains sparse, moderately stained neurons immediately adjacent to the third ventricle, with moderate fiber and terminal labeling. This fiber and terminal staining extends ventrally at its caudal pole into the arcuate region. The arcuate nucleus contains moderately stained cells and fibers, with numerous puncta throughout its rostral-to-caudal extent (Fig. 10A,B). Orphanin-containing neurons in this nucleus are more numerous in its dorsomedial part, and fibers within the arcuate primarily maintain a dorsal-to-ventral orientation. The median eminence contains an intense immunolabeled fiber plexus. Large, densely stained fibers fill the more medial aspect of the median eminence in its rostral part. In the middle to caudal regions, median eminence fibers are labeled more lightly in its medial aspect and are labeled intensely in the lateral aspects (Figs. 1B, 10A,B).

Lateral to the arcuate nucleus, lightly stained neurons are present only occasionally in the ventromedial hypothalamic nucleus. In untreated animals, moderate fibers and terminals are localized diffusely throughout the nucleus. Farther lateral, lightly immunolabeled neurons are observed in the medial tuberal nucleus, where no fiber or terminal labeling is noted. Moderately stained cells and fibers also are scattered in the dorsal hypothalamic area and the dorsomedial hypothalamic nucleus. I mmunostaining in this region extends laterally into the perifornical nucleus and persists caudally as lightly stained neurons in the posterior hypothalamus. Moderately labeled neurons are observed in the terete hypothalamic and tuberomammillary nuclei, and lightly labeled neurons are observed in the tuberal magnocellular nucleus.

In the mammillary region, moderate-to-heavy fiber and terminal labeling is present in the ventral and dorsal premammillary nuclei, with only scattered, lightly stained neurons observed. The medial mammillary nucleus contains light-to-moderate cell and fiber immunolabeling in its median division, whereas its medial and lateral divisions are devoid of staining. Neuronal labeling is most 

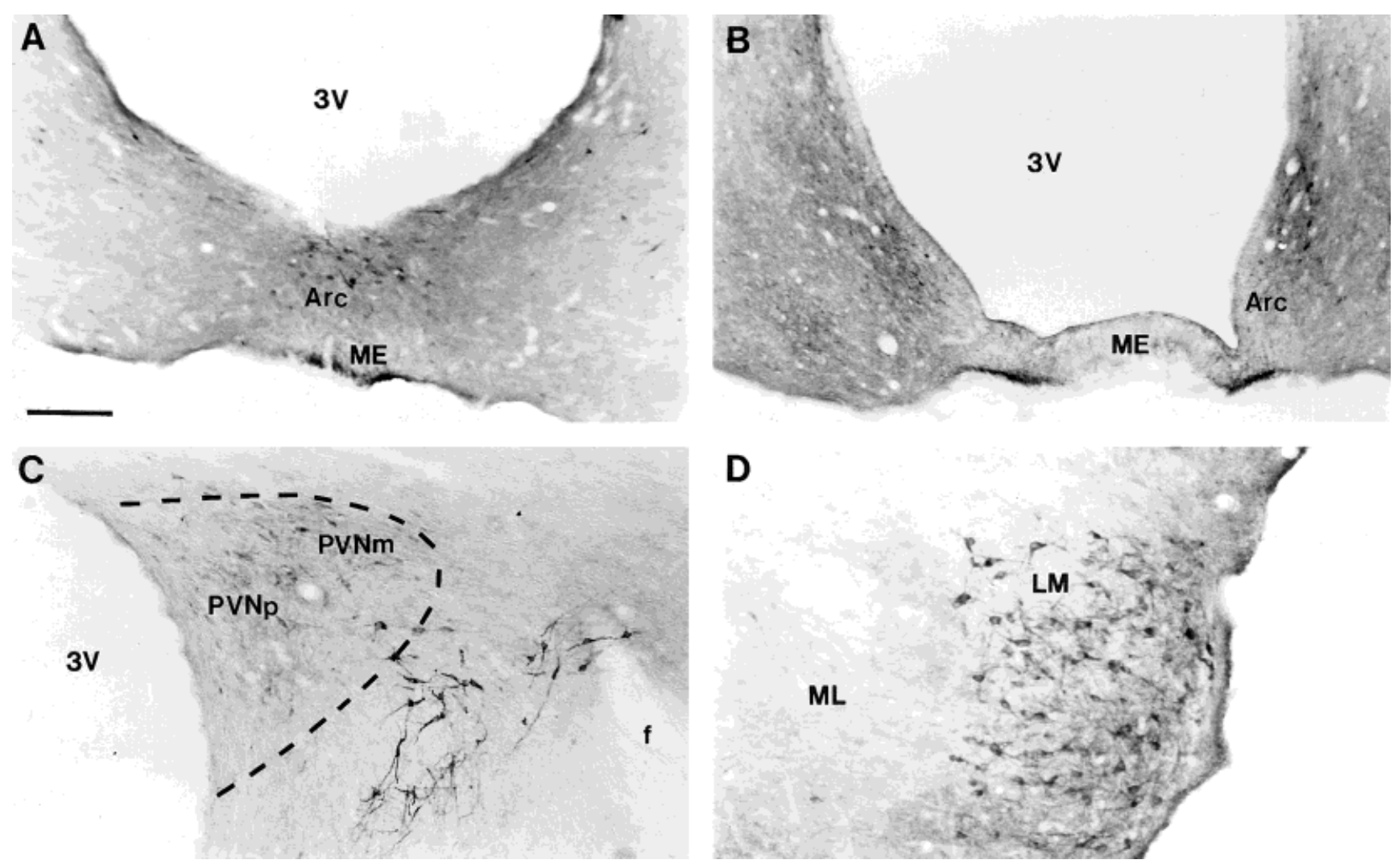

Fig. 10. Brightfield photomicrographs of orphanin immunoreactivity in the hypothalamus of colchicine-treated animals. A,B: Photomicrographs of rostral and caudal levels of the arcuate nucleus and median eminence. Note orphanin-containing median eminence fibers located medially at rostral levels and laterally at caudal levels. C: Orphanin immunolabeling in the paraventricular nucleus demon-

strating labeled parvocellular neurons medially with scattered immunolabeled neurons in the magnocellular part and darkly labeled neurons just lateral to this nucleus. Dashed line outlines the boundary of the paraventricular nucleus at that level. D: I mmunolabeling in the lateral mammillary nucleus. For abbreviations, see list. Scale bar $=$ $200 \mu \mathrm{m}$ in $A, B, D, 145 \mu \mathrm{m}$ in $C$.

pronounced in the lateral mammillary nucleus, which contains a dense plexus of darkly stained fibers and cells throughout (Fig. 10D). Moderate cell staining and strong fiber and terminal staining is observed in the supramammillary nucleus (Fig. 11B). The mammillary peduncle and supramammillary decussation are devoid of immunolabeling in this region.

\section{Amygdala}

In situ hybridization. Orphanin mRNA expression in the amygdaloid complex is relatively sparse in most nuclei, except for the central and medial amygdaloid nuclei, which contain intense OFQ mRNA expression (Fig $12 \mathrm{~A}, \mathrm{C})$. Rostrally, the anterior amygdaloid area contains occasional labeled neurons, particularly in its dorsal region. At the emergence of the central nucleus, scattered orphanin-containing neurons are observed in the lateral division, with the majority of mRNA expression confined to the medial division more caudally. This mRNA expression is moderate to heavy within the medial part of the central nucleus to its caudal extent (Fig. 12C). Light mRNA expression is observed in the basolateral and basomedial nuclei, increasing in the intraamygdaloid division of the bed nucleus of the stria terminalis. No mRNA expression is observed in the intercalated or lateral amygdal oid nuclei.

The medial nucleus has moderate expression rostrally in its anterodorsal part, with minimal expression in the

anteroventral division. This sparse distribution extends ventrally into the bed nucleus of the accessory olfactory tract. In the caudal one-third of the medial nucleus, mRNA expression increases dramatically. The posteroventral part of the nucleus contains moderate numbers of scattered neurons expressing orphanin mRNA, whereas the posterodorsal nucleus is filled completely with positive neurons (Fig. 12A). This intensity increases into the caudal pole of the medial nucleus, where the posterodorsal division is packed with OF Q-containing neurons. J ust caudal to the medial nucleus, the amygdalohippocampal area contains only scattered neurons with light mRNA levels. Messenger mRNA levels in the anterior cortical amygdaloid nucleus are very light, and this pattern persists caudally into the posterior cortical nucl eus. The posteromedial cortical nucleus contains light-to-moderate mRNA expression. The posterolateral cortical amygdal oid nucleus and the amygdal opiriform transition area have no mRNA expression.

Immunohistochemistry. OFQ peptide expression at the emergence of the amygdaloid region is very sparse, with a scattering of fibers and puncta and with no immunolabeled neurons in the anterior amygdaloid area. A moderate density of fibers and puncta reside in the rostral intercalated amygdaloid nuclei adjacent to the central nucleus; then, immunolabeling falls off dramatically, with 

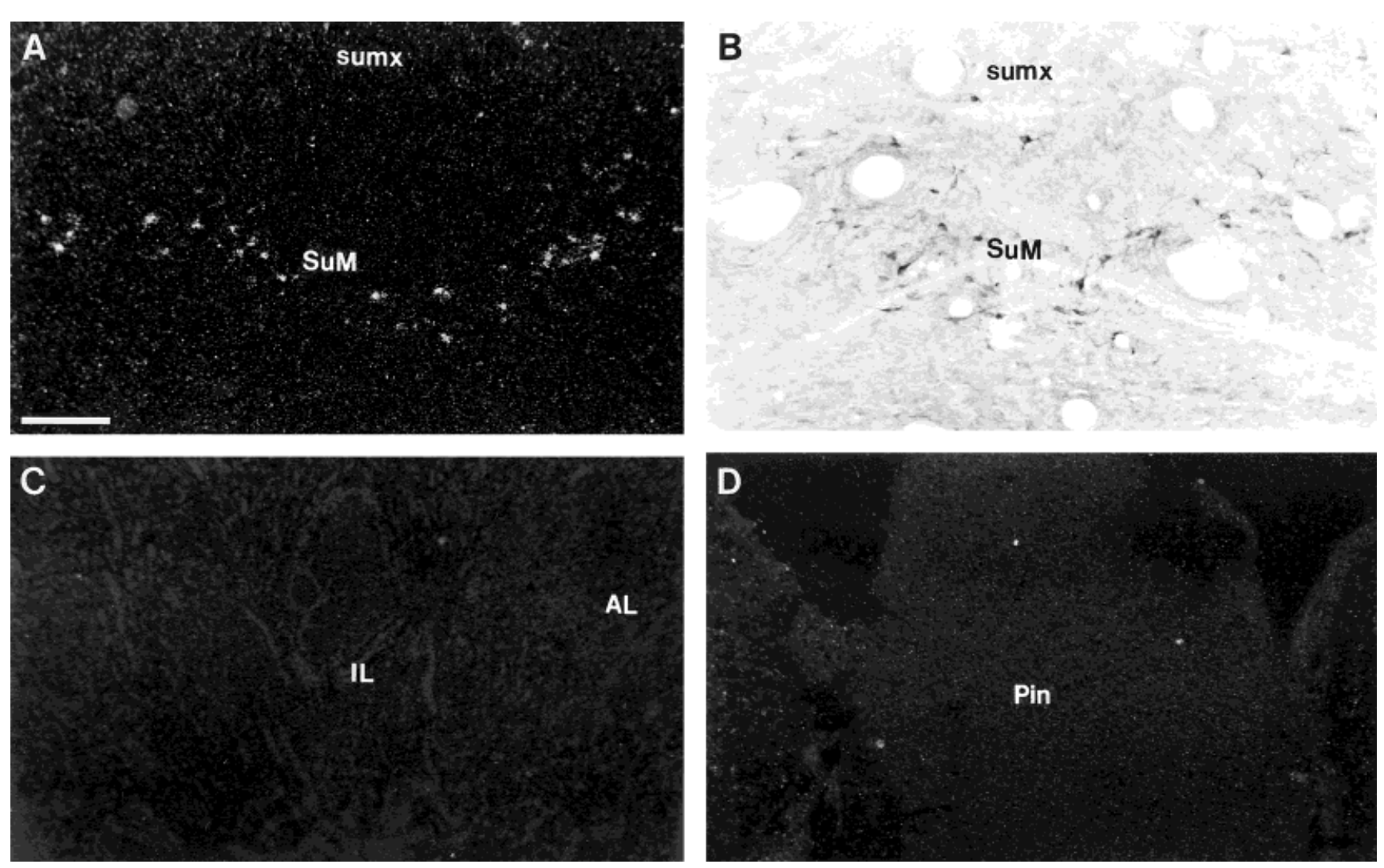

Fig. 11. A,B: Darkfield autoradiogram (A) and brightfield photomicrograph (B) of the supramammillary nucleus of the hypothalamus illustrating distribution of the prepro-OFQ precursor mRNA and OFQ peptide in this nucleus. C,D: Darkfield photomicrographs demonstrat-

only sparse terminal staining in the more caudal nuclei. The central nud eus contains moderate-to-heavy fiber staining in its rostral pole, with no immunolabeled cells present. Thenucleus quickly fills with a dense plexus of fibers, terminals, and numerous immunoreactive neurons by midcaudal levels. Heavy cell and fiber immunolabeling predominates within the medial division, whereas the lateral division contains primarily fibers and has very few immunolabeled neurons (Fig. 12D). The medial amygdaloid nucleus presents a variable staining pattern from its rostral to caudal poles. In its rostral pole, very lightly labeled fibers are seen in the anteroventral division. At the emergence of the anterodorsal division, fiber staining increase significantly, and lightly stained immunolabeled cells are observed. Throughout the caudal one-third of this nucleus, the posterodorsal division is filled with darkly stained fibers, terminals, and OFQ-containing neurons (Fig. 12B). The posteroventral division contains scattered, lightly labeled cells and fibers in its core and is surrounded by a dense plexus of fibers and terminals (Figs. 1C, 12B). Lateral to this region, scattered, moderately immunolabeled cells and fibers are observed in the intercalated nuclei. The intraamygdaloid division of the bed nucleus of the stria terminalis contains light fiber and terminal labeling with scattered, lightly labeled cells (Fig. 12D). The bed nucleus of the lateral olfactory tract contains scattered, lightly stained neurons with moderately stained ing absence of OFQ mRNA expression in the anterior and intermediate lobes of the pituitary (C) and pineal glands (D). For abbreviations, see list. Scale bar $=200 \mu \mathrm{m}$ in A,D, $100 \mu \mathrm{m}$ in B, $400 \mu \mathrm{m}$ in C.

fibers. I mmunolabeling in the remaining amygdaloid nuclei is sparse and includes lightly labeled, scattered cells and fibers in the basomedial and basolateral nuclei (Fig. 12D); light neurons and moderate fibers scattered throughout the posteromedial cortical nucleus; and light fibers in the anteromedial cortical nucleus. The amygdalohippocampal and amygdalopiriform transition areas are devoid of immunolabeling.

\section{Hippocampal formation and related structures}

In situ hybridization. At the level of the septal nuclei, the septohippocampal nucleus contains moderate mRNA expression. Dorsal to the corpus callosum, a cluster of intense mRNA-expressing neurons resides in the indusium griseum, persisting throughout its rostral-to-caudal extent. Ventral to this structure, the subfornical organ contains numerous mRNA-expressing neurons. The fornix is devoid of mRNA expression. More caudally, the dentate gyrus contains moderate numbers of prepro-OF Q-containing neurons, primarily within the granule cell layer. There are occasional scattered neurons within the molecular layer rostrally and within the polymorph layer caudally (Fig. 13A). The dentate hilus contains no mRNA expression. 

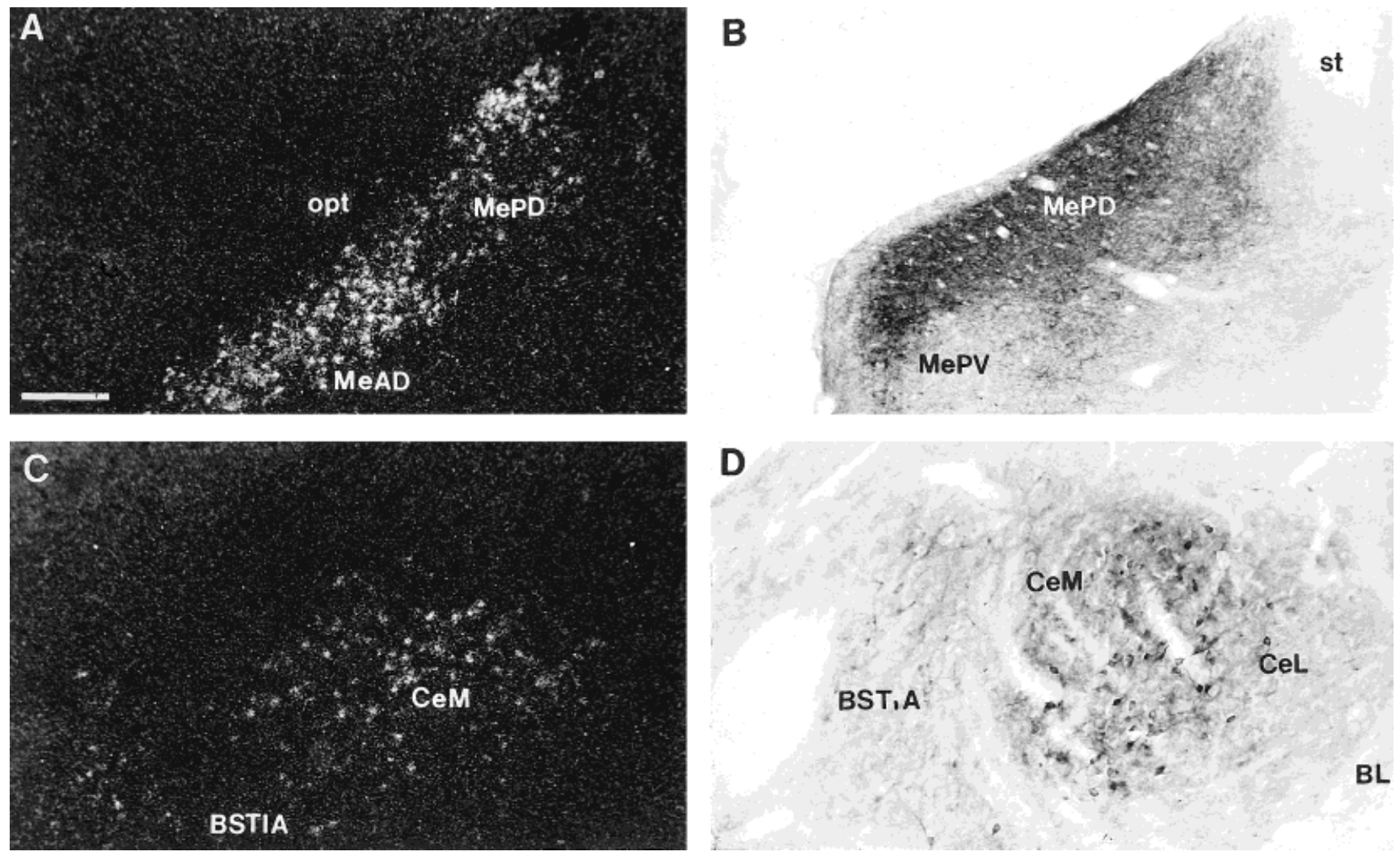

Fig. 12. Photomicrographs of mRNA expression and immunolabeling in the amygdala. A: Prepro-OFQ mRNA expression in the caudal medial nucleus. B: Brightfield photomicrograph of OFQ immunoreactivity in the posterodorsal and posteroventral parts of the medial nucleus (colchicine treated). C: OFQ mRNA expression in the central

nucleus. D: I mmunolabeling in the medial and lateral divisions of the central nucleus, basolateral nucleus, and intraamygdaloid bed nucleus of the stria terminalis (colchicine treated). For abbreviations, see list. Scale bar $=180 \mu \mathrm{m}$ in A, $200 \mu \mathrm{m}$ in B,C, $100 \mu \mathrm{m}$ in D.

In Ammon's horn, the CA1 field contains strong mRNA expression. Rostrally, it is primarily within the stratum pyramidal, with occasional mRNA-expressing neurons in the stratum radiatum ( $\mathrm{Fig}$. $13 \mathrm{~A}$ ). There is no $\mathrm{mRNA}$ expression detected in the stratum oriens. At more caudal levels, particularly in the ventral CA1 region, light mRNA expression is also observed in the stratum oriens. At rostral levels, little mRNA expression is detected in area CA2. This is in sharp contrast to the heavy mRNA levels observed in the adjacent CA1 and CA3 regions. In the caudal hippocampus, CA2 mRNA expression increases slightly in the pyramidal layer. An occasional mRNAexpressing neuron is observed in the stratum radiatum of area CA2, but no mRNA expression is observed in the stratum oriens. Rostrally in the CA3 field of Ammon's horn, there are numerous OFQ-containing neurons in the stratum lucidum extending into the hippocampal field from the stratum pyramidal, where scattered, mRNAcontaining neurons are observed. This persists into the caudal regions, where mRNA levels in the ventral CA3 field decrease in the stratum lucidum and increase in the stratum pyramidal. Messenger RNA expression in the stratum radiatum of area CA 3 is very light. In the dorsal subiculum, moderate mRNA expression persists throughout, with most OFQ-containing neurons confined to the pyramidal layer. In the ventral subiculum, mRNA expression is weak rostrally but increases in its more caudal aspect. Neurons expressing OF Q mRNA are numerous and

most dense in the pyramidal layer. Scattered neurons also are seen in the stratum radiatum and the stratum molecular. In the caudal forebrain, mRNA expression is light in the presubiculum and slightly heavier in the parasubiculum at all levels.

I mmunohistochemistry. In the rostral forebrain, the indusium griseum is densely packed with dark, immunoreactive fibers and cells. Ventral to this structure, staining extends into the septohippocampal nucleus and the tenia tecta (Fig. 6B). The subfornical organ contains moderate fiber labeling and scattered, lightly labeled cells. The fornix is devoid of immunolabeling.

In the dorsal dentate gyrus, moderate, darkly stained cells are scattered along the granule cell layer, with occasional lightly stained cells in the polymorph and molecular layers (Fig. 13B). These moderately sized cells likely represent interneurons and are localized primarily along the inner border of the polymorph layer, with fibers extending perpendicularly into the mol ecular layer. In the ventral dentate, neuronal immunolabeling becomes slightly more pronounced within the polymorph layer. The alveus contains no immunolabeling at all levels of the hippocampal formation. In the CA3 field of Ammon's horn, moderately sized, darkly immunolabeled cells are observed in the stratum pyramidal near the dentate hilus. In this region, moderately labeled fibers are seen extending into the stratum lucidum and the stratum oriens (Fig. 13C). Approaching the transition to CA2, immunolabeled pyra- 

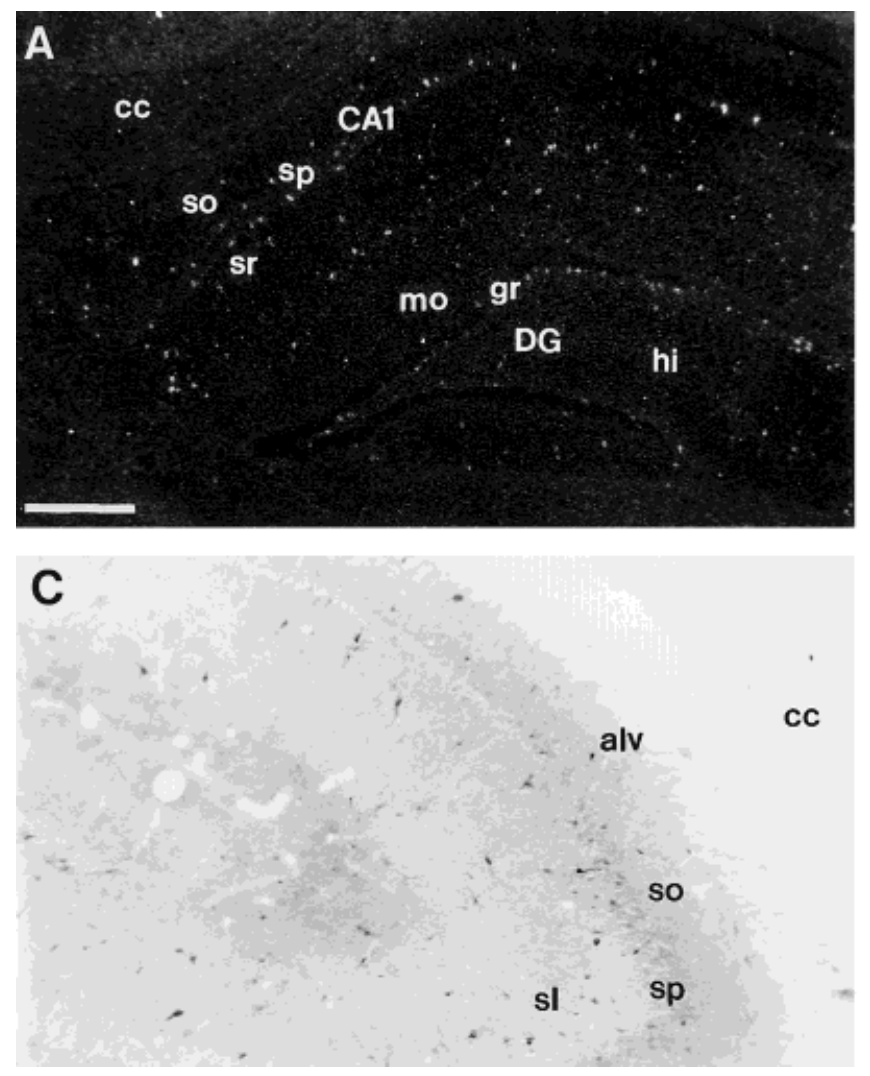

Fig. 13. Photomicrographs of orphanin mRNA expression in untreated animals and protein expression in colchicine-treated animals in the hippocampal formation. A: Prepro-OFQ mRNA expression in the dentate gyrus and CAl region of Ammon's horn. B: Brightfield

midal cells decrease in number, and numerous, darkly labeled neurons are observed in the stratum lucidum. In caudal CA3, moderate numbers of intensely stained neurons reside in the stratum pyramidal, and slightly fewer are seen in the stratum lucidum (Fig. 13C). Neuronal immunolabeling in the stratum radiatum is very sparse throughout the CA3 region. Very little immunolabeling is observed in area CA2 throughout its entire extent. Sparse, lightly labeled cells are seen in the stratum pyramidal. M oderately immunolabeled neurons are scattered scantly in the stratum radiatum adjacent to the dentate molecular layer. There is no fiber labeling noted in CA2. In area CA1, numerous darkly labeled neurons reside in the stratum pyramidal, with moderate fibers radiating into both the stratum oriens and the stratum radiatum near the dentate molecular layer (Fig. 3A). In ventral CA1, there is a dramatic decrease in stratum pyramidal neurons, with a moderate increase in orphanin-containing neurons in the stratum radiatum. Negligible fiber labeling is observed in caudal CA1. As CA1 transitions into the dorsal subiculum, there is a slight decrease in cell size, but the intensity of neuronal labeling remains strong (Fig. 13D). Perikarya are scattered throughout the dorsal region, with occasional scattered fibers also observed. Compared with its dorsal part, OFQ immunolabeling is decreased in the ventral subiculum. The presubiculum and parasubiculum contain scattered, lightly labeled cells with no immunolabeled fibers. The lamina dissecans of the entorhinal cortex is devoid of labeling.
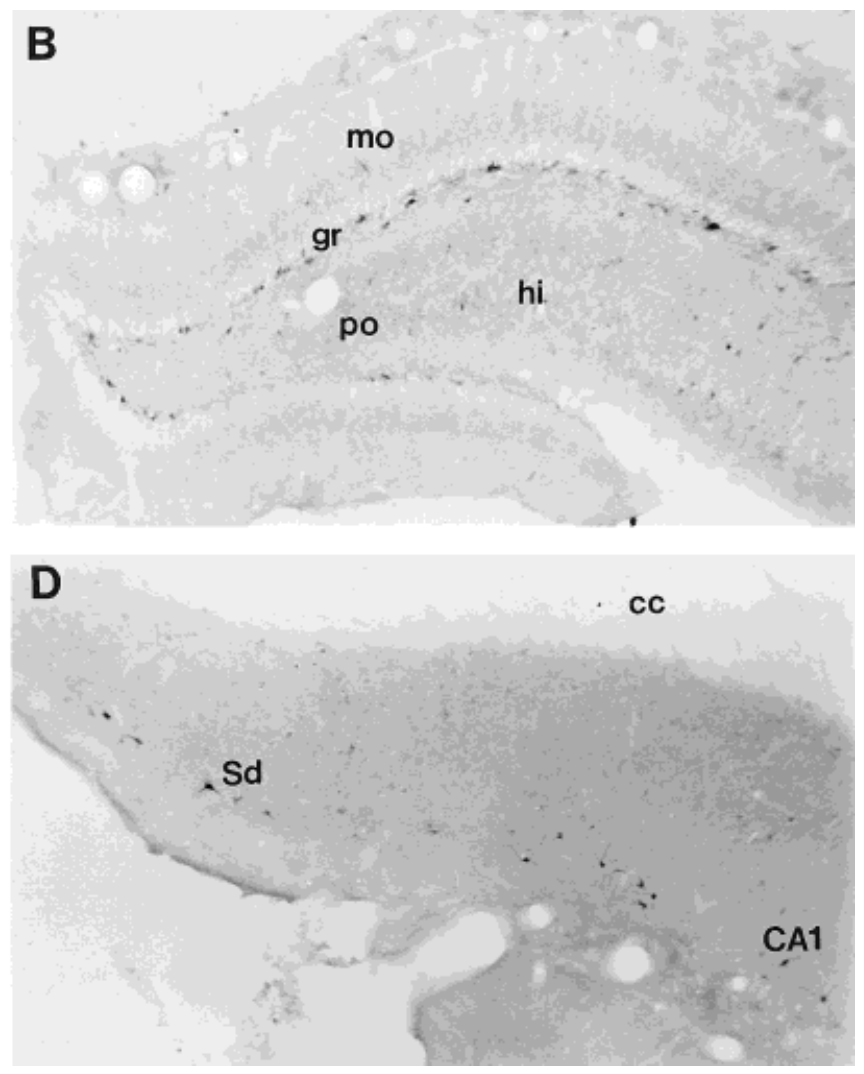

photomicrograph of OFQ immunoreactivity in the dentate gyrus. C: Higher power, detailed image of immunolabeling in CA3 area of Ammon's horn. D: Immunolabeling in the dorsal subiculum. For abbreviations, see list. Scale bar $=400 \mu \mathrm{m}$ in A, $200 \mu \mathrm{m}$ in B-D.

\section{Thalamus}

In situ hybridization. In the caudal basal telencephaIon, moderate mRNA expression in the anteroventral thalamic nucleus is observed adjacent to the posterior bed nudleus of the stria terminalis. At this level, strong mRNA expression fills the paratenial nucleus and extends into the anterior paraventricular and reuniens nuclei, where more moderate mRNA levels are observed. Messenger RNA expression in the paraventricular nucleus extends caudal to the posterior division, remaining moderate into its caudal pole. No OFQ mRNA expression is observed in theanterodorsal, anteromedial, interanterodorsal, paracentral, or rhomboid thalamic nudei. In the caudal one-third of the medial thalamic group, mRNA levels in the medial habenula are very light. The lateral habenula contains slightly more mRNA expression than the medial habenula, which is most pronounced in its caudal one-third. Scattered neurons containing OF Q mRNA are observed in the laterodorsal and mediodorsal thalamic nuclei. No mRNA expression is observed in the centromedial, centrolateral, or lateroposterior thalamic nuclei, in the mammillothalamic tract, or in the stria medullaris.

Lateral to the midline thalamic group, the reticular nudeus contains the heaviest mRNA expression in the entire thalamic region (Fig. 14A). Messenger RNAexpressing neurons are moderate rostrally but become very intense in the middle one-third, filling the nucleus throughout its rostral-to-caudal extent. Ventromedially, 

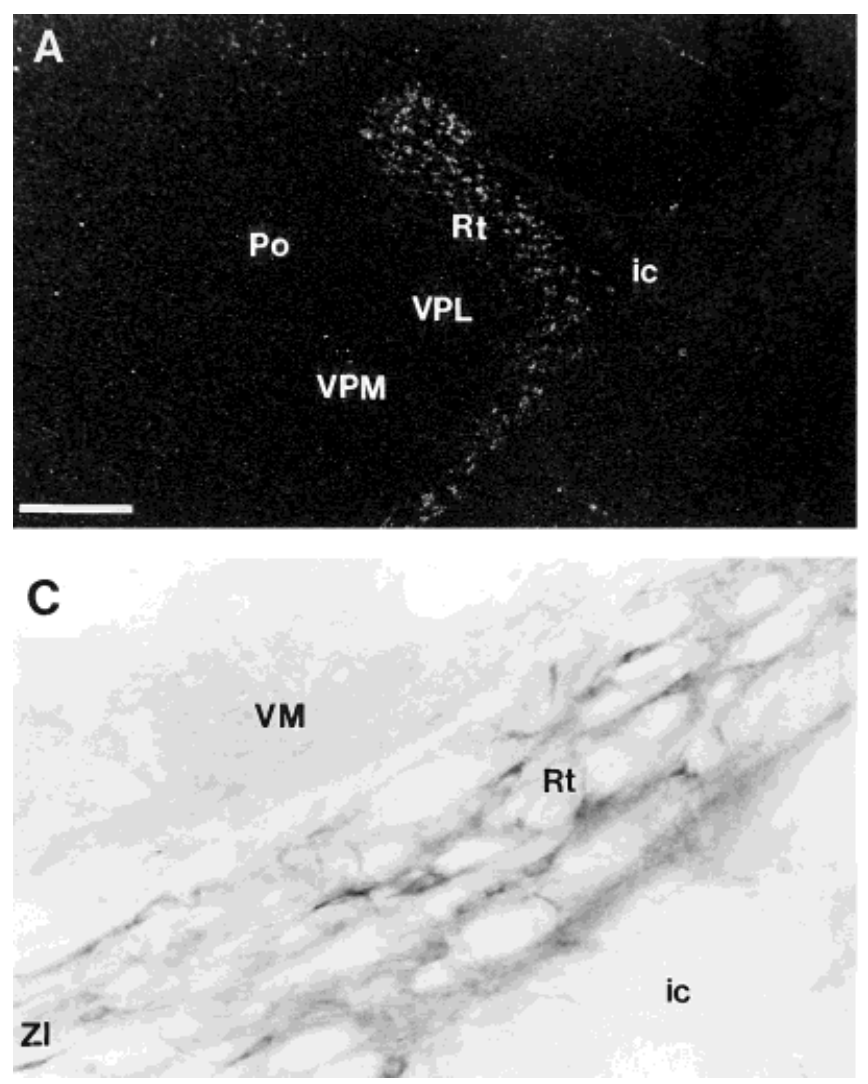

Fig. 14. Photomicrographs of mRNA expression and immunolabeling in the thalamus. A: Low-power, darkfield autoradiogram of prepro-OFQ mRNA expression in the reticular nucleus of the thalamus. B: Low-power image of immunolabeling at a similar level of the reticular nucleus (colchicine treated). C: High-power, detailed view of

intense mRNA expression from the reticular nucleus extends into the zona incerta, with high intensity in the ventral zona incerta and lower intensity in its dorsal division. Occasional OFQ-containing neurons are observed in the subincertal nucleus and farther caudal in the subgeniculate nucleus, just rostral to the peripeduncular nucleus in the midbrain. No mRNA expression is detected in the fields of Forel or in the ventrolateral, ventromedial, ventral posterolateral, and ventral posteromedial thalamic nuclei.

In the midbrain thalamus, mRNA expression is confined to scattered neurons in the rostral interstitial nucleus of the medial longitudinal fasciculus. This mRNA expression extends laterally into the subparafascicular nucleus of the thalamus, where mRNA levels are moderate. This mRNA expression remains strong throughout the parvocellular part of this nucleus, with scattered mRNA-expressing neurons in the adjacent prerubral fields. Laterally, there is no mRNA expression detected in the medial geniculate nucleus, and only occasional mRNA-expressing neurons are seen in the lateral geniculate. Adjacent to these structures, the suprageniculate thalamic nucleus contains a cluster of moderate mRNA-expressing cells, and the posterior thalamic group contains numerous, scattered, mRNA-containing neurons, particularly within the posterior limitans thalamic nucleus, where mRNA levels are moderate. At the emergence of the mesencephalon, the
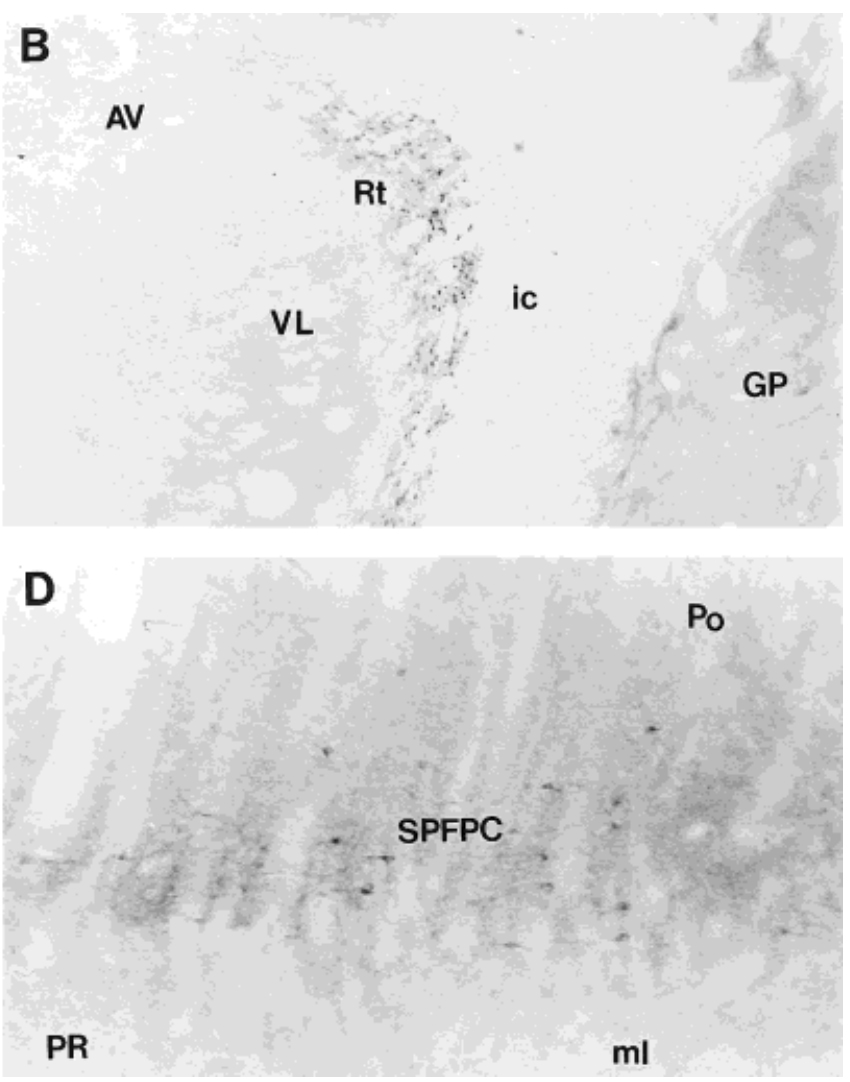

immunostaining in the reticular nucleus. D: Brightfield photomicrograph from the brainstem thalamus illustrating fiber and cell staining in the subparafascicular nucleus. For abbreviations, see list. Scale bar $=360 \mu \mathrm{m}$ in $A, 400 \mu \mathrm{m}$ in $B, 50 \mu \mathrm{m}$ in C, $100 \mu \mathrm{m}$ in D.

precommissural nucleus contains moderate mRNA expression.

Immunohistochemistry. The anterior paraventricular nucleus contains a moderate accumulation of terminals with dispersed fibers and occasional lightly labeled neurons. The adjacent paratenial nucleus is filled with fine terminals and fibers and with no immunolabeled neurons. This fine fiber and terminal field spreads dorsolaterally across the paracentral nucleus and into the adjacent anterodorsal nucleus. Very dense terminal labeling is seen at this level in the interanterodorsal thalamic nucleus. It persists throughout the nucleus and does not extend into adjacent regions. This immunolabeling pattern is observed in colchicine-treated and untreated animals. The anteroventral nucleus contains occasional lightly labeled fibers with no terminals. Lightly labeled fibers are scattered in the reuniens and rhomboid nuclei at this level, but no immunolabeled perikarya are identified. The stria medullaris is devoid of immunolabeling. The reticular nucleus contains numerous, intensely stained neurons in its dorsal aspect, with decreased numbers of immunoreactive neurons ventrally (Fig. 14B,C). There are lightly labeled, sparse fibers interspersed among the cells in the dorsal region. This pattern of labeling persists to its caudal extent, with ventromedial extension of immunolabeled neurons into the zona incerta. In untreated animals, the zona incerta also contains moderate amounts of immunola- 

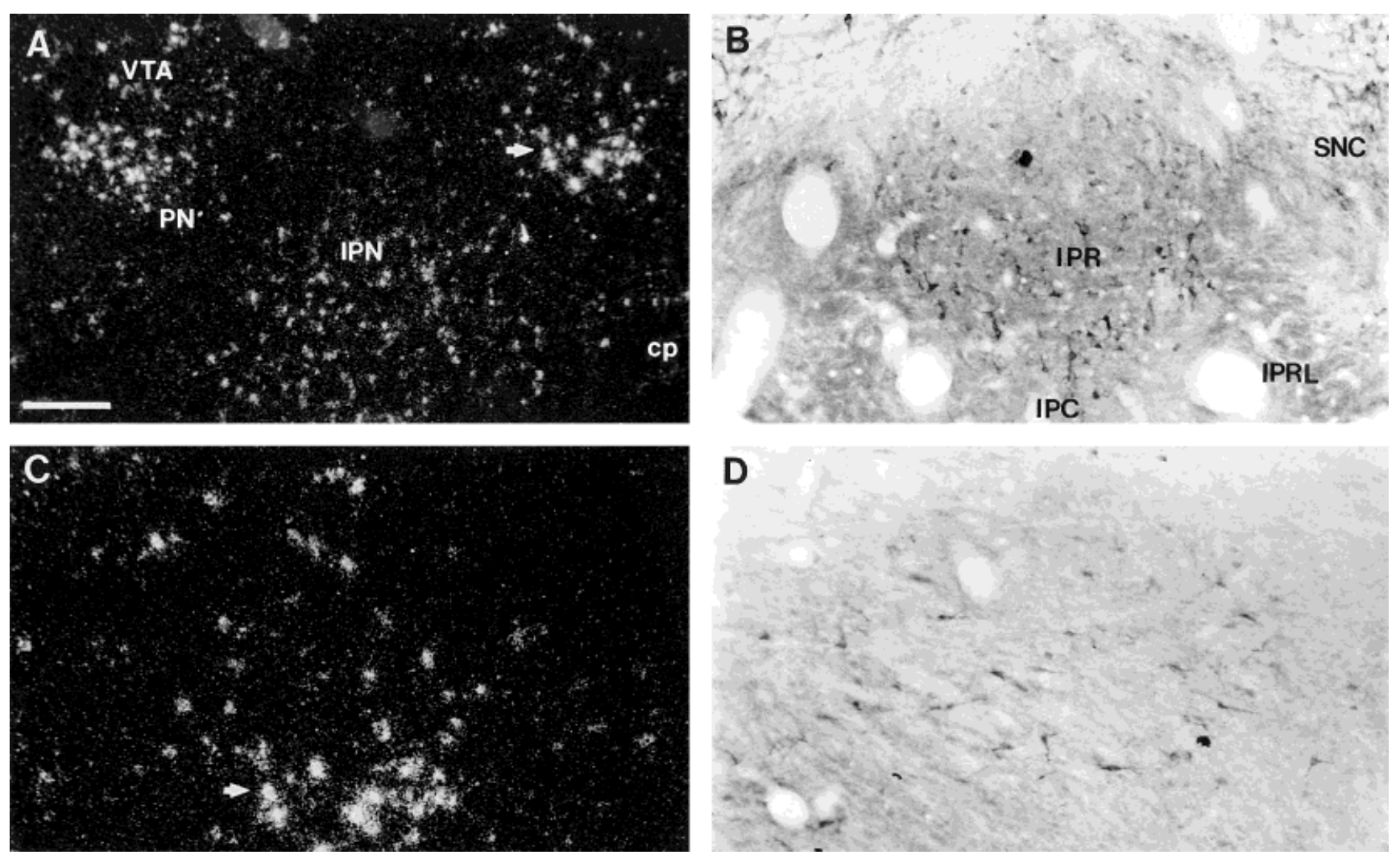

Fig. 15. Photomicrographs of mRNA expression and immunolabeling in the ventral rostral mesencephalon. A: Prepro-OFQ mRNA expression in the interpeduncular nucleus. B: Brightfield photomicrograph of OFQ protein expression in the interpeduncular nucleus demonstrates immunolabeled neurons that are concentrated mostly in

bel ed fibers and puncta. No immunolabeling is observed in the adjacent prerubral field and the nuclear fields of F orel. Dorsal to these structures, there is prominent cell, fiber, and terminal labeling in the subparafascicular thalamic nucleus (Fig. 14D).

In the caudal thalamus, a dense, immunoreactive fiber bundle courses through the medial habenula. Medial to this fiber bundle, scattered, darkly stained neurons are observed. Staining in the lateral habenula is confined to scattered, lightly labeled terminals. This light terminal staining extends medioventrally intothe posterior paraventricular nucleus, where lightly labeled terminals, fibers, and scattered immunolabeled neurons are observed to in its caudal pole. Here, a dramatic increase in terminal labeling occurs in the transition into the precommissural nudeus, where moderate immunolabeled fibers and cells are observed. The remainder of the thalamus is relatively devoid of immunolabeling. The anteromedial, central medial, laterodorsal, mediodorsal, and centrolateral nuclei and the ventral nuclear group contain no immunolabeling. Caudally, there is light staining noted in the posterior thalamic nuclear group, the lateral posterior nucleus, the subgeniculate nucleus, and the lateral and medial geniculate bodies. Adjacent to these nuclei, the suprageniculate thalamic nucleus and posterior limitans thalamic nucleus contain lightly stained neurons, with no fiber or terminal labeling noted.

its rostral division (colchicine treated). C: High-powered view of mRNA-expressing neurons in the ventral tegmental area at the level depicted in A (arrows). D: Scattered, immunolabeled neurons in the ventral tegmental area (colchicinetreated). For abbreviations, seelist. Scale bar $=200 \mu \mathrm{m}$ in A, $100 \mu \mathrm{m}$ in B-D.

\section{Mesencephalon}

In situ hybridization. Messenger RNA expression in brainstem thalamic and basal ganglia structures is described above. In the rostral ventral midbrain, moderate mRNA expression is observed initially within the rostrolateral subdivision of the interpeduncular nucleus. Message expression intensifies into the lateral and dorsal divisions and remains strong (Fig. 15A). The mammillary peduncle, fasciculus retroflexus, rubrospinal tract, and medial and lateral Iemniscus are devoid of mRNA expression at this level. The rostral ventral tegmental area contains scattered neurons expressing OFQ mRNA. These levels increase substantially in the ventral tegmental area proper, where moderate-to-heavy mRNA expression is localized ventromedially and extends into its dorsolateral part. The paranigral nucleus contains intense expression throughout its extent (Fig. 15C). No expression is observed in the prerubral field or parabrachial pigmented nucleus.

In the rostral dorsal midbrain, the olivary pretectal nudleus contains no mRNA expression, with moderate expression in the ventral anterior pretectal region. Moderate mRNA expression is seen also in the nucleus of the optic tract and in the posterior pretectal nucleus, and a cluster of intense mRNA expression is observed in the nudleus of the posterior commissure, with lighter mRNA expression into its magnocellular part. No mRNA-express- 

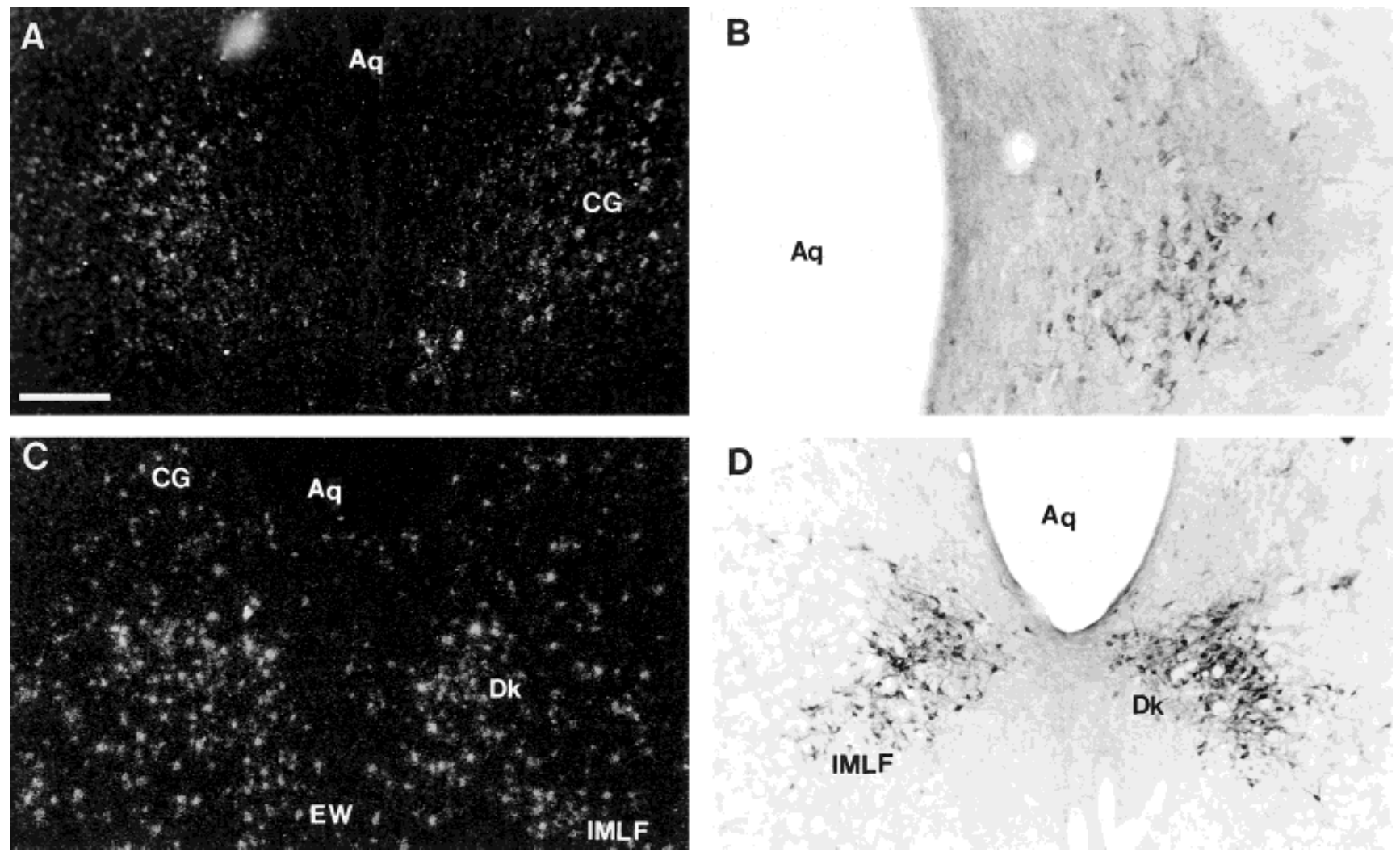

Fig. 16. Messenger RNA expression and immunolabeling in the periaqueductal region of the mesencephalon. A: mRNA-expressing neurons in the ventral central gray. B: Brightfield photomicrograph of intensely immunolabeled neurons in the ventral division of the central gray. C: Robust orphanin mRNA expression in the nucleus of Darks-

ing neurons are observed in the posterior commissure or in the commissure of the superior colliculus. In the superior colliculus, mRNA expression is sparse in the superficial gray and is distributed more moderately in the optic and intermediate gray layers. Other than occasional scattered neurons within the deep gray layer, no other layer of the superior colliculus contains OF Q mRNA expression. In the inferior colliculus, the external cortex contains numerous mRNA-expressing neurons in layers II and III. Occasional scattered neurons are observed in layers II and III of the dorsal cortex of the inferior colliculus, with negligible mRNA expression observed in the central collicular nucleus, the intercollicular nucleus, and the commissure of the inferior colliculus.

Laterally in the rostral midbrain, heavy mRNA expression in the substantia nigra, pars compacta, persists into the pars lateralis and intensifies farther away at the medial edge of the peripeduncular nucleus, which contains intense expression throughout its extent (Fig. 2E). The retrorubral field contains moderate numbers of mRNAcontaining neurons. The brachium of the inferior colliculus and its nucleus contain no mRNA expression, whereas lightly scattered neurons are present within the subbrachial nucleus. Negligible mRNA expression is observed in the cuneiform nucleus; in the dorsal, intermediate, and ventral nuclei of the lateral lemniscus; in the mesencephalic trigeminal nucleus; in the paralemniscal nucleus; and in the retrorubral nucleus.

chewitsch and the interstitial nucleus of the medial longitudinal fasciculus. D: Intense orphanin immunolabeling in the interstitial nucleus of the medial longitudinal fasciculus and the nucleus of Darkschewitsch (colchicine treated). For abbreviations, see list. Scale bar $=200 \mu \mathrm{m}$ in $A, C, D, 100 \mu \mathrm{m}$ in $B$.

In the midline of the rostral midbrain, the nucleus of Darkschewitsch is filled completely with the most intense mRNA expression in the mesencephalon. OFQ-expressing neurons fill this nucleus throughout its rostral-to-caudal extent and extend ventrolaterally into the interstitial nucleus of the medial longitudinal fasciculus, where mRNA expression is quite strong (Fig. 16C). Dorsal to the nucleus of Darkschewitsch, the central gray also contains very strong expression, which is more prominent in the ventral part of the nucleus, spreading to its lateral borders (Fig. 16A). There is a dramatic drop in mRNA intensity in the dorsal central gray, which contains only moderate mRNA levels. Scattered mRNA-expressing neurons are present in its pontine division. Ventral to the central gray, the Edinger-Westphal and medial accessory oculomotor nuclei are conspicuously devoid of mRNA expression (Fig. 16C). In contrast, the supraoculomotor central gray is moderately labeled with OF Q-containing neurons. Farther caudally, the raphenucl ear compl ex contains prominent mRNA expression. The rostral linear raphe nucleus contains moderate mRNA expression. J ust posterior to this region, in the caudal linear raphe nucleus, light to moderate mRNA levels are observed. The dorsal raphe emerges with moderate mRNA expression, which persists throughout its rostral-to-caudal extent. Numerous mRNA-containing neurons are observed also throughout the caudal linear raphe ventrally, with extension caudally into the median raphe (Fig. 18A). The paramedian raphe contains little mRNA 

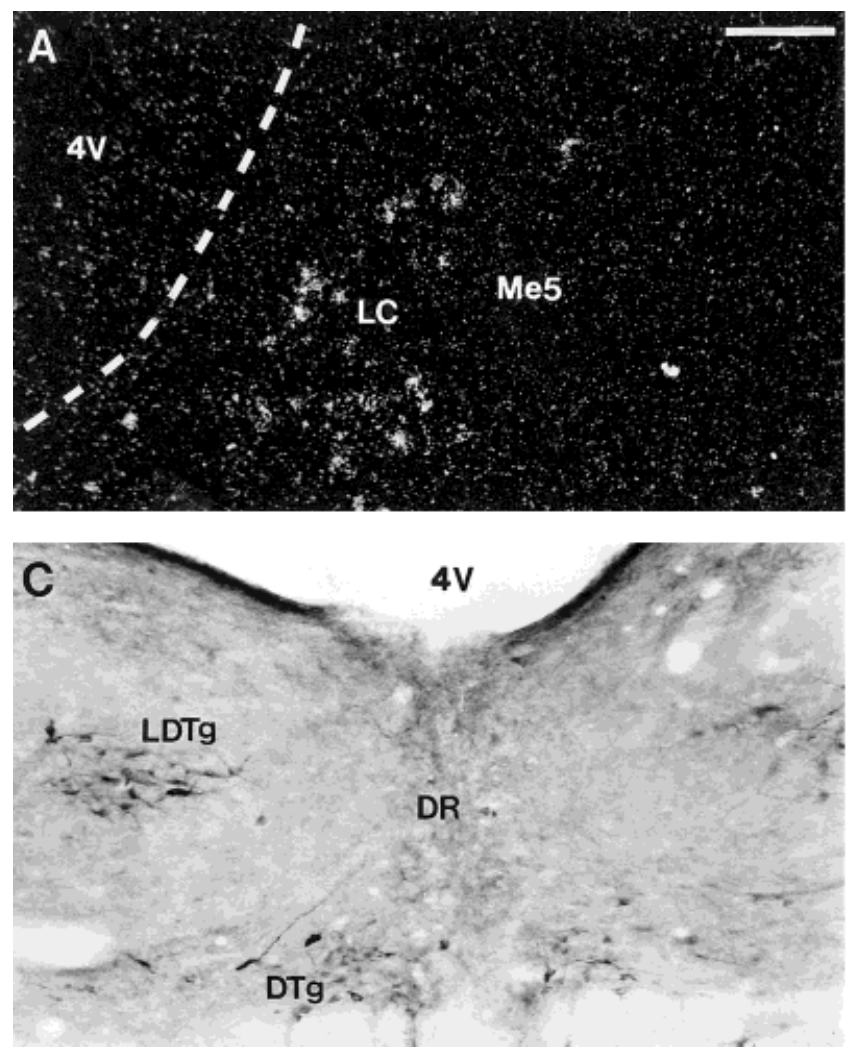

Fig. 17. Photomicrographs of orphanin mRNA and protein expression in the dorsal metencephalon. A: mRNA-expressing neurons are numerous in the locus coeruleus, whereas the adjacent mesencephalic trigeminal nucleus is devoid of mRNA expression. B: Brightfield photomicrograph of OFQ immunoreactivity in the locus coeruleus. Again, note the lack of immunolabeling in the adjacent mesencephalic trigeminal nucleus in this colchicine-treated animal. C: Lightly immu-

expression (Fig. 18A), and the paratrochlear nucleus contains no mRNA expression.

In the remainder of the midbrain, scattered, mRNAexpressing neurons are observed within the deep mesencephalic nucleus and in the magnocellular and parvocellular parts of the red nucleus. The central trigeminal tract, dorsal longitudinal fasciculus, rhabdoid nucleus, superior cerebellar peduncle, microcellular, subpeduncular and ventrolateral tegmental nuclei, sensory root of the trigeminal nerve, reticulotegmental nucleus, and rostral pontine nuclei are devoid of mRNA expression. Moderate mRNA expression is observed in the pontine reticular nucleus, in its oral and caudal parts, extending laterally into the peduncul opontine tegmental nucleus, where mRNA levels increase. Moderate mRNA expression is observed also in the dorsal, laterodorsal, and ventral tegmental nuclei. The nucleus of the trapezoid body contains heavy mRNA expression at the emergence of the ventral metencephal on.

Immunohistochemistry. Immunohistochemical staining in brainstem thalamic and basal ganglia structures is described above. Rostrally, the interpeduncular nucleus contains strong immunolabeling. There are numerous immunolabeled neurons in the rostral division (Fig. 15B), and only lightly label ed, scattered neurons are found in the caudal and lateral divisions. The dorsal division contains darkly labeled neurons with moderate fibers and termi-
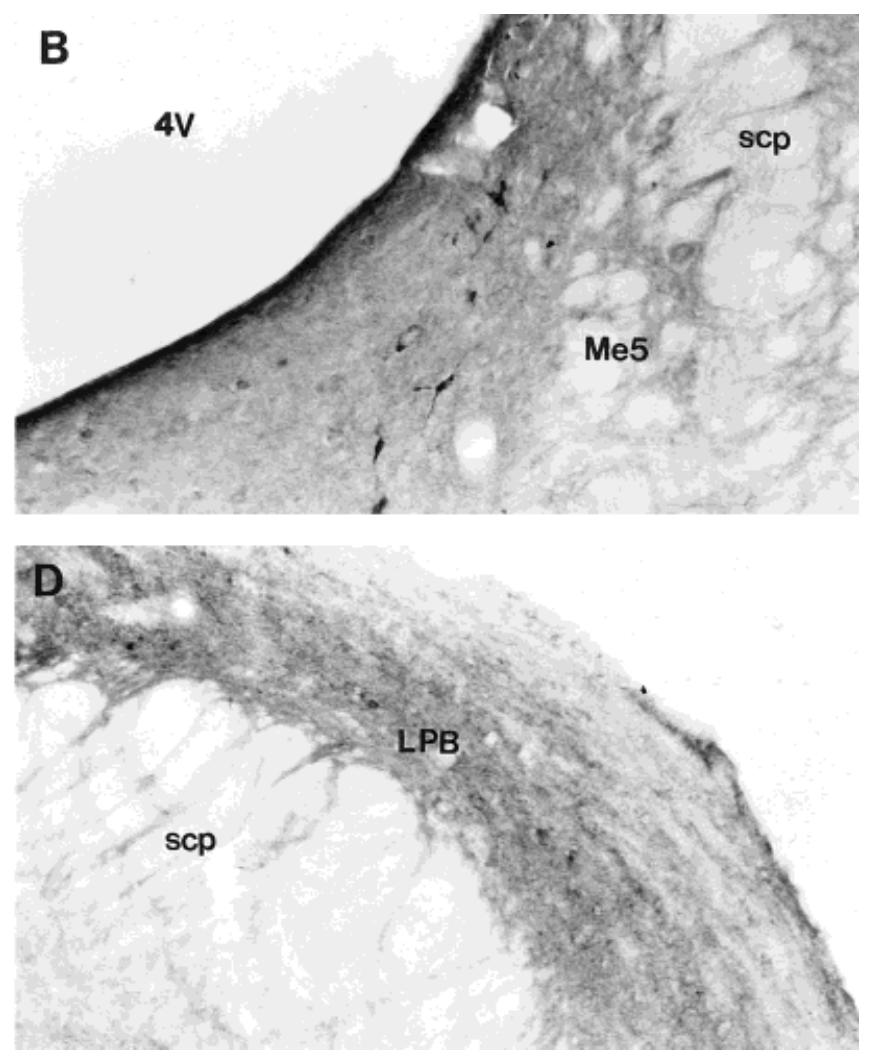

nolabeled neurons and fibers in the dorsal raphe with intense immunolabeling in the dorsal tegmental and laterodorsal tegmental nuclei (colchicine treated). D: Moderate fiber and terminal labeling in the lateral parabrachial nucleus (colchicine treated). Scattered, lightly immunolabeled neurons also are evident. For abbreviations, see list. Scale bar $=100 \mu \mathrm{m}$.

nals that extend into the ventral tegmental area. No immunolabeling is observed in the prerubral field, and lightly scattered OFQ-containing fibers are seen in the parvocellular part of the red nucleus. Fibers extend to the magnocellular part, where lightly stained, immunolabeled neurons are seen. The retrorubral field contains light cell immunolabeling, with scattered fibers in its ventrolateral aspect. This pattern extends caudally and ventrolaterally intothe pedunculopontinetegmental nucleus, wheredarkly stained neurons are present. The rostral ventral tegmental area contains numerous moderately stained neurons and lightly stained fibers scattered throughout. This staining pattern intensifies caudally into the ventral tegmental area proper (Fig. 15D), where scattered, darkly labeled neurons and fibers extend from the dorsolateral interpeduncular nucleus into this region. Scattered, darkly stained neurons spread from the lateral part of theventral tegmental area into the paranigral nucleus, where moderately stained neurons and scattered fibers are observed. Caudally, immunolabeled neurons in the substantia nigra, pars lateralis, extend to the peripeduncular nucleus, where numerous, intensely stained neurons fill the region. Moderate fiber staining also fills this nucleus and is observed best in untreated animals. Moderate fibers are observed also in the medial lemniscus and dorsally in the region of 

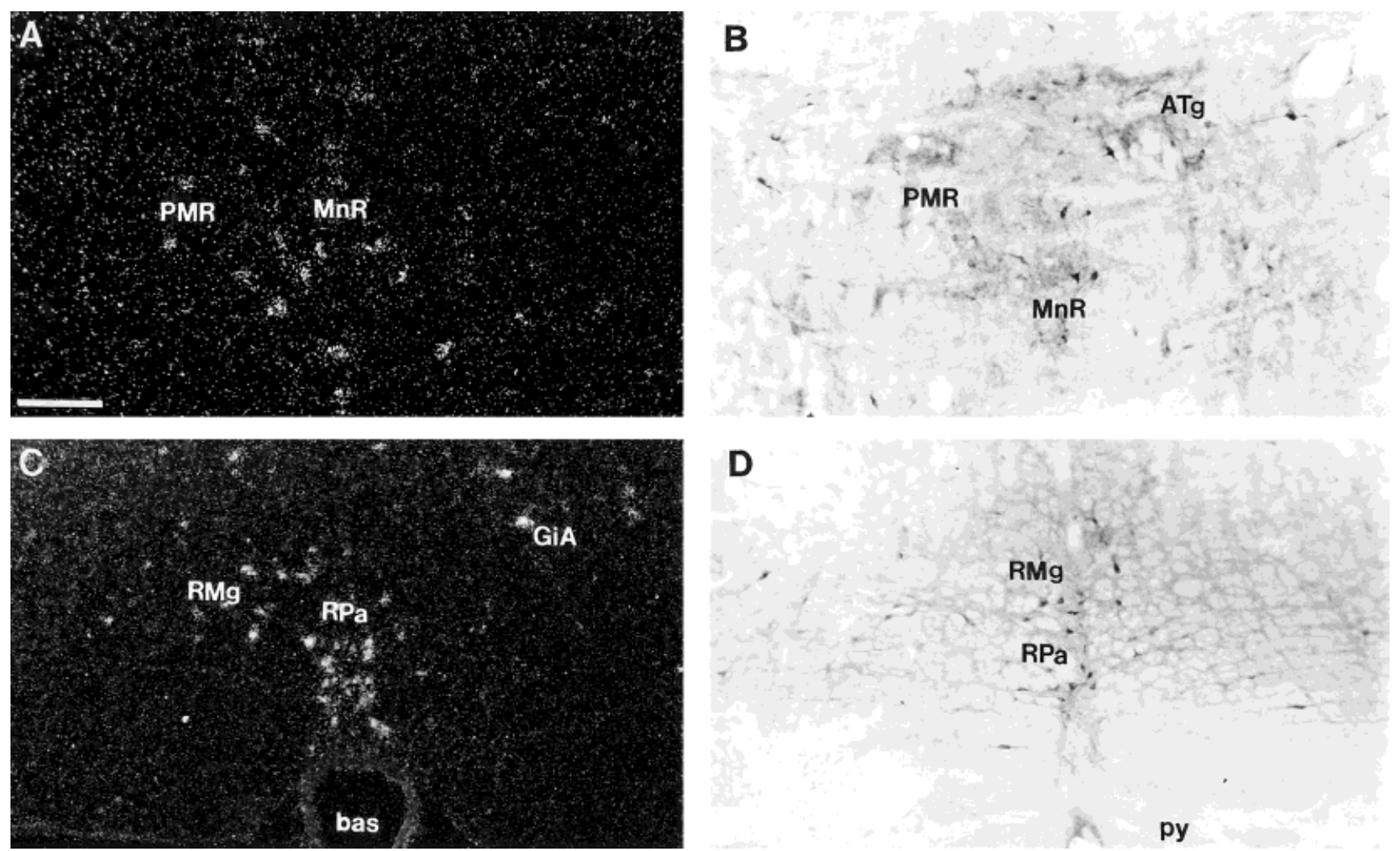

Fig. 18. Photomicrographs of mRNA expression and immunolabeling in brainstem raphe regions. A: mRNA-expressing neurons are scattered in the median and paramedian raphe nuclei. B: I mmunolabeled neurons and fibers in the median and paramedian raphe nuclei.

the deep mesencephalic nuclei. The cerebral and mammillary peduncles are without immunostaining.

In the dorsal region of the rostral midbrain, several moderately immunostained neurons are observed in the nucleus of the posterior commissure, the posterior pretectal nucleus, the olivary pretectal nucleus, and the nucleus of the optic tract. Lightly labeled, scattered neurons are observed in the magnocellular nucleus of the posterior commissure. There is moderate to heavy neuronal labeling with light fiber labeling in the dorsal and ventral divisions of the anterior pretectal nucleus. Lightly labeled, OFQcontaining fibers also are seen in the nucleus of the optic tract. The posterior commissure, the commissure of the superior colliculus, and the central tegmental tract are devoid of immunolabeling. In the superior colliculus, the zonal layer contains occasional lightly labeled fibers but no immunolabeled neurons. There are moderate numbers of lightly labeled neurons in the superficial gray layer that increase in number and intensity of staining in the optic nerve and intermediate gray layers, where labeled neurons are moderately stained. Although fibers are present in theselayers, they remain very sparse, even in untreated animals. No immunolabeling is observed in the intermediate white, deep white, or deep gray layers of the superior colliculus or in the intercollicular nucleus. In the inferior brachium, scattered, moderately stained cells are observed primarily in layers II and III of the external cortex. There are very few fibers, and no terminal labeling in this region. This pattern persists to the caudal extent of the external

C: mRNA expression in the raphe magnus and raphe pallidus nucleus. D: Darkly immunolabeled neurons in the raphe magnus and raphe pallidum. For abbreviations, see list. Scale bar $=100 \mu \mathrm{m}$ in A,B, 200 $\mu \mathrm{m}$ in $\mathrm{C}, \mathrm{D}$.

cortex of the inferior colliculus. Occasional lightly labeled fibers and cells are observed in the dorsal cortex, and the central nucleus contains only an occasional scattered, lightly stained neuron. There is no immunolabeling in the brachium of the inferior colliculus or in the commissure of the inferior colliculus. Within the nucleus of the brachium of the inferior colliculus, moderately stained fiber processes are observed.

At the midline, numerous, intensely stained neurons, fibers, and terminals fill the ventral and lateral aspects of the central gray (Fig. 16B). The heaviest fiber and terminal immunolabeling is observed adjacent to the aqueduct, with only scattered, lightly labeled cells and fibers in the dorsal central gray. I n caudal central gray regions, immunolabeling of neurons increases in its dorsal part. Ventrolateral to the central gray rostrally, numerous, intensely immunolabeled cells with moderate fibers and terminals fill the nucleus of Darkschewitsch (Fig. 16D). This intense immunolabeling persists to the caudal extent of this nucleus. Strongly immunolabeled neurons and fibers extend ventrolaterally to the interstitial nucleus of the medial longitudinal fasciculus (Fig. 16D). Lightly scattered cells are observed also in the deep mesencephalic nuclei of the midbrain. No immunolabeling is observed in the Edinger-Westphal nucleus, the medial accessory oculomotor nucleus, the supraoculomotor central gray, the dorsal longitudinal fasciculus, or the superior cerebellar peduncle. Ventral to the central gray, several lightly immunolabeled neurons with scattered fibers reside in the 
dorsal raphe (Fig. 17C). This labeling pattern extends along the midline into the median raphe. The adjacent paramedian raphe also contains scattered, darkly stained cells (Fig. 18B). Scattered neurons with moderate staining are observed in the rostral linear raphe. This pattern continues into the caudal midbrain, with scattered dark neurons and lightly labeled fibers in the caudal linear raphe. Scattered fibers and cells also are observed in the anterior (Fig. 18B) and ventral tegmental nuclei. The laterodorsal and dorsal tegmental nuclei contain numerous, darkly labeled neurons and fibers (Fig. 17C). The reticulotegmental, subpeduncular, and ventrolateral tegmental nuclei are devoid of labeling.

In the caudal mesencephalon, the pontine reticular nucleus contains scattered, moderately stained neurons and lightly labeled fibers in its oral part. This labeling extends laterally intothe paralemniscal nucleus. Noimmunolabeling is observed in the lateral lemniscus or in the ventral, dorsal, or lateral nuclei associated with it. The cuneiform nucleus, mesencephalic trigeminal nucleus, paratrochlear nucleus, parabigeminal nucleus, longitudinal fasciculus, rubrospinal tract, and sensory root of the trigeminal nerve are devoid of immunolabeling. Ventrolaterally at this level, scattered, lightly immunol abeled fibers are present in the pontine nuclei, and caudally, moderate numbers of modestly stained neurons lie in the nucleus of the trapezoid body and the in the rostral preolivary region, entering the rostral metencephalon.

\section{Metencephalon}

In situ hybridization. In the dorsal rostral pons, the locus coeruleus contains moderate mRNA expression (Fig. 17A) with light to moderate levels in the pontine central gray and adjacent dorsal raphe. Moderate to intense mRNA expression is observed in the dorsomedial tegmental area and the laterodorsal tegmental nucleus, with increased mRNA expression caudally in the posterodorsal tegmental nucleus. The lateral parabrachial nucleus contains numerous, scattered, OFQ-containing neurons, whereas the medial parabrachial nucleus is devoid of mRNA expression. Negligible expression is observed in the subcoeruleus nucleus, principal sensory trigeminal nucleus, Kolliker-Fuse nucleus, trigeminal motor nucleus, anterior ventral cochlear nucleus, medial longitudinal fasciculus, mesencephalic trigeminal nucleus (Fig. 17A), and superior cerebellar peduncle.

In the ventral rostral pons, the nucleus of the trapezoid body contains intense mRNA expression, with light-tomoderate expression in the adjacent superior paraolivary nudeus (Fig. 19A). Moderate-to-strong mRNA expression is observed in the medioventral periolivary nucleus, with scattered neurons observed in the dorsal, lateroventral, and superior periolivary nuclei and in the lateral superior olive (Fig. 19B). No mRNA expression is observed in the caudal periolivary nucleus or medial superior olive. Scattered neurons with intense mRNA levels reside in the region of the A5 cell group (Fig. 19A), whereas no OFQ mRNA is detected in the A7, C1, C2, or C3 cell groups. The pyramidal tract and the root of the abducens nerve contain no mRNA expression.

In the caudal pons, no mRNA expression is seen in the sixth, seventh, or eighth nerves or in the associated abducens and facial nuclei. Laterally, the paratrigeminal nucleus contains a cluster of moderate mRNA-expressing neurons. In the vestibular complex, light to moderate
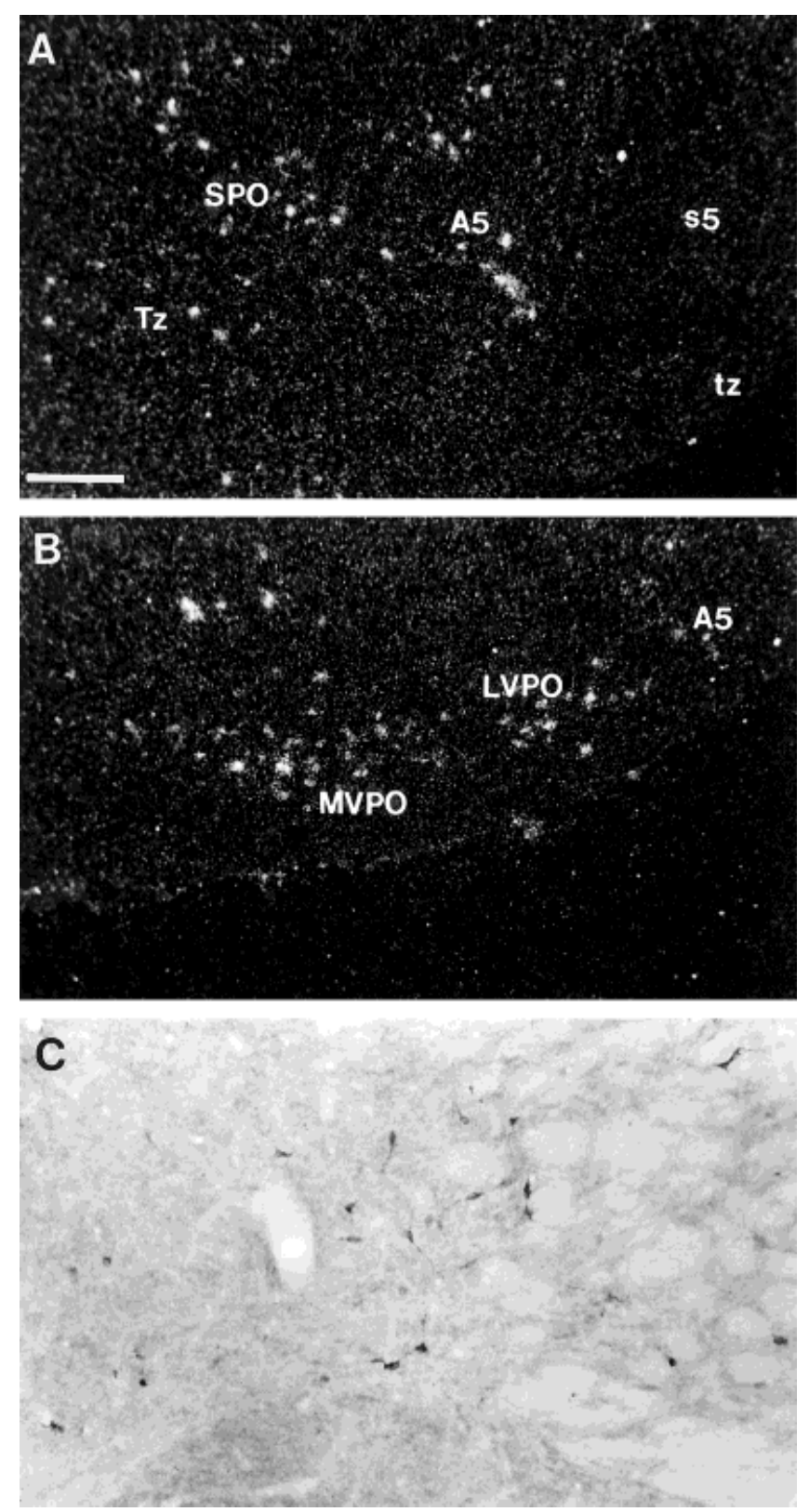

Fig. 19. Photomicrographs of mRNA expression and immunolabeling in the in the caudal metencephalon. A: mRNA expression in the superior paraolivary nucleus. Note scattered mRNA-expressing neurons within the region of the A5 cell group. B: Higher power view of scattered mRNA-expressing neurons in the medioventral and lateroventral periolivary nuclei. C: Brightfield photomicrograph of moderately immunolabeled neurons in the ventral part of the medial vestibular nucleus (colchicine treated). For abbreviations, see list. Scale bar $=200 \mu \mathrm{m}$ in $A, B, 100 \mu \mathrm{m}$ in $C$.

mRNA expression is scattered throughout the superior and medial vestibular nuclei, primarily in their dorsal parts. Messenger RNA levels are slightly higher in the lateral vestibular nucleus, mostly in its lateral part. Moderate mRNA expression is observed in the caudal half of the medioventral vestibular nucleus, and scattered mRNA-expressing cells are observed in the spinal vestibular nucleus and dorsal cochlear nucleus. The ventral 

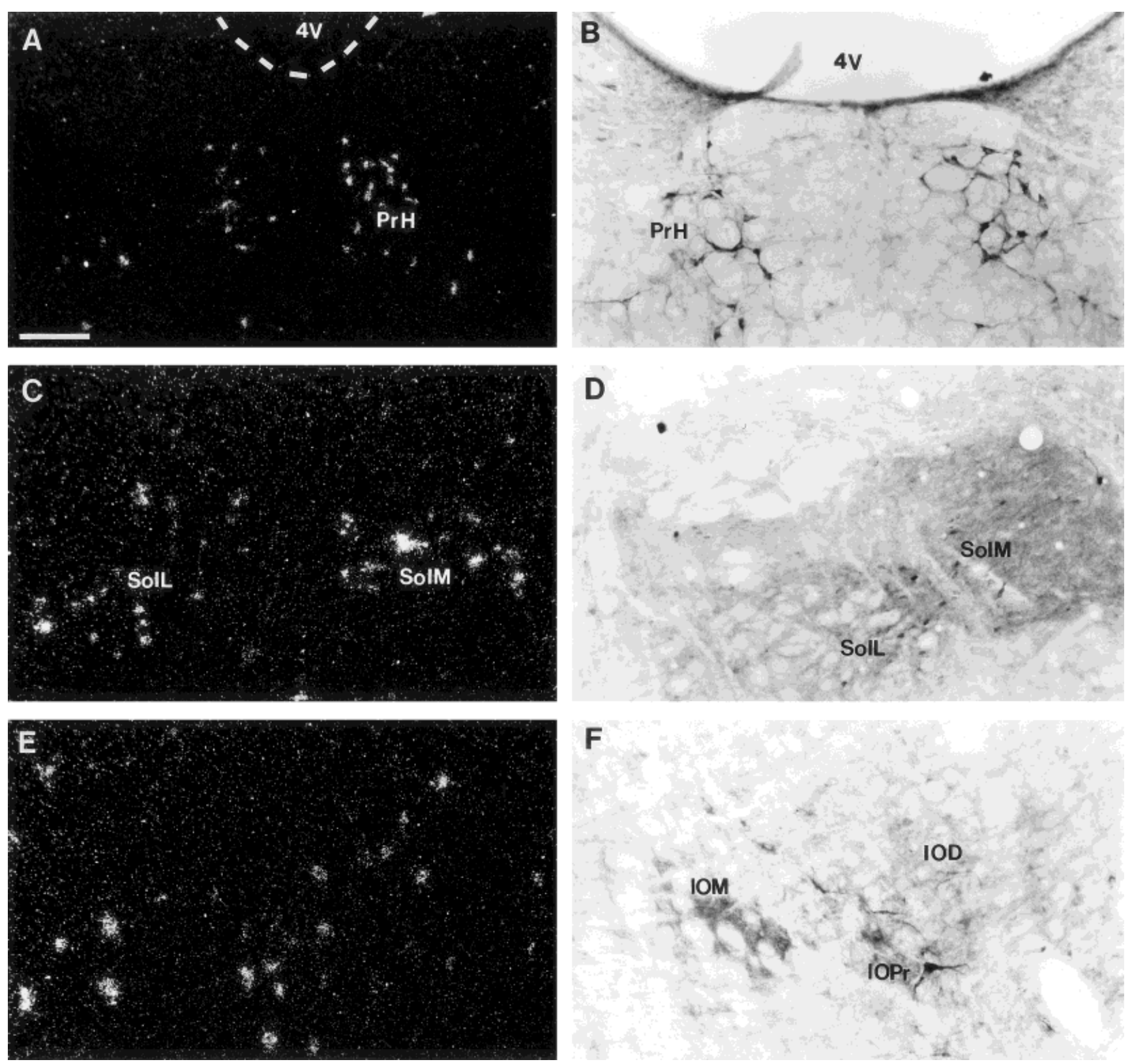

Fig. 20. Photomicrographs of OFQ mRNA and protein expression in the mylencephalon. A: Intense mRNA expression in the prepositus hypoglossus. Dashed lines outline the boundary of the $4^{\text {th }}$ ventricle. B: Brightfield photomicrograph of darkly immunolabeled neurons in the prepositus hypoglossus. C: mRNA-expressing cells in the medial and lateral divisions of the midcaudal solitary nucleus. D: I mmunolabeling in the medial and lateral divisions of the solitary nucleus

(colchicine treated). E: mRNA-expressing neurons in the medullary lateral paragigantocellular reticular nucleus. F: I mmunolabeling in the inferior olivary nucleus demonstrating scattered cells, fibers, and terminals in the medial, dorsal, and principal divisions (colchicine treated). For abbreviations, see list. Scale bar $=200 \mu \mathrm{m}$ in A, $100 \mu \mathrm{m}$ in $\mathrm{B}-\mathrm{F}$.

posterior cochlear nucleus and inferior cerebellar peduncle are devoid of mRNA expression. In the dorsal caudal pons, the abducens nucleus has no mRNA expression, but the adjacent supragenual nucleus contains moderate mRNA expression. This persists caudally into the prepositus hypoglossus, where intense mRNA expression is observed throughout its extent (Fig. 20A). In the reticular formation, scattered neurons expressing OFQ mRNA are observed in the parvocellular, intermediate, and dorsal paragigantocellular reticular nuclei. Large neurons with

moderate intensity are observed in the gigantocellular nucleus and its alpha subdivision. Only sparse mRNA expression is observed in the lateral paragigantocellular nucleus in the pons, intensifying in the medulla (Fig. 20E).

In the pontine raphe complex, modest mRNA expression in the dorsal raphe persists caudally in its dorsal extension, whereas high mRNA expression is observed in the pontine raphe nudeus. Moderate mRNA expression is observed in the oral pontine reticular nucleus and becomes more sparse into the caudal pontine reticular nucleus. In 

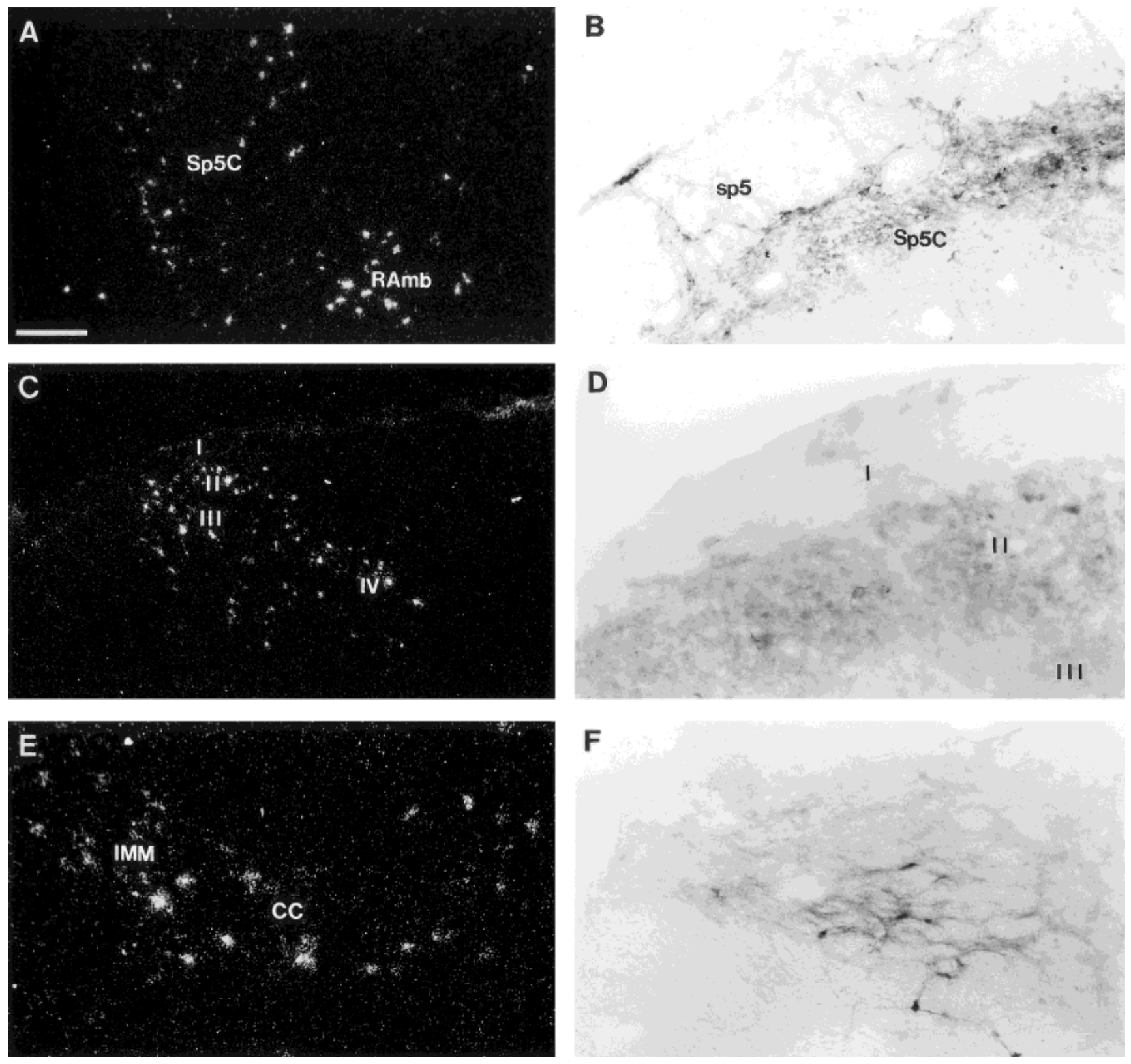

Fig. 21. Photomicrographs of mRNA expression and immunolabeling in the caudal medulla and spinal cord. A: mRNA-expressing neurons in the caudal spinal trigeminal nucleus with extension medially into the dorsal medullary reticular nucleus and ventrally into the retroambiguous nucleus. B: Brightfield photomicrograph of immunolabeling within the caudal part of the spinal trigeminal nucleus demonstrating heavily immunolabeled fibers and terminals with scattered, intensely labeled neurons. Note that immunolabeling is confined primarily to the lateral part of the nucleus (colchicine

the caudal pons, intense mRNA expression is observed in the raphe magnus and raphe pallidus (Fig. 18C), but is much decreased in the ventral pontine reticular nucleus. The spinal trigeminal nuclear complex has a varied mRNA expression pattern, from rostral to caudal. Rostrally, the principal sensory trigeminal nucleus is devoid of mRNA expression; however, in the caudal pons, the oral and interpolar parts of the spinal trigeminal nucleus contain

treated). C: mRNA expression in the dorsal horn of the cervical spinal cord demonstrating heavy expression within laminae II and III. D: Immunolabeling in the dorsal horn demonstrating terminals and scattered neurons within laminae II and III (colchicine treated). E: : RRNA-expressing neurons in lamina $X$ and in the intermediome dial cell column of the thoracic spinal cord. F : I mmunolabeled fibers and cells within the lateral spinal nucleus (colchicine treated). For abbreviations, see list. Scale bar $=200 \mu \mathrm{m}$ in A,C, $100 \mu \mathrm{m}$ in B,E,F, $50 \mu \mathrm{m}$ in D.

scattered, mRNA-containing neurons. Messenger RNA expression does not increase until the emergence of the caudal spinal trigeminal nucleus in the medulla (Fig. 21A).

I mmunohistochemistry. I mmunolabeling in the dorsal part of the rostral pons is generally sparse. The mesencephalic trigeminal nucleus and subcoeruleus contain no immunolabeling. The locus coeruleus contains modest numbers of darkly stained neurons and lightly 
labeled terminals (Fig. 17B). Scattered, lightly labeled neurons are present in the pontine central gray and in the laterodorsal and posterodorsal tegmental nuclei. The dorsomedial tegmental nudeus contains a cluster of moderately immunolabeled neurons with scattered fibers. In the lateral region of the dorsal metencephal on, moderate cell and light fiber immunostaining is present in the lateral parabrachial nucleus (Fig. 17D). The superior cerebellar peduncle, medial parabrachial nucleus, A7 noradrenaline cell group, and Kolliker-Fuse nucleus are devoid of immunolabeling.

In the ventral rostral pons near the midline, the nucleus of the trapezoid body is filled with darkly immunolabeled neurons and few lightly labeled fibers. The lateral rostral periolivary region contains an occasional darkly labeled neuron but is filled mostly with moderately immunolabeled fibers and terminals, which are seen well in untreated animals. Moderately immunolabeled cells and fibers are observed in the superior periolivary nucleus, lateroventral periolivary nudeus, medioventral periolivary nucleus, and lateral superior olive. The medial superior olive is devoid of immunolabeling. Cell immunolabeling is present in the lateral and dorsal superior ol ive but is significantly less than that observed in the periolivary nuclei. Occasional lightly labeled fibers and no cells reside in the caudal periol ivary nucleus. Scattered, lightly i mmunolabeled neurons are observed in the region of the A5 noradrenaline cell group. Immunolabeling was not observed in the $\mathrm{C} 1, \mathrm{C} 2$, or $\mathrm{C} 3$ adrenaline cell groups.

In the caudal pons, lightly immunolabeled cells and fibers are observed primarily extending through the medial, lateral, and superior vestibular nuclei. Fiber staining remains light throughout, but cells become more numerous and darkly stained caudally in the medial nucleus and laterodorsal part of the lateral vestibular nucleus. In the midcaudal region of the superior vestibular nucleus, a cluster of intense immunoreactivity is observed just adjacent to the inferior cerebellar peduncle. This extends as light immunolabeling into the dorsal cochlear nucleus. At caudal levels, more immunolabeled neurons are observed in the superior, lateral, and ventral medial vestibular nuclei (Fig. 19C), with decreased labeling in the medial vestibular region. Scattered, darkly stained neurons are observed in the spinal vestibular nucleus, continuing into its caudal pole at the emergence of the solitary nucleus. The anterior and posterior ventral cochlear nuclei are devoid of labeling.

In the pontine raphe complex, the dorsal raphe contains scattered, moderately immunolabeled cells and fibers, which diminish significantly in the region of the dorsal and laterodorsal tegmental nuclei (Fig. 17C). Neuronal immunolabeling increases significantly ventral and caudal into the pontine raphe nucleus and raphe magnus (Fig. 18D). In the reticular formation, darkly immunolabeled perikarya are scattered throughout the gigantocel lular, lateral paragigantocellular, and lateral reticular nuclei. No immunoreactive fibers or terminals are observed in these regions. The parvocellular reticular nucleus contains scattered, lightly label ed fibers but is devoid of immunoreactive cells. Few modestly labeled neurons are present in the dorsal gigantocellular, caudal pontine, and lateral reticuIar nuclei. Cranial nerve nuclei and fibers are relatively unlabeled in the pontine region. The oral trigeminal nucleus does contain an occasional scattered fiber but has no terminal or neuronal immunolabeling. The remainder of the pontine cranial nerves and associated nuclei are devoid of immunolabeling. Other regions with no detectable immunolabeling include the inferior cerebellar peduncle, the medial longitudinal fasciculus, the pyramidal tract, the sensory root of the trigeminal nerve, the motor and principal sensory nuclei of the trigeminal nerve, and the rostral and superior paraolivary nuclei.

\section{Mylencephalon}

In situ hybridization. In the cerebellar hemispheres, preproorphanin mRNA expression is confined to scattered neurons in the granular layer. No mRNA expression is detected within the mol ecular or Purkinje cell layers of any cer ebellar lobule. Within the deep cerebell ar nud ei, moderate numbers of neurons expressing OFQ mRNA are observed in the medial (fastigial) cerebellar nudeus, with slightly less intensity in its dorsolateral protuberance. No mRNA expression is detected in the lateral (dentate) or interposed cerebellar nuclei.

Scattered OF Q-containing neurons are occasionally observed in the external cuneate nucleus, with the cuneate nucleus and nucleus gracilus both devoid of mRNA expression. There is no OFQ mRNA expression detected in the ninth or twelfth cranial nerves, in the dorsal motor nudleus of the tenth nerve, or in the hypoglossal nucleus. The prepositus hypogl ossus contains intensemRNA expression, which is observed initially in the caudal pons, persisting throughout its extent into the medulla (Fig. 20A). The nucleus ambiguous is filled with intense mRNA expression throughout its extent and at its caudal boundary. Messenger RNA expression becomes slightly more intense into the retroambiguous nucleus in the caudal medulla (Fig. 21A). The rostral solitary nucleus emerges with moderate Messenger RNA expression. This persists in the medial and lateral subdivisions, with mRNA levels increasing caudally. In the caudal extent of the solitary nucleus, mRNA expression is very strong in its lateral and medial divisions and is moderate in the commissural division (Fig. 20C). Located within the solitary nuclear complex, the solitary tract contains no mRNA expression.

In the ventral medulla, the inferior olivary complex contains weak OF Q mRNA expression at its rostral boundary. The medial and dorsomedial nuclei are devoid of mRNA expression, with scattered mRNA-containing neurons observed in its principal and dorsal nuclei as well as in subnuclei $A$ and $B$ of the medial subdivision. In the reticular formation, light-to-moderate mRNA expression is seen in the gigantocellular, gigantocellular al pha, intermediate, and parvocellular reticular nuclei, and more intense expression is seen in the lateral paragigantocelluIar nucleus (Fig. 20E ). The adjacent paramedian reticular nucleus contains an occasional positive neuron but otherwise is devoid of mRNA expression. Caudally, the lateral reticular and paragigantocellular nuclei and the dorsal and ventral medullary reticular fields contain scattered, large neurons with strong mRNA expression. At the midline, the caudal interstitial nucleus of the medial Iongitudinal fasciculus contains intense mRNA expression, particularly in its ventral aspect. Orphanin mRNA expression persists in this nucleus to its caudal extent, extending to the raphe obscurus. In the caudal part of the raphe complex, the raphe magnus contains numerous intensely labeled neurons, with a moderate number of OFQcontaining neurons in the raphe pallidus nucleus to its caudal extent (Fig. 18C). 
In the caudal mylencephal on, very strong mRNA expression is noted in the spinal trigeminal nucleus. Messenger RNA expression is localized primarily in the lateral aspect of this nucleus. Very strong mRNA expression extends dorsally into the dorsomedial spinal trigeminal nucleus and ventrally into the nucleus ambi guous and retroambiguous nucleus caudally (Fig. 21A). Messenger RNA levels remain moderate to strong throughout the dorsomedial nucleus. Continuing into the transition into the cervical spinal cord, mRNA intensity in the caudal spinal trigeminal nucleus is the most intense in the mylencephalon.

Immunohistochemistry. No specific orphanin immunoreactivity was observed in the cerebellar hemispheres, as stated above. A dense plexus of cells and fibers is observed in the fastigial (medial) nucleus, with moderate to heavy immunolabeling. This labeling drops off slightly into its dorsolateral protuberance but is still quite strong to its caudal extent. No immunolabeling is observed in the dentate (lateral) or interposed cerebellar nuclei or any of their corresponding parts.

Immunolabeling within the cranial nerve nuclei of the medulla is relatively sparse. There is no immunolabeling observed the in ninth, tenth, and twelfth cranial nerves or in their associated nuclei. Throughout its extent, the nucleus ambiguous contains a cluster of darkly immunolabeled neurons with moderate fiber staining. This immunolabeling remains confined to this nucleus and persists to the retroambiguous nucleus at the level of the pyramidal decussation. The retroambiguous nucleus contains numerous, densely immunolabeled, OFQ-containing neurons. Very strong neuronal immunolabeling is also observed in the prepositus hypoglossus, with dark immunoreactive fibers visualized (Fig. 20B). At this level, the caudal interstitial nucleus of the medial longitudinal fasciculus contains moderate numbers of labeled neurons and fibers.

In the dorsal medulla, the nudeus of the solitary tract is strongly immunolabeled. The inclusive solitary tract itself is devoid of immunolabeling. A cluster of numerous, lightly immunolabel ed cells with dark fibers and terminals is seen in the rostral solitary nucleus. At more caudal levels, immunolabeling in the solitary nucleus diverges slightly, with heavier terminal and fiber labeling in the medial and lateral parts, and with heavier cell staining in the medial and commissural parts (Fig. 20D). In this dorsal region, darkly stained neurons are observed in the supragenual nucleus medially, and the cuneate and external cuneate nuclei and nucleus gracilus are devoid of immunolabeling. Ventral to the solitary nucleus, darkly labeled neurons and fibers are scattered throughout the reticular formation. Scattered, moderately labeled neurons are observed in the caudal gigantocellular reticular nucleus alpha and the lateral paragigantocellular nucleus. The inferior olive contains numerous darkly immunolabeled cells and scattered fibers in its principal nucleus. There are also lightly stained cells and scattered fibers within the anterior, medial, and dorsal nuclei (Fig. 20F). The dorsomedial division is without immunolabeling. The raphe nuclei in this ventral medullary region contain scattered, moderately labeled neurons into the caudal medulla. This OFQ immunoreactivity is primarily in the raphe magnus and pallidus (Fig. 18D), with scattered, lightly labeled fibers and neurons in the midline raphe obscurus.

In the lateral medulla, the interpolar spinal trigeminal nucleus contains sparse fiber labeling and no cell staining. This persists until the emergence of the caudal spinal trigeminal nucleus, which emerges with a heavily immunolabeled fiber and terminal field, interspersed with numerous darkly labeled neurons (Fig. 21B). Similar to mRNA expression, immunolabeling extends dorsally into the dorsomedial spinal trigeminal nucleus, which contains moderate cell and fiber staining, and ventrally into nucleus ambiguous, where intense neuronal immunolabeling is observed. The pattern of OFQ immunoreactivity in the caudal spinal trigeminal nucleus persists past the caudal medulla and into the cervical spinal cord as a continuum with the heavy fiber and terminal fields in the dorsal horn.

\section{Spinal cord}

In situ hybridization. Proximally, intense mRNA expression in the caudal spinal trigeminal nucleus transitions into the rostral dorsal horn of the cervical cord, where mRNA expression is intense in lamina II and is very light in laminae III, V, and VI (Fig. 21C). Scattered neurons are also seen in lamina VIII dorsally. Intense mRNA expression is evident in Iamina $X$ adjacent to the central canal. Extending ventrally from this region, large, scattered neurons with strong mRNA expression are observed in the ventral horn, in the ventral aspect of Iamina VII, and in what appear to be large ventral motor neurons in lamina IX, which also are observed in immunohistochemical staining (Fig. 2G). The lateral cervical nucleus shows light mRNA expression. I n the thoracic spinal cord, lamina I is devoid of OFQ mRNA-containing neurons, but lamina II has heavy expression. Other than occasional neurons in laminae III and V, there is no other mRNA expression observed in the dorsal horn. Messenger RNA levels are moderate in lamina $X$ of the thoracic cord, with most neurons lying lateral in this region in the intermediomedial cell column, where moderate numbers of OFQcontaining neurons are present (Fig. 21E). Again, there are scattered, large, intensely labeled cells in the ventral part of laminae IX of the ventral horn. The dorsal root ganglia contains scattered cells expressing OFQ mRNA that are very few in number and are confined centrally in the ganglia. No mRNA expression is observed in thelateral spinal nucleus, the intermediolateral cell column, the dorsal corticospinal tract, the gracile fasciculus, thelateral funiculus, or the ventral funiculus in the thoracic cord region.

Immunohistochemistry. Proximally, intense immunostaining from the caudal spinal trigeminal nucleus persists into laminae II and III of the dorsal horn (Figs. 3E, 21D). Lamina I contains scattered terminals and fibers, which are observed best in untreated animals, but no cells. The lateral cervical nucleus is filled with a dense plexus of immunolabeled fibers with moderate cell staining (Fig. 21F). Moderate puncta and fibers are seen in lamina IV, and only lightly labeled, scattered terminals and minimal fibers seen in laminae $\mathrm{V}$ and VI. Fiber and terminal labeling increases in the dorsal part of lamina VII, extending medially to form a moderate pl exus of fibers and terminals within lamina $X$. Several moderately labeled neurons also are found within this lamina. The dorsal aspect of Iamina VIII contains some lightly scattered fibers and no neurons. Large immunolabeled neurons are scattered throughout the ventral portion of Iamina VIII, ventrolaterally in Iamina IX, and in the ventral aspects of Iamina VII proximally. No immunolabeling is observed within the cuneate or gracile fasciculus, the 
dorsal corticospinal tract, the lateral funiculus, or the ventral funiculus.

In the thoracic spinal cord, there is modest fiber and terminal staining in laminae I and III, with moderate numbers of dark neurons in lamina II. The lateral spinal nucleus contains heavy fiber and moderate cell staining, with no extension to the lateral funiculus, which is devoid of immunolabeling. Laminae IV and $\mathrm{V}$ have moderatefiber and terminal labeling, but no immunolabeled neurons are evident. Moderately immunolabeled fibers and puncta are seen in Iamina VII and in the dorsal part of lamina VIII. Terminal and fiber labeling in lamina $X$ is strong, with scattered immunol abeled neurons al so present. I mmunolabeled neurons are present in the intermediomedial cell column near lamina X. Large moderately stained neurons also are observed in the ventral horn in this region. Cells are observed primarily in lamina IX, with occasional smaller, immunolabeled neurons observed in Iamina VIII.

\section{DISCUSSION}

In situ hybridization and immunohistochemistry results demonstrate a diffuse distribution of OFQ in the adult male rat CNS. These findings are in general agreement with early in situ hybridization studies on the distribution of the preproorphanin precursor in the rat and mouse (Houtani et al., 1996; Mollereau et al., 1996b; Nothacker at al., 1996; Pan et al., 1996; Henderson and McKnight, 1997). In these studies, OF Q precursor mRNA was demonstrated in several brain areas, induding the cortex, striatum, lateral septum, bed nucleus of the stria terminalis, thalamus, amygdala, hypothalamus, substantia nigra, central gray, raphe nuclei, pedunculopontine nucleus, superior and inferior colliculi, olivary complex, spinal trigeminal nucleus, and spinal cord dorsal horn. There are few areas of disagreement between the findings in the present mapping study and initial surveys for mRNA expression. By using Northern blot analysis of the preproorphanin precursor in the rat, Mollereau et al. (1996b) demonstrated specific expression of preproorphanin mRNA in several brain areas. They found no mRNA expression in the pituitary, weak expression in the cortex and hippocampus, and strong mRNA expression in the hypothalamus and striatum. The strong mRNA expression observed by this group in the striatum is in contrast to the paucity of mRNA expression and peptide labeling observed in the striatum of the rat in our study. In situ analysis by Houtani et al. (1996) detected orphanin mRNA in the nucleus of the lateral lemniscus and in the inferior vestibular area, two brainstem regions in which we found no mRNA or peptide expression. In general, however, the overall mRNA distribution they observed was similar to ours.

There were very few regions where mismatch occurred between immunostaining and mRNA expression. I n layers II , III , and V of the temporal cortex; layers II and III of the occipital cortex; the medial orbital cortex; the medial anterior olfactory nucleus; the anteroventral nucleus of the thalamus; the lateral habenula; the subgeniculate nudleus; the lateral interpeduncular nucleus; medial subnucleus $B$ of the inferior olive; lamina $V$ of the cervical spinal cord; laminae IIII and VIII of the thoracic spinal cord; and the dorsal root ganglia, light-to-moderate mRNA expression was detected, but no neuronal immunolabeling was seen. This disparity could represent regions where immunolabeling was not sensitive enough to detect OFQ peptide production within cell bodies, but it also may represent regions where preproorphanin mRNA is present but is not being translated into the OFQ peptide. In addition, the precursor molecule may be undergoing posttranslational processing, making it unavailable for immunolabeling by using our OFQ sequence. Although an antiserum directed against a different portion of the preproorphanin sequence may generate neuronal labeling in these few regions, the general immunostaining pattern generated with our OFQ antiserum correlates excellently with in situ hybridization results. In addition, immunoreactivity generally was not observed in structures that were devoid of OFQ mRNA expression, the exceptions being scattered immunolabeled neurons observed in the stria terminalis, the stratum oriens of region CA2 of Ammon's horn, the terete nucleus of the hypothalamus, the central nucleus of the inferior colliculus, the rostral preolivary nucleus, the paralemniscal nucleus, and the lateral spinal nudeus. All of these regions are devoid of mRNA expression but contain light neuronal immunolabeling.

\section{Colchicine treatment}

Colchicine injection into the lateral ventricle markedly altered OFQ immunohistochemical staining in the rat brain, allowing us to closely analyze neuronal elements containing the OFQ peptide. In the untreated animals, neuronal labeling was observed in several regions (e.g., lateral septum, hypothalamus, reticular nudeus of the thalamus, nucleus of Darkschewitsch, dorsal tegmental nud eus, nucleus of the solitary tract, nudeus ambiguous), but intensity of labeling was significantly diminished. In contrast, fiber and terminal labeling was more pronounced in untreated rats than in colchicine-treated animals. In treated animals, fiber and terminal labeling was present in similar structures, but was diminished. Such a pattern of immunolabeling is expected in animals treated with an inhibitor of microtubule-dependent axonal transport, such as colchicine.

Although it has been used extensively in immunohistochemical mapping studies, recent reports have raised the possibility that colchicine treatment induces an increase in mRNA levels for certain neuropeptides in the rat brain (Cortes et al., 1990; Ceccatelli et al., 1991; Kiyama and Emson, 1991). If such an effect does occur, then the authors argue that some mRNA labeling seen in colchicine-treated animals could represent artifact rather than true mRNA expression. In our experiences, and in the present study, we have not found that colchicine treatment produces such an effect. An excellent correlation was observed between preproorphanin mRNA distribution in untreated animals and that of the OFQ peptide in colchicine-treated and untreated animals. In general, every area that contained mRNA expression also demonstrated some degree of immunolabeling, and more importantly, the counter also held true; in no areas of the rat CNS were immunolabeled neurons detected where mRNA-expressing cells were not localized. Our in situ hybridization technique is generally more sensitive in detecting cell bodies than immunohistochemistry, because it detects not only neurons that synthesize OF Q but also those that have the potential to synthesize OFQ peptide. Messenger RNA expression, therefore, is more perceptible than immunolabeling in the CNS in those animals that were the least stressed of all (noncolchicine treated and nonperfused). Colchicine treatment, although it can provide a valuable benefit in detecting 
OF Q-containing cell bodies, produced no neuronal labeling in areas devoid of mRNA expression in our hands.

\section{Antiserum specificity}

The anti-OFQ antiserum generated for use in the present study has not been utilized in any prior studies. After detailed analysis of several bleeds from both rabbits, affinity purification was performed on two bleeds. Antisera from bleed 6, animal 217, was chosen for this study based on quality and reliability of staining and on specificity of immunolabeling. This antiserum was noted to be quite specific in most areas studied. By preabsorbing the OFQ antiserum with a $25-\mu \mathrm{M}$ concentration of OFQ peptide prior to tissue application, immunolabeling was blocked completely in virtually every CNS structure analyzed. However, there were some exceptions that warrant discussion. In the forebrain, there is very strong fiber labeling in the ventral lateral septum. In preabsorption control studies, very small numbers of these fibers are not blocked completely, although they remain very lightly stained. Lateral to the paraventricular nucleus of the hypothalamus, there is a cluster of very intensely immunolabeled neurons with scattered fibers. In preabsorption controls, fiber labeling in this region is blocked completely, but several of the neurons remain immunolabeled. Although they are not blocked completely, the numbers of neurons labeled are very few, and the intensity of labeling is very light. Outside of the cerebellum (discussed below), there are no other structures in the CNS in which immunolabeling is not blocked completely (Fig. 3). The two regions (discussed above) might represent cross reactivity of the antiserum with other peptides in these areas, but this is unlikely. If such cross reactivity did indeed exist, then one would assume not only that there would be somewhat stronger immunoreactive labeling in preabsorption controls but also that there would be labeling in several other CNS regions. Because this unblocked labeling was found only in areas of intense immunolabeling under regular conditions, the OFQ antiserum may not be blocked $100 \%$ by using a $25-\mu \mathrm{M}$ concentration of peptide, detecting peptide in only these regions.

In the cerebellum, immunostaining observed in the fastigial nucleus was blocked completely in preabsorption controls. Specific mRNA expression also was observed in this nucleus. In the cerebellar lobules, OFQ expression is not so clear. Scattered mRNA-containing neurons were observed in the granular layer and were shown to be specific in RNase and sense control studies, but Purkinje cells were found to have no prepro-OFQ mRNA content. In immunohistochemical studies, the cerebellum contained numerous, large, immunoreactive neurons within the Purkinje cell layer of the cerebellum. These neurons were seen in all lobules and were unblocked completely in preabsorption control studies. These neurons were present in colchicine-treated and untreated animals, so this staining was not an effect of colchicine. In addition, other CNS regions with large neuronal el ements (e.g., thered nucleus, cranial nerve motor nuclei) did not demonstrate such staining, so this was not an artifact of large neuron size. It is possible that, specifically within the cerebellar hemispheres where this unique labeling pattern is found, there may be some elements that cross react with nonorphanin-specific antibodies within the OFQ antiserum. In this most likely scenario, 1) this cross reactivity is specific to the cerebellar hemisphere and is not even seen in the cerebellar deep nuclei, 2) it is not colchicine-dependent, and 3 ) it is not seen in any fiber or terminal elements. The immunolabeling pattern in the cerebellar hemisphere, therefore, is treated as nonspecific artifact in this study. Based on the remainder of our preabsorption controls and on their exceptional correlation with in situ expression, we are confident that all other immunolabeling patterns in this study are specific for the OF Q peptide.

\section{Comparisons with endogenous opioid systems}

The distributions of the endogenous opioid peptide precursors, proopiomelanocortin, proenkephalin, and prodynorphin, have been studied in detail (Kachaturian et al., 1985), as has the distributions of the corresponding $\mu, \kappa$, and $\delta$ opioid receptors (Mansour et al., 1993, 1994, 1995a,b, 1996). Since its discovery, the ORL 1 receptor has been shown to differ markedly from the known opioid receptors not only in its structure and interactions with known opioid agonists (Meng et al., 1996; Sim et al., 1996; Ma et al., 1997) but also in its distribution (Chen et al., 1994; Fukuda et al., 1994; Lachowicz et al., 1994; Anton et al., 1996). Likewise, the distribution of the endogenous ligand for the ORL 1 receptor, OF Q, as demonstrated in this study, is distinct from that of other opioid peptides. Close analysis of the distribution of these peptide-receptor systems, however, points to numerous CNS regions in which the opioid and orphanin systems may interact.

\section{Proopiomelanocortin and the $\mu$ receptor}

Proopiomelanocortin, which gives rise to the endogenous opioid, $\beta$-endorphin, has a very limited neuronal distribution, with cell bodies encountered only in the arcuate nucleus, anterior pituitary, and nucleus of the solitary tract. I ts fiber distribution is more widespread, with most pronounced fiber labeling found in the bed nucleus of the stria terminalis, central and medial nuclei of the amygdala, dorsomedial and arcuate nuclei of the hypothalamus, paraventricular nucleus of the thalamus, central gray, the raphe nuclear complex, lateral parabrachial nucleus, mesencephalic trigeminal nucleus, and nucleus of the solitary tract (Kachaturian et al., 1985). In contrast, the $\mu$ receptor has a much broader distribution pattern, with heavy receptor binding observed in fibers and perikarya within the neocortex, striatum, nucleus accumbens, anterior cortical and medial amygdala nuclei, most thalamic nuclei, the presubiculum, dentate gyrus, medial mammillary nucleus, substantia nigra pars compacta, central gray, superior colliculus, inferior colliculus, parabrachial nucleus, dorsal and paramedian raphe, raphe magnus, pontine reticular formation, nucleus ambiguous, nucleus of the solitary tract, spinal trigeminal nucleus, and substantia gelatinosa of the dorsal horn of the spinal cord (Mansour et al., 1995a).

In the rat brain, the arcuate nucleus of the hypothalamus and nucleus of the solitary tract are the only structures in which cell bodies may express both OFQ (Figs. $10 A, B, 20 C, D)$ and $\beta$-endorphin peptides, regions in which orphanin may play a modulatory role on $\beta$-endorphincontaining neurons. The arcuate nucleus has been shown to contain abundant orphanin receptors, and OFQ has recently been shown to inhibit $\beta$-endorphin neurons and secretory cells in the arcuate through activation of inward $\mathrm{K}^{+}$currents (Wagner et al., 1998). Within the bed nucleus of the stria terminalis, central and medial nuclei of the 
amygdala, dorsomedial and arcuate nuclei of the hypothalamus, paraventricular nucleus of the thalamus, central gray, dorsal raphe, lateral parabrachial nucleus, and nucleus of the solitary tract, regions with abundant $\beta$-endorphin fibers, orphanin fiber immunolabeling is robust. Orphanin-like receptor immunoreactivity is present in these areas as well (Anton et al., 1996), providing opportunity for OFQ interaction with the proopiomelanocortin system. Within the dentate gyrus, $\mu$-receptor immunoreactivity has been shown to localize to interneurons within the granule cell layer (Mansour et al., 1995a), very similar to what was demonstrated for OFQ in this study (Fig. 13B). Mu-Receptor immunoreactivity in cell bodies within the central gray, raphenuclei, lateral parabrachial nucleus, nucleus ambiguous, solitary nucleus, and lamina II of the dorsal horn (Mansour et al., 1995a) also localizes in a distribution very similar to what was observed for orphanin in this study (Figs. 3E , 16A,B, 17D, 18, 20C,D, 21D). In addition, OFQ also is localized in neurons in the pars compacta of the substantia nigra (F ig. 8D), another area in which the $\mu$ receptor is localized within cell bodies and binding is dense. Expression of OF Q within cell bodies that coexpress the $\mu$-receptor protein and have dense $\mu$ binding would provide strong evidence for possible $\mu$ modulation of this peptide within these structures. Other areas in which OFQ is strongly expressed and $\mu$-receptor expression is robust include the medial amygdal oid nucleus (Fig. 12A,B) and the paraventricular nucleus of the thalamus.

\section{Prodynorphin and the $\kappa$ receptor}

Prodynorphin-containing cell bodies are expressed primarily in the striatum, dentate gyrus, central nucleus of the amygdala, paraventricular, supraoptic, ventromedial and arcuate nuclei of the hypothalamus, Iateral hypothaIamic area, anterior pituitary, substantia nigra pars reticulata central gray, parabrachial nucleus, Iateral reticular nucleus, nucleus of the solitary tract, spinal trigeminal nucleus, and dorsal horn of the spinal cord. Fibers containing prodynorphin are very heavy in the forebrain in nudeus accumbens, ventral pallidum and globus pallidus, CA3 area of Ammon's horn, paraventricular nucleus of the hypothalamus, and pars reticulata of the substantia, but they are less dispersed in the brainstem, with moderate fiber plexuses found in the central gray, the raphe nuclear complex, parabrachial nucleus, solitary nudeus, spinal trigeminal nucleus, and dorsal horn (Kachaturian et al., 1985). The densest concentrations of $\kappa$-receptor binding and cell immunolabeling are found in the nucleus accumbens, olfactory tubercle, medial preoptic area, bed nucleus of the stria terminalis, medial nucleus of the amygdala, paraventricular nucleus of the thalamus, several hypothalamic nuclei, including the supraoptic, paraventricular, ventromedial, and medial mammillary nuclei, superior colliculus, ventral tegmental area, substantia nigra, central gray, dorsal raphe, parabrachial nucleus, dorsal tegmental nucleus, caudal nucleus of the solitary tract, and spinal trigeminal nucleus (Mansour et al., 1995b, 1996).

There are several regions in which orphanin-containing cell bodies could coexist or colocalize with dynorphincontaining neurons, including the dentate gyrus (Fig. 13B), central nudeus of the amygdala (Fig. 12C,D), paraventricular and arcuate nuclei of the hypothalamus (Fig. 10), lateral hypothalamic area, pars reticulata of the substantia nigra (Fig. 3C), central gray (Fig. 16A,B), interpeduncular nudeus (Fig. 15A,B), paramedian raphe and raphe magnus (Fig. 18), lateral reticular nucleus, solitary nucleus (Fig. 20C,D), spinal trigeminal nucleus, (Fig. 21A,B) and dorsal horn of the spinal cord (Fig. 21C, D). Within the CA3 region of Ammon's horn, the central gray, parabrachial nucleus, caudal spinal trigeminal nudeus, nucleus of the solitary tract, and dorsal horn of the spinal cord, orphanin is strongly expressed in cells and fibers, and the ORL 1 receptor also is intensely immunolabeled (Anton et al., 1996). These regions also contain robust dynorphin fiber labeling and moderate $к-$ receptor localization and binding, providing possible sites of dynorphin and orphanin system interactions. The core of the nucleus accumbens (Fig. 6C,D), medial preoptic area (Fig. 9F), bed nucleus of the stria terminalis (Fig. 9C,D), paraventricular and ventromedial nuclei of the hypothalamus, median eminence (Fig. 1B), and medial nucleus of the amygdala (Fig. 12A,B) contain abundant OFQ fiber and cell staining and robust $\kappa$-receptor localization and binding. These distribution patterns also provide evidence for possible $\kappa$ modulation of OF Q within these structures. It is of interest to note that the substantia (nigra) pars reticulata contains a very dense prodynorphin cell and fiber plexus. Although this structure contains only light $\kappa$ binding and receptor content, it possesses a moderate amount of OFQ peptide and abundant ORL1-containing fibers, providing a likely milieu for orphanin-opiate interaction in this basal ganglia structure.

\section{Proenkephalin and the $\delta$ receptor}

Proenkephalin is the most widely distributed of the endogenous opioid peptides (Kachaturian et al., 1985), with the densest concentration of enkephalin-containing cell bodies in the cingulate and neocortex, anterior olfactory nucleus, olfactory tubercle, piriform cortex, striatum, nucleus of the diagonal band, bed nucleus of the stria terminalis, central nudeus of the amygdala, hippocampal formation, paraventricular, arcuate, and ventromedial nuclei of the hypothalamus, central gray, interpeduncular nucleus, inferior colliculus, raphe nudei, parabrachial nucleus, dorsal tegmental nucleus, medial vestibular nucleus, lateral reticular nucleus, nucleus of the solitary tract, spinal trigeminal nucleus, and dorsal horn of the spinal cord. Enkephalin-containing fibers are most pronounced in the nucleus accumbens, globus pallidus, hippocampal formation, ventromedial nudeus of the hypothalamus, central gray, solitary nucleus, spinal trigeminal nucleus, and dorsal horn. Delta-Receptor localization and binding are most prominent the neocortex, anterior olfactory nucleus, nucleus accumbens, striatum, olfactory tubercle, medial and basolateral nuclei of the amygdala, hippocampal formation, interpeduncular nucleus, pontine nuclei, nucleus of the trapezoid body, lateral reticular nucleus, spinal trigeminal nucleus, and dorsal horn of the spinal cord (Mansour et al., 1995b).

Enkephalin-containing neurons have a high likelihood of colocalizing or coexpressing with OFQ in several structures in which orphanin-containing neurons are present, including the cingulate and piriform cortices (Fig. 6A), diagonal band, bed nucleus of the stria terminalis (Fig. 9C,D), central nucleus of theamygdala (Fig. 12C,D), hippocampal formation (Fig. 13), paraventricular and arcuate nuclei of the hypothalamus (Fig. 10), central gray (Fig. $16 \mathrm{~A}, \mathrm{~B}$ ), interpeduncular nucleus (Fig. 15A,B), paramedian raphe and raphemagnus ( $\mathrm{Fig}$. 18), lateral reticular nucleus (Fig 20E), solitary nudeus (Fig. 20C,D), spinal trigeminal 
nudeus (Fig. 21A,B), and dorsal horn of the spinal cord (Fig. 21C,D). Enkephalin-containing fibers in the nucleus accumbens, hippocampus ventromedial nucleus of the hypothalamus, central gray, interpeduncular nucleus, solitary nucleus, and dorsal horn are within regions where orphanin-containing fibers also are present. These regions also contain heavy ORL 1 immunoreactivity (Anton et al., 1996) and may beareas of orphanin modulation of enkephalin activity. Although not yet demonstrated in the brain, OFQ has been shown to modulate enkephalin release in myenteric plexus preparations (Gintzler et al., 1997). The neocortex, cingulate cortex, nudleus accumbens, ventromedial nucleus of the hypothalamus, medial nucleus of the amygdala, interpeduncular nucleus, spinal trigeminal nudeus, and substantia gelatinosa of the dorsal horn contain strong OFQ neuronal and/or fiber labeling as well as numerous neurons with $\delta$-receptor protein and robust binding. The strong overlapping distribution of the $\delta$ receptor with orphanin fibers in these nuclei provides sites for enkephalin or other opioid modulation of the orphanin peptide.

\section{Functional considerations}

Comparison with ORL 1 receptor distribution. In their detailed analysis of the distribution of the ORL1 receptor, Anton et al. (1996) did not include an analysis of orphanin receptor mRNA distribution but, rather, focused on the distribution of the receptor protein. Similar to our findings with $\mathrm{OFQ}$, those authors found that the orphanin receptor was distributed diffusely the rat CNS. In their study, Anton et al. reported very few neurons containing ORL 1 receptor immunoreactivity, with virtually all immunostaining confined to fibers and puncta. Orphanin receptor immunoreactivity was observed within somata in the dentate gyrus of the hippocampus, the red nucleus, the pontine reticular nud eus, gigantocellular and paragigantocellular reticular nuclei, lamina IX of the spinal cord, and the central cervical nucleus. This is in sharp contrast to the diffuse distribution of OFQ-containing perikarya reported in our analysis. Densest ORL1 receptor fiber and terminal staining was observed in the neocortex, cingulate cortex, piriform cortex, entorhinal cortex, dorsal and ventral pallidum, triangular and medial septum, medial preoptic area, central and medial nuclei of the amygdala, cortical amygdala, Ammon's horn, subiculum, anterior olfactory nucleus, claustrum, endopiriform nucleus, mammillary bodies, parafascicular and posterior thalamic nuclei, substantia nigra, ventral tegmental area, interpeduncular nucleus, central gray, dorsal raphe, trigeminal motor nucleus, suprafacial nucleus, nucleus ambiguous, nucleus of the solitary tract, dorsal nucleus of the vagal nerve, hypoglossal nudeus, parvocellular reticular nudeus of the medulla, and lamina II of the spinal cord. Lighter fiber and terminal labeling was observed in numerous other structures diffusely throughout the CNS. Mismatch between the receptor and neurotransmitter distributions like what we observed with the orphanin system is not unique and has been demonstrated extensively in the opioid peptide and receptor systems (K achaturian et al., 1985; Mansour et al., 1995b). When comparing ORL 1 receptor immunohistochemical distribution with OFQ peptide distribution, it is clear that they differ markedly in their anatomical and structural localization. However, on close analysis, multiple anatomical circuits become evident in which peptidereceptor interactions may provide insights into functional roles for this new orphanin system.
Limbic-hypothalamic-pituitary adrenal axis. The function of the limbic-hypothalamic-pituitary adrenal ( $L$ HPA) axis has been studied extensively, and much is known concerning its role at the behavioral, anatomic, and cellular levels (Herman et al., 1996; Herman and Cullinan, 1997). It is generally accepted that two types of stressors are involved in the initiation of the stress response: those involving an immediate physiologic threat (systemic stressors) and those requiring interpretation by higher brain structures (processive stressors). Whereas processive stressors are likely channeled through limbic forebrain circuits involved in the L-HPA axis and then to the paraventricular nucleus of the hypothalamus, systemic stressors probably are relayed directly to the paraventricular nucleus through brainstem cholinergic neurons. The L-HPA axis is a steroid-sensitive system (Herman and Cullinan, 1997) because many of these stress-related nuclei are sensitive to circulating glucocorticoid levels.

Several forebrain nuclei are known to be involved in stress-excitatory circuits. Of these, the medial, central, and posterior medial cortical nuclei of the amygdala and the lateral bed nucleus of the stria terminalis possess both mineral ocorticoid receptors and OF Q-containing neuronal and fibers elements. Glucocorticoid receptors also are found in the central nucleus. Stress-inhibitory circuits include the medial bed nucleus of the stria terminalis, the medial preoptic area, and the dorsomedial, ventromedial, arcuate and suprachiasmatic nuclei of the hypothalamus. Mineralocorticoid receptors are found in the medial preoptic area, and glucocorticoid receptors are found in the medial preoptic area, arcuate nucleus, bed nucleus of the stria terminalis, and ventromedial nucleus. With the exception of the suprachiasmatic nucleus, OF Q immunolabeling and mRN A expression are seen in all of these nuclei. Other forebrain regions with direct input into this circuitry are the ventral subiculum, prefrontal cortex, and hippocampal formation, all of which have orphanincontaining neurons and glucocorticoid receptors.

There is considerable evidence supporting a role for brainstem catecholaminergic neurons in the regulation of the stress axis (Plotsky et al., 1989). Their action is on L-HPA activation and appears to be stimulatory by way of $\alpha$-1-adrenergic receptors. Direct noradrenergic input onto neurons in the parvocellular paraventricular nucleus is through the ventral noradrenergic bundle, which is supplied primarily by the $A 2, C 1, C 2$, and $C 3$ cell groups in the brainstem. Orphanin peptide is not expressed in these regions, making it unlikely that OFQ plays a modulatory role in these direct inputs. The locus coeruleus, one of the most stress-responsive nudei in the brain (Herman et al., 1996), is thought to modulate L-HPA activation indirectly through multisynaptic connections with forebrain regions, such as the prefrontal cortex, hippocampus, and amygdala. Orphanin mRNA and peptide is localized in all of these regions, providing possible regions in which OFQ may modulate noradrenergic in put into the stress axis. A role for serotonin in L-HPA activation is supported by the finding that destruction of serotonin neurons in the dorsal raphe reduces corticosterone and adrenocorticotropin responses to stressful stimuli (Herman et al., 1996), and neurons within the raphe complex provide direct projections to the parvocel lular paraventricular nucleus. Orphanin peptide and mRNA are local ized within many neuronal and/or fiber elements within the raphe system, allowing 
involvement of OFQ in the modulation of brainstem serotonergic activation of the L-HPA axis.

At present, little has been shown behaviorally to support an role for orphanin in the stress response. Recently, J enck et al. (1997) demonstrated that OF Q can modulate anxiety states generated by acute stress. Those authors concluded that OFQ may act as an anxiolytic in certain stressful circumstances. Orphanin indeed may play a modulatory role on the stress response through inhibitory effects on L-HPA activation. If so, then its role as an anxiolytic agent could be explained.

Learning and memory. The hippocampal formation is not only intimately involved in the function of the L-HPA axis, it is also a critical structure in learning and memory. OFQ is found throughout the hippocampal formation, and OF Q-containing neurons are also observed in the entorhinal cortex, which has direct projections to the entire hippocampal formation. I $n$ addition, ORL 1 receptor immunoreactivity is strong in all hippocampal regions (Anton et al., 1996). Orphanin has been reported to reversibly inhibit voltage-gated calcium channels in pyramidal neurons from areas CA 1 and CA3 (Knoflach et al., 1996) and to inhibit synaptic transmission and long-term potentiation in area CA1 of Ammon's horn and the dentate gyrus (Yu et al., 1997). The latter effect is thought to be postsynaptic in nature (Yu and Xie, 1998). Microinjections of OFQ into the CA3 region of adult rats have been shown to impair spatial learning (Sandin et al., 1997). These findings remain controversial, because the effects of orphanin on motor behavior were not taken into account (see below). However, in support of the findings by Sandin et al., recent studies on knockout mice lacking the orphanin receptor demonstrated enhancement of spatial attention in the water-finding test (Mamiya et al., 1998) and facilitation of Iong-term potentiation and memory (Manabe et al., 1998). Initial studies support a role for this peptide in learning and memory, and its distribution throughout the hi ppocampal formation and entorhinal cortex supports this concept as well.

Motor systems. Orphanin-containing neurons are located in the globus pallidus, entopeduncular nucleus, and substantia nigra, and significant OFQ-containing fibers are found in these structures and in the striatum. In addition, the lateral bed nucleus of the stria terminalis, a component of the extended central amygdaloid complex (Alheid et al., 1995), has abundant OFQ peptide content and has direct projections to the retrorubral field, ventral tegmental area, and substantia nigra, pars compacta. These structures possess abundant ORL 1 receptor density (Anton et al., 1996) and give rise to major dopaminergic projections. Early behavioral effects observed with central administration of this peptide may reflect a conceivable role of OF Q in the modulation of gross locomotive behavior.

OFQ also is localized within brainstem structures that direct several aspects of fine motor control and balance, including vestibular nuclei, deep cerebellar nuclei, and the inferior olive. Proprioceptive input from the dorsal columns of the spinal cord is integrated in the dorsal olivary nudeus, which relays information to the cerebel lar vermis, which, in turn, has very strong inputs into the medial (fastigial) cerebellar nucleus. The fastigial nudeus projects heavily to nuclei involved with visual integration and to the spinal vestibular nucleus. Orphanin-containing cell bodies are expressed consistently throughout this circuitry, and, although ORL 1 immunoreactivity is light in these areas (Anton et al., 1996), orphanin binding is prominent in many of these structures (personal observations). Input into the principal olivary nucleus originates primarily in visual integration areas and association cortices. This nucleus projects to the lateral cerebellar hemispheres, which have strong input to all vestibular nuclei except the lateral nucleus. Orphanin peptide content is very strong in the visual nuclei, which project to the principal ol ivary nucleus (nucleus of Darkschewitsch, interstitial nucleus of the medial Iongitudinal fasciculus, and medial accessory oculomotor nucleus), as well as within the principal olivary nucleus itself. The vestibular nuclei provide integration of proprioceptive input and provide efferents from the lateral vestibular nucleus to the inferior olive and from the spinal vestibular nucleus to the cerebellum and reticular formation. The medial and superior vestibular nuclei have projections to the cerebellum, spinal cord, thalamus, and lateral paragigantocellular reticular nucleus.

The effects of orphanin on gross motor function are somewhat controversial and are largely unknown at this point. Orphanin has been implicated in producing hypolocomotion in rats (Devine et al., 1996a) and in stimulating locomotion and exploratory behavior in mice (Florin et al., 1996). Many early behavioral tests using intraventricular orphanin may have been confounded by the fact that higher doses of this peptide have been shown to seriously disrupt motor behavior in adult rats (D.P. Devine, personal communication). Indeed, OFQ is localized within many structures in the CNS that are intimately involved in locomotion, balance, and proprioception. It remains to be determined exactly what role orphanin plays in motor function, but the presence of OF Q in the basal ganglia and in the vestibular and visual motor systems supports a modulatory rolefor this peptide in these related behaviors. The effects of this peptide on motor function should be considered when analyzing other behavioral effects.

Reinforcement and reward. The nudeus accumbens has been implicated in a number of functions, including drug reinforcement and locomotor behavior (Koob et al., 1991). Little is known concerning possible motivational or reward effects of OFQ in relation to this region. Rats have been shown to develop tolerance to locomotor effects induced by orphanin (Devine et al., 1996a), but they failed to demonstrate conditioned place preference when given intraventricular injections of this peptide (Devine et al., 1996b). I n addition, it has been reported that injections of OFQ into the lateral ventricle of the rat suppresses dopamine release in the nucleus accumbens (Murphy et al, 1996). Orphanin is strongly expressed in several structures involved in this circuitry, including the substantia nigra and the ventral tegmental area. These regions contain direct projections to the nucleus accumbens and ventral pallidum, both of which have abundant ORL 1 receptor (Anton et al., 1996). The inability to generate conditioned place preference or aversion in earlier studies in the rat may have been limited by locomotor effects of this peptide (D.P. Devine, personal communication), and the abundance of OFQ within this mesoaccumbens circuitry still may indicate a modulatory role for this peptide in reinforcement behaviors.

One particular reinforcing behavior that appears to be influenced by the accumbens nucleus is that of feeding behavior. Feeding as a behavioral act is complicated, requiring several somatomotor and autonomic events re- 
lated to searching for and handling of food, eating, and digesting. This process involves multiple CNS circuits that are involved in the integration of olfactory, visual, and auditory information and many brainstem centers that are involved in the acts of mastication and digestion. The lateral septum, a region with high OF Q content, has direct projections to the medial hypothalamus and the lateral hypothalamic area. It has been postulated that these structures are central in the initiation and control of food intake (King and Nance, 1986). In addition, some mesoaccumbens-lateral hypothalamic interactions may be more central in motivating effects of food intake. A recent report by Cabeza de Vaca and Carr (1998) demonstrated a definite enhancement in the central rewarding effect of abused drugs in animals undergoing food restriction. Although the nucleus accumbens is thought to be central in the mechanism, those authors also argue for a major role of the lateral hypothalamus, a region with abundant orphanin content.

Pomonis et al. (1996) initially demonstrated that injections of OF Q into thelateral ventricle of the rat stimulated feeding to a degree similar to that seen with injection of other opiates. This response however, was blocked by naloxone, making it more likely that it may have been an opiate-driven event. More recently, Stratford et al. (1997) demonstrated that injections of orphanin into the ventromedial hypothalamic nucleus or the nudeus accumbens increased food intake in rats. By using small doses of orphanin (2.5-25 nM), they demonstrated orphaninspecific stimulation of this motivational behavior with injections into both regions. The rol e of OFQ in stimulation of feeding behavior gains further support in a recent study by Leventhal et al. (1998), which demonstrates a reduction of OFQ-induced hyperphagia by central administration of an ORL 1 antisense probe. Much remains to be answered concerning the possible role of OFQ in mechanisms of motivation and reinforcement. However, early behavioral findings, coupled with the presence of OF Q and its ORL 1 receptor to varying degrees within many structures involved in this circuitry, support involvement of the orphanin system.

Sexual behavior. The anatomic distribution of OFQ also argues for a possiblefunctional role in sexual behavior and sexually dimorphic pathways. Evidence for sexual dimorphism was first reported in the medial preoptic area by Gorski et al. (1980). Sexual dimorphism emerges early in development, is related to differences in neuronal production, and appears to be regulated by circulating gonadal steroids (J acobson and Gorski, 1981; Davis et al., 1996). A steroid-sensitive, enkephalinergic sexual dimorphism has also been described in the medial preoptic region (Watson et al., 1986; Simerly et al., 1988). Other forebrain nuclei that have major connections with the medial preoptic area also demonstrate sexual dimorphism, including the medial amygdala (N ishizuka and Arai, 1983), medial and lateral parts of the bed nucleus of the stria terminalis (Guillamon et al., 1988), and several hypothalamic nuclei, including the arcuate nucleus, ventromedial nucleus, and tuberomammillary nucleus (Urban et al., 1993; Borisova et al., 1996; Gonzales et al., 1996). The circuitry that is involved primarily in the medial preoptic area, bed nucleus of the stria terminalis, and medial nucleus of the amygdala is not only sexually dimorphic, but it also has been shown to be critical for normal sexual behavior in the male hamster (Neal and Newman, 1989).
The medial preoptic area also shares inputs with the arcuate and ventromedial nuclei of the hypothalamus. These limbic regions contain some of the highest amounts of orphanin in the forebrain. Furthermore, the lateral septum, which contains abundant orphanin peptide and mRNA expression, also is known to possess androgen and estrogen receptors and vasopressin immunoreactivity. This nucleus is al so sexually dimorphic and sex-hormone sensitive (J akab and Leranth, 1995). The lateral septum has profound hypothalamic projections and receives concentrated input from the hippocampal formation, a region known to be sexually dimorphic (Madeira et al., 1991). What role orphanin plays in sexual dimorphism or in sexual behavior is not known. However, its heavy content throughout circuitry that is not only sexually dimorphic but also intimately involved in sexual behavior makes it likely that orphanin plays a major role in the development or maintenance of this behavior. Supporting this notion, it has been reported recently that OFQ microinjections into the ventromedial nucleus of the hypothalamus facilitate lordosis in female rats (Sinchak et al., 1997).

Pain perception. Several studies have demonstrated a modulatory role for orphanin in pain perception, although its effects on the pain response remain controversial (Henderson and McKnight, 1997). Studies to date have shown that orphanin plays an important modulatory role in pain perception, producing analgesia in some models (King et al., 1997; Rossi et al., 1997; Tian et al., 1997a,b; Yamamoto et al., 1997) and antagonizing analgesia in others, tempting some to depict its actions as antiopioid (Grisel et al., 1996; Mogil et al., 1996a,b; Xu et al., 1996; Dawson-Basoa and Gintzler, 1997; Heinricher et al., 1997; Morgan et al., 1997; J hamandas et al., 1998). OFQ also has been implicated as an antagonist of morphine analgesia (Hao et al ., 1997; Tian et al., 1997b; Zhu et al., 1997), although morphine analgesia has been demonstrated in mice lacking the ORL1 receptor gene. It is interesting to note that these ORL1-deficient animals were unable to devel op tolerance to the anal gesic affects of morphine after repeated doses (Ueda et al., 1997). Recent studies have also implicated orphanin in pain induction from nonnoxious stimuli (allodynia; Okuda-Ashitaka et al., 1996; Hara et al., 1997; Minami et al., 1997).

Much is known concerning the ascending and descending pain pathways, particularly those involving endogenous opioid systems (Mansour et al., 1995b). In this context, somatosensory inputs from laminae I and II of the dorsal horn of the spinal cord and from the spinal trigeminal nucleus ascend directly to the posterior and centrolateral nuclei of the thalamus and then are relayed to the somatosensory cortex. This ascending information is modulated at many levels, including, initially, within the substantia gelatinosa, and by passing inputs from the reticular formation. Descending information from the somatosensory cortex ultimately terminates in the dorsal horn of the spinal cord, relaying feed-back information for nociception modulation. These inputs are not direct and arrive at the spinal cord by way of the central gray, raphe magnus, and al pha division of the gigantocellular reticular formation (Mansour et al., 1995b). These projections are modulated further in passing by inputs from the dorsal raphe, median raphe, lateral parabrachial nucleus, and reticular formation. It has long been known that endogenous opioid peptides and receptors strongly influence these nociceptive pathways. It is also important to note 
here that OFQ is physically present along all parts of this pain circuitry as well, with OFQ-containing neurons and fibers found in the central gray, the raphe nuclei, the lateral parabrachial nucleus, the reticular formation nuclei, the spinal trigeminal nucleus, and the superficial laminae of the spinal cord.

Although colocalization has not been demonstrated, OF Q has been shown to have an overlapping distribution with opioid peptides in several pain modulatory regions, including the dorsal horn of the spinal cord, spinal trigeminal nucleus, raphe nuclei, locus coeruleus, and central gray (Schulz et al., 1996). In addition, there is an accumulating body of evidence supporting modulatory influences of OFQ on painful inputs into the CNS as both an agonist and an antagonist to analgesia. It is presently hypothesized that the outer two-thirds of the substantia gelatinosa play a major role in the modulation of nociception, and this regi on contains a myriad of various neurotransmitters, including opioid peptides (Ribeiro-da-Silva, 1995). Orphanin immunoreactivity has been demonstrated quantitatively in Iamina II , and OF Q-containing fibers paralleling endogenous opioids have been identified (Riedl et al., 1996; Schuligoi et al., 1997). Cell recordings from substantia gelatinosa neurons have shown that exogenous OFQ depresses excitatory postsynaptic potentials evoked by stimulation of dorsal root ganglia (Lai et al., 1997; Liebel et al., 1997). I ntrathecal orphanin also has been shown to inhibit C-fiber-evoked discharge of dorsal horn neurons (Stanfa et al., 1996). These studies clearly support a role for orphanin inhibition of Iamina II neurons within the spinal pathway of the rat spinal cord.

Opioid- and orphanin-containing cell bodies also are numerous in the rostral ventromedial medulla, a region in which the ORL 1 receptor al so has been identified (Anton et al., 1996). This region includes reticular formation and raphe neurons that are known to have an antinociceptive influence to noxious stimuli. Electrophysiologic and pharmacologic studies in this region have demonstrated an inhibitory role of OF Q on the firing of these neurons in the presence of morphine activation, leading the authors to hypothesize that OFQ exerts an "antiopioid" effect by suppressing firing of these cells (Heinricher at al., 1997). Finally, microinjections of morphine and OFQ into the central gray have demonstrated that OFQ attenuates morphine-induced analgesia in awake rats (Morgan et al., 1997). Separate studies have shown that microinjections of OFQ alone demonstrate inhibitory actions on central gray neurons (Vaughan et al., 1997).

In conclusion, the anatomic localization of OFQ within important structures along the ascending and descending pain pathways, its proximity to the endogenous opioid peptide systems, and mounting physiologic and behavioral evidence appear to support a major role for orphanin in pain modulation. It is important to note that it has been demonstrated recently that the ORL 1 and $\mu$ antisera label different fibers in pain-processing regions of the rat brain (Monteillet-Agius et al., 1998). Therefore, it is most likely that ORL 1 and $\mu$ influences on pain perception occur through predominantly different fiber systems.

Autonomic and physiologic functions. There have been several studies supporting a role for orphanin in control of basic autonomic and physiologic mechanisms, including cardiovascular control (Gumusel et al., 1997; Champion and Kadowitz, 1997a, b; Champion et al., 1997 and water and electrolyte balance (Kapusta et al., 1997).
Application of OFQ onto arterial rings from the cat demonstrates vasorelaxant properties (Gumusel et al., 1997), and this peptide has been shown to induce hypotension (Champion and Kadowitz, 1997a,b) and to decrease cardiac output (Champion et al., 1997) in rats. Although the role of OFQ in autonomic circuitry is not clear, L-glutamate stimulation of the zona incerta has been shown to decrease heart rate and blood pressure (Spencer et al., 1988) in the rat. Intraventricular administration of OF Q also has been shown to induce diuresis and antinatriuresis in the rat, implicating this peptide in the central control of water balance and possibly in the regulation of blood pressure (Kapusta et al., 1997). Peripheral intravenous infusion of orphanin also produces diuresis and inhibits salt wasting, implying that this effect also may have a peripheral component. It should be noted, however, that the OFQ doses used by Kapusta et al. were magnitudes higher than those used in studies that elicited analgesic, nociceptive, and motor effects. In support of a role for OFQ in water balance, the ORL1 receptor is highly expressed in the supraoptic and paraventricular nuclei of the hypothalamus (Anton et al., 1996). The diuretic and antinatriuretic effects of OF Q may be vasopressin mediated, because OF Q has been shown to inhibit firing of vasopressin-containing neurons in the supraoptic nudeus of the hypothalamus (Doi et al., 1998), or it may involve peripheral modulation of renal sympathetic nerves.

Orphanin involvement in noradrenergic and serotonergic systems also may play a role in cardiovascular control and fluid balance. Treatments that increase central extracellular serotonin increase sodium excretion, and renal denervation attenuates natriuresis produced by intraventricular administration of serotonin (Montes and J ohnson, 1990). In addition, activation of serotonergic neurons in the ventromedial medulla produces a drop in blood pressure and heart rate by inhibiting central sympathetic outflow (Kalkman and F ozard, 1991). This effect is limited to the medial serotonergic cell group in this region, with stimulation of laterally located neurons inducing hypertension in these same animals. Numerous orphanin-containing neurons are located in the region of the noradrenergic A5 cell group in the caudal mesencephalon and metencephalon. This cell group is known to project to autonomic nuclei of the brainstem and spinal cord (Byrum and Guyenet, 1987), with direct spinal projections to the intermediate gray and intermediolateral (sympathetic preganglionic) cell column in the spinal cord and to the nucleus of the solitary tract. Chemical stimulation of neurons in the $A 5$ region has been reported to induce a fall in blood pressure (Neil and Loewy, 1982). The localization of orphanin within neurons in the dorsal raphe and ventromedial medulla and within the region of the A5 cell group raises the possibility of col ocalization with noradrenergic or serotonergic projection neurons controlling blood pressure, cardiac output, and sodium balance.

The nucleus of the solitary tract contains numerous OF Q mRNA-expressing cells and immunoreactive neurons and abundant ORL 1 receptor (Anton et al., 1996). Autonomic efferents from this nucleus project to the intermediolateral cell column of the spinal cord, nucleus ambiguous, dorsal motor nucleus of the vagal nerve, ventrolateral medulla, A5 cell group, parabrachial nucleus, and numerous forebrain regions (Saper, 1995). Solitary nucleus projections to the preganglionic parasympathetic neurons in the medulla and sympathetic neurons in the spinal cord 
influence numerous autonomic responses. In addition, efferents to the medullary reticular formation influence gastrointestinal, cardiovascular, and respiratory reflexes. The brainstem orphanin system is localized diffusely within major autonomic control centers. Although initial studies have demonstrated an OF Q influence on primarily cardiovascular function and water balance, this peptide may be involved in several autonomic and physiologic functions, including general arousal, cardiovascular tone, respiratory drive, gastrointestinal function, and general visceral sensory feedback.

Special sensory systems. Brainstem special sensory systems provide extensive input to higher centers through strong olfactory, gustatory, and visceral sensory information that regulates the medial preoptic area, anterior hypothalamus, dorsomedial hypothalamus, and ventromedial hypothalamus and through visual and auditory information to the mammillary bodies. OFQ is present in several nuclei within these circuits and probably plays some role in the integration and/or processing of this information.

OFQ is highly expressed within nuclei that integrate visual information, particularly the nucleus of Darkschewitsch, pretectum, and superior colliculus, providing a medium for OFQ involvement in visual sensory integration, as well modulation of output to the spinal cord, the midline pontine and medullary nuclei, the hypothalamus, and the intralaminar thalamic nuclei. In the forebrain, the lateral mammillary nucleus contains a very dense plexus of OFQ-containing neurons and fibers. This nucleus is influenced strongly by both visual and auditory stimuli and is thought to be involved the processing of visual and auditory information, and it has been shown to have direct cortical connections (Simerly, 1995). Although the majority of brainstem auditory regions have little OF Q and ORL 1 content, structures primarily involved with the integration of high frequency sound in the rat (Aitkin et al., 1984) contain abundant OFQ expression. Such information is integrated directly in the trapezoid body, lateral superior olive, and inferior colliculus. Orphanin expression is strong in the nucleus of the trapezoid body, which projects directly to the lateral superior olive, which, in turn, projects to the inferior colliculus. These structures contain moderate amounts of ORL1 immunoreactivity (Anton et al., 1996) as well as OFQ-containing cell bodies, supporting a role for OFQ in the integration of high-frequency sounds. It is important to note that, given the presence of OF Q and the ORL 1 receptor within the auditory nuclei described above, as well as in the inferior olive and the vestibular system, the OFQ system may be involved in the integration of auditory and vestibular information and possibly plays a major role in an animal's ability to adapt to visual, proprioceptive, and auditory cues in its environment. Little is known concerning a role for OFQ in visual or auditory processing, but a recent study in ORL1-deficient mice has shown that these animals demonstrate an insufficient recovery of hearing ability after adaptation to sound exposure(Nishi et al., 1997).

A brief mention should be made of the possible role of orphanin in the integration of olfactory and gustatory information. Cranial nerves that carry gustatory and somatosensory axons from the oral cavity are distributed throughout the nud eus of the solitary tract in a topographical fashion (Altschuler et al., 1989). Gustatory information from the solitary nucleus is relayed to the parabrachial nucleus. Gustatory neurons within the parabrachial nucleus are located primarily in the medial part, where OF Q is not present, but abundant ORL 1 receptor immunoreactivity (Anton et al., 1996) is observed. The parabrachial nucleus relays gustatory information to the ventral posteromedial thalamus, then to the dorsal insular cortex, and also directly to the central nucleus of the amygdala. Olfactory stimulus perception and integration also may be modulated by OFQ. The entorhinal cortex, which contains neurons with OF Q-like immunoreactivity and OF Q mRNA expression, receives substantial olfactory input from the olfactory bulbs and the piriform cortex. This structure, in turn, projects by way of the perforant pathway tothehippocampal formation and to other higher centers (Schwerdtfeger et al., 1990). There are no data to date supporting a role for orphanin in the processing of olfactory or gustatory information. However, as discussed above, injections of OF Q into the lateral ventricle of the rat appear to increase feeding behavior (Pomonis et al., 1996). It is highly likely that signals from gustatory and ol factory centers are important in the complex series of behaviors involved with feeding. Orphanin FQ, by its presence within major nuclei in these systems, may be involved in the stimulatory effects of intraventricular orphanin on feeding behavior.

\section{CONCLUSIONS}

We have demonstrated that OF Q, the novel endogenous agonist of the ORL 1 receptor, is distributed widely throughout the CNS of the adult male rat. We have also established a very close correlation between preproorphanin mRNA and OFQ peptide expression. In addition, analysis of the immunohistochemical distribution of the ORL 1 receptor demonstrates correspondence of the orphanin peptide with its endogenous receptor, providing the groundwork for study of specific anatomic systems in deciphering the multiple behavioral and physiologic roles of this neuropeptide. Orphanin FQ and the ORL 1 receptor are expressed in critical components of numerous neural circuits, supporting their possible involvement in various CNS systems, including nociception, modulation of the L-HPA stress axis, motivation and reward, learning and memory, gross motor control, balance and proprioception, sexual, aggressive, and investigatory behaviors, control of autonomic and physiologic functions, and integration of special sensory input.

Although much claim has been made on naming this molecule "nociceptin" due to its possible antagonism of analgesic modalities, the distribution of the orphanin system in the CNS is very diffuse and includes numerous forebrain and brainstem circuits and systems. Orphanin FQ and its receptor most likely play a major role in many behaviors and physiologic functions, making nociceptin too limiting a nomendature for such an important neuropeptide. We support the continued use of "orphanin FQ" when referring to this neuropeptide as we continue to unravel its role in the CNS.

\section{ACKNOWLE DGMENTS}

The authors thank Sharon Burke, Robert Pavlic, and J ames Stewart for their superb technical assistance. This work was sponsored by a National Institute of Mental Health Training grant to C.R.N. (NIMH 5 T32 MH15794) and by a National Institute of Drug Abuse grant to S.J .W. (NIDA RO1 DA08920). 


\section{LITERATURE CITED}

Abdulla FA, Smith PA. 1997. Nociceptin inhibits T-type $\mathrm{Ca}^{2+}$ channel current in rat sensory neurons by G-protein-independent mechanisms. J Neurosci 17:8721-8728.

Aitkin LM, I rving DRF, Webster WR. 1984. Central neural mechanisms of hearing. In: Smith ID, editor. Handbook of physiology. New York: American Physiological Society. p 675-737.

Alheid GF, de Olmos J S, Beltramino CA. 1995. The amygdala and extended amygdala. In: Paxinos G, editor. The rat nervous system. Sydney, Australia: Academic Press, Inc. p 495-578.

Altschuler SM, Bao X, Bieger D, Hopkins DA, Miselis RR. 1989. Viscerotopic representation of the upper alimentary tract in the rat: sensory ganglia and nuclei of the solitary tract and spinal trigeminal tracts. J Comp Neurol 283:248-268.

Anton B, Fein J , To T, Li X, Silberstein L, Evans CJ . 1996. Immunohistochemical localization of ORL-1 in the central nervous system of the rat. J Comp Neurol 368:229-251.

Ardati A, Henningsen RA, Higelin J , Reinscheid RK, Civelli O, Monsma FJ . 1997. Interaction of $\left[{ }^{3} \mathrm{H}\right.$ ] orphanin $\mathrm{FQ}$ and ${ }^{125}$ - $^{-} \mathrm{yr}_{14}$-orphanin $\mathrm{FQ}$ with the orphanin FQ receptor: kinetics and modulation by cations and guanine nucleotides. Mol Pharmacol 51:816-824.

Borisova NA, Proshlyakova EV, Sapronova AY, U grumov MF. 1996. Androgen-dependent sex differences in the hypothalamic serotoninergic system. Eur J Endocrinol 134:232-235.

Bunzow J R, Saez C, Mortrud M, Bouvier C, Williams J T, Low M, Grandy DK. 1994. Molecular cloning and tissue distribution of a putative member of the rat opioid receptor gene family that is not a mu, delta or kappa opioid receptor type. FEBS Lett 347:284-288.

Butour J L, Moisand C, Mazarguil H, Mollereau C, Meunier J C. 1997. Recognition and activation of the opioid receptor-like ORL 1 receptor by nociceptin, nociceptin analogs and opioids. Eur J Pharmacol 321:97-103.

Byrum CE. Guyenet PG. 1987. Afferent and efferent connections of the A5 noradrenergic cell group in the rat. J Comp Neurol 261:529-542.

Cabeza de Vaca S, Carr KD. 1998. Food restriction enhances the central rewarding effect of abused drugs. J Neurosci 18:7502-7510.

Ceccatelli S, Cortes R, Hökfelt T. 1991. Effect of reserpine and colchicine on neuropeptide mRNA levels in the rat hypothalamic paraventricular nucleus. Brain Res Mol Brain Res 9:57-69.

Champion HC, Kadowitz PJ . 1997a. Nociceptin, an endogenous ligand for the ORL 1 receptor, has novel hypotensive activity in the rat. Life Sci 60:PL 241-PL 245.

Champion HC, Kadowitz PJ . 1997b. [Tyr1]-nociceptin, a novel nociceptin analog, decreases systemic arterial pressure by a naloxone-insensitive mechanism in the rat. Biochem Biophys Res Commun 234:309-312.

Champion HC, Czapla MA, Kadowitz PJ . 1997. Nociceptin, an endogenous ligand for the ORL1 receptor, decreases cardiac output and total peripheral resistance in the rat. Peptides 18:729-732.

Chen Y, Fan Y, Liu J, Mestek A, Tian M, Kozak CA, Yu L. 1994. Molecular cloning, tissue distribution and chromosomal localization of a novel member of the opioid receptor gene family. FEBS Lett 347:279-283.

Civelli O, Nothacker H-P, Bourson A, Ardati A, Monsma F, Reinscheid R. 1997. Orphan receptors and their natural ligands. J Recept Signal Transduct Res 17:545-550.

Connor M, Vaughan CW, Chieng B, Christie MJ . 1996. Nociceptin receptor coupling to potassium conductance in locus coeruleus neurons in vitro. Br J Pharmacol 119:1614-1618.

Connor M, Yeo A, Henderson G. 1997. The effect of nociceptin on Ca2+ channel current and intracellular $\mathrm{Ca}^{2+}$ in the SH-SY 5Y human neuroblastoma cell line. Br J Pharmacol 118:205-207.

Cortes R, Ceccatelli S, Schalling M, Hökfelt T. 1990. Differential effects of intracerebroventricular colchicine administration on the expression of mRNAs for neuropeptides and neurotransmitter enzymes, with special emphasis on galanin: an in situ hybridization study. Synapse 6:369-391.

Davis EC, Popper P, Gorski RA. 1996. The role of apoptosis in sexual differentiation of the sexually dimorphic nucleus of the preoptic area. Brain Res 734:10-18.

Dawson-Basoa M, Gintzler A. 1997. Nociceptin (orphanin FQ) abolishes gestational and ovarian sex steroid-induced antinociception and induces hyperalgesia. Brain Res 750:48-52.

Devine DP, Taylor L, Reinscheid RK, Monsma FJ , Civelli O, Akil H. 1996a. Rats rapidly devel op tolerance to the locomotor-inhibiting effects of the novel neuropeptide orphanin F Q. Neurochem Res 21:1387-1396.

Devine DP, Reinscheid RK, Monsma FJ , Civelli O, Akil H. 1996b. The novel neuropeptide orphanin F Q fails to produce conditioned place preference or aversion. Brain Res 727:225-229.
Doi N, Dutia MB, Russell JA. 1998. Inhibition of rat oxytocin and vasopressin supraoptic nucleus neurons by nociceptin in vitro. Neuroscience 84:913-921.

Dooley CT, Houghten RA. 1996. Orphanin F Q: receptor binding and analog structure activity relationships in rat brain. Life Sci 59:PL 23-PL 29.

Dooley CT, Spaeth CG, Berzetei-Gurske IP, Craymer K, Adapa ID, Brandt SR, Houghten RA, Toll L. 1997. Binding and in vitro activities of peptides with high affinity for the nociceptin / orphanin FQ receptor, ORL 1. J Pharmacol Exp Ther 283:735-741.

Faber ES, Chambers J P, Evans RH, Henderson G. 1996. Depression of glutamatergic transmission by nociceptin in the neonatal rat hemisected spinal cord preparation in vitro. Br J Pharmacol 119:189-190.

Florin S, Suaudeau C, Meunier J C, Costentin J . 1996. Nociceptin stimulates locomotion and exploratory behaviour in mice. Eur J Pharmacol 317:9-13.

Florin S, Suaudeau C, Meunier J C, Costentin J . 1997a. Orphan neuropeptide Nocll, a putative pronociceptin maturation product, stimulates Iocomotion in mice. Neuroreport 8:705-707.

Florin S, Leroux-Nicollet I, Meunier J C, Costentin J . 1997b. Autoradiographic localization of $\left[{ }^{3} \mathrm{H}\right.$ ]nociceptin binding sites from telencephalon to mesencephalic regions in the mouse brain. Neurosci Lett 230:33-36.

Fukuda K, Kato S, Mori K, Nishi M, Takeshima H, I wabe N, Miyata T, Houtani T, Sugimoto T. 1994. cDNA cloning and regional distribution of a novel member of the opioid receptor family. FEBS L ett 343:42-46.

Gintzler AR, Adapa ID, Toll L, Medina VM, Wang L. 1997. Modulation of enkephalin release by nociceptin. Eur J Pharmacol 325:29-34.

Giuliani S, Maggi CA. 1996. Inhibition of tachykinin release from peripheral endings of sensory nerves by nociceptin, a novel opioid peptide. Br J Pharmacol 118:1567-1569.

Gonzales S, Diaz F, Vallejo G, Arias J L. 1996. Functional sexual dimorphism of the nucleolar organizer regions in the tubomammillary nucleus. Brain Res 736:1-6.

Gorski RA, Harlan RE, J acobson CC, Shryne J E, Southam AM. 1980 Evidence for the existence of a sexually dimorphic nucleus in the preoptic area of the rat. J Comp Neurol 193:529-539.

Grisel J E, Mogil J S, Belknap J K, Grandy DK. 1996. Orphanin FQ acts as a supraspinal, but not a spinal, anti-opioid peptide. Neuroreport 7:2125-2129.

Guerrini R, Calo G, Rizzi A, Bianchi C, Lazarus LH, Salvadori S, Temussi PA, Regoli D. 1997. Address and message sequences for the nociceptin receptor: a structure-activity study of nociceptin-(1-13)-peptide amide. J Med Chem 40:1789-1793.

Guillamon A, Segovia S, del Abril A. 1988. Early effects of gonadal steroids on the neuron number in the medial posterior region of the lateral division of the bed nucleus of the stria terminalis in the rat. Brain Res Dev Brain Res 44:281-290.

Gumusel B, Hao Q, Hyman A, Chang J K, Kapusta DR, Lippton H. 1997 Nociceptin: an endogenous agonist for central opioid likel (ORL 1) receptors possesses systemic vasorelaxant properties. LifeSci 60:PL 141-PL 145.

Halford WP, Gebhardt BM, Carr DJ . 1995. Functional role and sequence analysis of a lymphocyte orphan opioid receptor. J Neuroimmunol 59:91-101.

Hao J, Wiesenfeld-Hallin Z, Xu XJ . 1997. Lack of cross-tolerance between the antinociceptive effect of intrathecal orphanin FQ and morphine in the rat. Neurosci Lett 223:49-52.

Hara N, Minami T, Okuda-Ashitaka E, SugimotoT, Sakai M, Onaka M, Mori H, Imanishi T, Shingu K, I to S. 1997. Characterization of nociceptin hyperalge sia and allodynia in conscious mice. Br J Pharmacol 121:401-408.

Heinricher MM, McGaraughty S, Grandy DK. 1997. Circuitry underlying antiopioid actions of orphanin FQ in the rostral ventromedial medulla. J Neurophysiol 78:3351-3358.

Henderson G, McKnight AT. 1997. The orphan opioid receptor and its endogenous ligand nociceptin/orphanin FQ. TIPS 18:293-300.

Herman J P, Chantal MF, Cullinan WE. 1996. Neuronal circuit regulation of the hypothalamo-pituitary-adrenocortical stress axis. Crit Rev Neurobiol 10:371-394.

Herman J P, Cullinan WE. 1997. Neurocircuitry of stress: central control of the hypothalamo-pituitary-adrenocortical axis. TINS 20:78-84.

Houtani T, Nishi M, Takeshima H, Nukada T, Sugimoto T. 1996. Structure and regional distribution of nociceptin/orphanin $\mathrm{FQ}$ precursor. Biochem Biophys Res Commun 219:714-719.

I keda K, Kobayashi K, Kobayashi T, Ichikawa T, Kumanishi T, Kishida H, Yano R, Manabe T. 1997. Functional coupling of the nociceptin/ orphanin F Q receptor with the G-protein-activated K+ (GI RK) channel. Brain Res Mol Brain Res 45:117-126.

J acobson CD, Gorski RA. 1981. Neurogenesis of the sexually dimorphic nucleus of the preoptic area in the rat. J Comp Neurol 196:519-529. 
J akab RL, Leranth C. 1995. The septum. In: Paxinos G, editor. The rat nervous system. Sydney, Australia: Academic Press, Inc. p 405-442.

J enck F, Moreau J L, Martin J R, Kilpatrick GJ , Reinscheid RK, Monsma FJ , Nothacker H-P, Civelli O. 1997. Orphanin FQ acts as an anxiolytic to attenuate behavioral responses to stress. Proc Natl Acad Sci USA 94:14854-14858.

J hamandas KH, Sutak M, Henderson G. 1998. Antinociceptive and morphine modulatory actions of spinal orphanin FQ. Can J Physiol Pharmacol 76:314-324.

Kachaturian H, Lewis ME, Schafer MK-H, Watson SJ . 1985. Anatomy of the CNS opioid systems. TINS 8:111-119.

Kalkman HO, Fozard J R. 1991. 5HT receptor types and their role in disease. Curr Opin Neurol Neurosurg 4:560-565.

Kapusta DR, Sezen SF, Chang J K, Lippton H, Kenigs VA. 1997. Diuretic and antinatriuretic responses produced by the endogenous opioid-like peptide, nociceptin (orphanin FQ). Life Sci 60:PL 15-PL 21.

King MA, Rossi GC, Chang AH, Williams L, Pasternak GW. 1997. Spinal analgesic activity of orphanin $\mathrm{FQ} /$ nociceptin and its fragments. Neurosci Lett 223:113-116.

King TR, Nance DM. 1986. Neuroestrogenic control of feeding behavior and body weight in rats with kainic acid lesions of the lateral septal area. Physiol Behav 37:475-481.

Kiyama H, Emson PC. 1991. Colchicine-induced expression of proneurotensin mRNA in rat striatum and hypothalamus. Brain Res Mol Brain Res 9:353-358.

Knoflach F, Reinscheid RK, Civelli O, Kemp JA. 1996. Modulation of voltage-gated calcium channels by orphanin FQ in freshly dissociated hippocampal neurons. J Neurosci 16:6657-6664.

Koob GF, Swerdlow NR, Vaccarino F, Hubner C, Pulvirenti L, Weiss F. 1991. Functional output of the basal forebrain. In: Napier TC, Kalivas PW, Hanin I, editors. The basal forebrain: anatomy to function. New York: Plenum Press. p 291-305.

LachowiczJ E, Shen Y, Monsma FJ , Sibley DR. 1994. Molecular cloning of a novel $\mathrm{G}$ protein-coupled receptor related to the opiate receptor family. J Neurochem 64:34-40.

Lai CC, Wu SY, Dun SL, Dun NJ . 1997. Nociceptin-like immunoreactivity in the dorsal horn and inhibition of substantia gelatinosa neurons. Neuroscience 81:887-891.

Leventhal L, Mathis J P, Rossi GC, Pasternak GW, Bodnar RJ . 1998 Orphanin opioid receptor antisense probes block orphanin FQ-induced hyperphagia. Eur J Pharmacol 349:R1-R3.

Liebel J T, Swandulla D, Zeilhofer HU. 1997. Modulation of excitatory synaptic transmission by nociceptin in superficial dorsal horn neurons of the neonatal rat spinal cord. Br J Pharmacol 121:425-432.

Lou LG, Ma L, Pei G. 1997. Nociceptin/orphanin FQ activates protein kinase $\mathrm{C}$, and this effect is mediated through phospholipase $\mathrm{C} / \mathrm{Ca}^{2+}$ pathway. Biochem Biophys Res Commun 240:304-308.

Ma L, Cheng ZL, Fan GH, Cai YC, J iang LZ, Pei G. 1997. Functional expression, activation and desensitization of opioid receptor-like receptor ORL 1 in neuroblastoma x glioma NG108-15 hybrid cells. FEBS Lett 403:91-94.

Madeira MD, Sousa N, Paula-Barbosa MM. 1991. Sexual dimorphism in the mossy fiber synapses of the rat hippocampus. Exp Brain Res 87:537-545.

Makman MH, Lyman WD, Dvorkin B. 1997. Presence and characterization of nociceptin (orphanin FQ) receptor binding in adult rat and human fetal hypothalamus. Brain Res 762:247-250.

Mamiya T, Noda M, Takeshima H, Nabeshima T. 1998. Enhancement of spatial attention in nociceptin/orphanin FQ receptor-knockout mice. Brain Res 783:236-240.

Manabe T, Noda Y, Mamiya T, Katagirl H, Houtani T, Nishi M, Noda T, Takahashi T, Sugimoto T, Nabeshima T, Takeshima H. 1998. Facilitation of long-term potentiation and memory in mice lacking nociceptin receptors. Nature 394:577-581.

Mansour A, Thompson RC, Akil H, Watson SJ . 1993. Delta opioid receptor mRNA distribution in the brain: comparison to delta receptor binding and proenkephalin mRNA.J Chem Neuroanat 6:351-362.

Mansour A, Fox CA, Burke S, Meng F, Thompson RC, Akil H, Watson SJ . 1994. Mu, delta and kappa opioid receptor mRNA expression in the rat CNS: an in situ hybridization study. J Comp Neurol 350:412-438.

Mansour A, Fox CA, BurkeS, Akil H, Watson SJ . 1995a. Immunohistochemical localization of the cloned $\mu$ opioid receptor in the rat CNS. J Chem Neuroanat 8:283-305.

Mansour A, Fox CA, Akil H, Watson SJ . 1995b. Opioid receptor mRNA expression in the rat CNS: anatomical and functional implications. TINS 18:22-29.
Mansour A, Burke S, Pavlic RJ , Akil H, Watson SJ . 1996. Immunohistochemical localization of the cloned kappa 1 receptor in the rat CNS. Neuroscience 71:671-690.

Marchese A, Docherty J M, Nguyen T, Heiber M, Cheng R, Heng HH, Tsui LC, Shi X, George SR, O'Dowd BF. 1994. Cloning of human genes encoding novel $G$ protein-coupled receptors. Genomics 23:609-618.

Mathis J P, Ryan-Moro J , Chang A, Hom J S, Scheinberg DA, Pasternak GW. 1997. Biochemical evidence for orphanin $\mathrm{FQ}$ /nociceptin receptor heterogeneity in mouse brain. Biochem Biophys Res Commun 230:462-465.

Meng F, Taylor LP, Hoversten MT, U eda Y, Ardati A, Reinscheid RK, Monsma FJ, Watson SJ, Civelli O, Akil H 1996. Moving from the orphanin $\mathrm{FQ}$ receptor to an opioid receptor using four point mutations. J Biol Chem 271:32016-32020.

Meunier J C, Mollereau C, Toll L, Suaudeau C, Moisand C, Alvinerie P, Butour J L, Guillemot J C, Ferrara P, Monsarrat B, Mazarguil H, Vassart G, Parmentier M, Costentin J . 1995. I solation and structure of the endogenous agonist of opioid receptor-likeORL 1 receptor. Nature 377:532-535.

Minami T, Okuda-Ashitaka E, Nishizawa M, M ori H, I to S. 1997. Inhibition of nociceptin-induced allodynia in conscious mice by prostaglandin D2. $\mathrm{BrJ}$ Pharmacol. 122:605-610.

Mogil J S, Grisel J E, Zhangs G, BelknapJ K, Grandy DK. 1996a. Functional antagonism of mu-, delta- and kappa-opioid antinociception by orphanin FQ. Neurosci Lett 214:131-134.

Mogil J S, Grisel J E, Reinscheid RK, Civelli O, Belknap J K, Grandy DK. 1996b. Orphanin FQ is a functional anti-opioid peptide. Neuroscience 75:333-337.

Mollereau C, Parmentier M, Mailleux P, Butour J L, Moisand C, Chalon P, Caput D, Vassart G, Meunier J C. 1994. ORL 1, a novel member of the opioid receptor family. Cloning, functional expression and localization. FEBS Lett 341:33-38.

Mollereau C, Moisand C, Butour J L, Parmentier M, Meunier J C. 1996a. Replacement of $\mathrm{GIn}^{280}$ by His in TM 6 of the human ORL 1 receptor increases affinity but reduces intrinsic activity of opioids. FEBS Lett 395:17-21.

Mollereau C, Simons MJ, Soularue P, Liners F, Vassart G, Meunier J C, Parmentier M. 1996b. Structure, tissue distribution, and chromosomal localization of the prepronociceptin gene. Proc Natl Acad Sci USA 93:8666-8670.

Montes R, J ohnson AK. 1990. Efferent mechanisms mediating renal sodium and water excretion induced by centrally administered serotonin. Am J Physiol 259:R1267-R1273.

Montiel J L, Cornille F, Roques BP, Noble F. 1997. Nociceptin/orphanin FQ metabolism: role of aminopeptidase and endopeptidase 24.15. J Neurochem 68:354-361.

Monteillet-Agius G, Fein J , Anton B, Evans C. 1998. ORL-1 and mu opioid receptor antisera label different fibers in areas involved in pain processing. J Comp Neurol 399:373-383.

Morgan MM, Grisel J E, Robbins CS, Grandy DK. 1997. Antinociception mediated by the periaqueductal gray is attenuated by orphanin FQ. Neuroreport 8:3431-3434.

Murphy NP, Ly HT, Maidment NT. 1996. Intracerebroventricular orphanin FQ/nociceptin suppresses dopamine release in the nucleus accumbens of anaesthetized rats. Neuroscience 75:1-4.

Neal CR, Newman SW. 1989. Prodynorphin peptide distribution in the forebrain of the Syrian hamster and rat: a comparative study with antisera against dynorphin A, dynorphin B and the C-terminus of the prodynorphin precursor molecule. J Comp Neurol 288:353-386.

Neil JJ, Loewy AD. 1982. Decreases in blood pressure in response to L-glutamate microinjections into the A5 catecholamine cell group. Brain Res 241:271-278.

Nicol B, Lambert DG, Rowbotham DJ , Smart D, McKnight AT. 1996 Nociceptin induced inhibition of $\mathrm{K}^{+}$evoked glutamate release from rat cortical slices. Br J Pharmacol 119:1081-1083.

Nishi M, Houtani T, Noda Y, Mamiya T, Sato K, Doi T, Kuno J , Takeshima H, Nukada T, Nabeshima T, Yamashita T, Noda T, Sugimoto T. 1997. Unre strained nociceptive response and disregulation of hearing ability in micelacking the nociceptin/orphanin FQ receptor. EMBOJ 16:1858-1864.

Nishizuka M, Arai Y. 1983. Male-female differences in the intra-amygdaloid input to the medial amygdala. Exp Brain Res 52:328-332.

Noble F, Roques BP. 1997. Association of aminopeptidase N and endopeptidase 24.15 inhibitors potentiate behavioral effects mediated by nociceptin/orphanin FQ in mice. FEBS Lett 401:227-229.

Nothacker H-P, Reinscheid RK, Mansour A, Henningsen RA, Ardati A, Monsma FJ , Watson SJ , Civelli O. 1996. Primary structure and tissue distribution of theorphanin FQ precursor. Proc Natl Acad Sci USA 93:8677-8682. 
Okuda-Ashitaka E, Tachibana S, Houtani T, Minami T, Masu Y, Nishi M, Hiroshi T, Sugimoto T, I to S. 1996. I dentification and characterization of an endogenous ligand for opioid receptor homologue ROR-C: its involvement in llodynic response to innocuous stimuli. Mol Brain Res 43:96-104.

Pan YX, Xu J , Pasternak GW. 1996. Cloning and expression of a cDNA encoding a mouse brain orphanin FQ/nociceptin precursor. Biochem J 315:11-13.

Paxinos G, Watson C. 1986. The rat brain in stereotaxic coordinates. Sydney, Australia: Academic Press. Inc.

Plotsky PM, Cunningham ET, Widmaier EP. 1989. Catecholaminergic modulation of corticotropin-releasing factor and adrenocorticotropin. Endocrine Rev 10:437-451.

Pomonis J D, Billington CJ, Levine AS. 1996. Orphanin FQ, agonist of orphan opioid receptor ORL 1, stimulates feeding in rats. Neuroreport 8:369-371.

Quigley DI, McDougall J , Darland T, Zhang G, Ronnekliev O, Grandy DK, Allen RG. 1998. Orphanin FQ is the major OFQ 1-17-containing peptide produced in the rodent and monkey hypothalamus. Peptides 19:133-139.

Reinscheid RK, Nothacker H-P, Bourson A, Ardati A, Henningsen RA Bunzow J R, Grandy DK, Langen H, Monsma FJ, Civelli O. 1995 Orphanin FQ: a neuropeptide that activates an opioid-like G proteincoupled receptor. Science 270:792-794.

Reinscheid RK, Ardati A, Monsma FJ , Civelli O. 1996. Structure-activity relationship studies on the novel neuropeptide orphanin FQ. J Biol Chem 271:14163-14168.

Reinscheid RK, Higelin J, Henningsen RA, Monsma FJ , Civelli O. 1998. Structures that delineate orphanin FQ and dynorphin A pharmacologic selectivities. J Biol Chem 273:1490-1495.

Ribeiro-da-Silva A. 1995. The substantia gelatinosa of the spinal cord. In: Paxinos G, editor. The rat nervous system. Sydney, Australia: Academic Press, Inc. p 47-59.

Riedl M, Shuster S, Vulchanova L, WangJ , Loh HH, EldeR. 1996. Orphanin $\mathrm{FQ}$ /nociceptin-immunoreactivenervefibers parallel thosecontaining endogenous opioids in rat spinal cord. Neuroreport 7:1369-1372.

Rossi GC, Leventhal L, Pasternak GW. 1996. Naloxone sensitive orphanin FQ-induced analgesia in mice. Eur J Pharmacol 311:R7-R8.

Rossi GC, Leventhal L, Bolan E, Pasternak GW. 1997. Pharmacological characterization of orphanin $\mathrm{FQ}$ /nociceptin and its fragments. J Pharmacol Exp Ther 282:858-865.

Saito Y, Maruyama K, Saido TC, Kawashima S. 1995. N23K, a gene transiently up-regulated during neural differentiation, encodes a precursor protein for a newly identified neuropeptide nociceptin. Biochem Biophys Res Commun 217:539-545.

Saito $\mathrm{Y}, \mathrm{Maruyama} \mathrm{K}$, Kawano $\mathrm{H}$, Hagino-Yamagishi $\mathrm{K}$, Kawamura $\mathrm{K}$, Saido TC, Kawashima S. 1996. Molecular cloning and characterization of a novel form of neuropeptide gene as a developmentally regulated molecule. J Biol Chem 271:15615-15622.

Saito Y, Maruyama K, Saido TC, Kawashima S. 1997. Overexpression of a neuropeptidenociceptin/orphanin FQ precursor gene, N23K/N27K, induces neurite outgrowth in mouse NS20Y cells.J Neurosci Res 48:397-406.

Sandin J , Georgieva J , Schott PA, Ogren SO, Terenius L. 1997. Nociceptin/ orphanin microinjected into hippocampus impairs spatial learning in rats. Eur J Neurosci 9:194-197.

Saper CB. 1995. The central autonomic system. In: Paxinos G, editor. The rat nervous system. Sydney, Australia: Academic Press, Inc. p 107-135.

Schuligoi R, Amann R, Angelberger P, Peskar BA. 1997. Determination of nociceptin-like immunoreactivity in the rat dorsal spinal cord. Neurosci Lett 224:136-138.

Schulz S, Schreff M, Nuss D, Gramsch C, Hollt V. 1996. Nociceptin/orphanin FQ and opioid peptides show overlapping distribution but not co-localization in pain-modulatory brain regions. Neuroreport 7:3021-3025.

Schwerdtfeger WK, Buhl EH, Germroth P. 1990. Disynaptic olfactory input to the hippocampus mediated by stellate cells in entorhinal cortex. J Comp Neurol 292:163-177.

Shimohigashi Y, Hatano R, Fujita T, Nakashima R, Nose T, Sujaku T, Saigo A, Shinjo A, Nagahisa A. 1996. Sensitivity of opioid receptor-like receptor ORL1 for chemical modification on nociceptin, a naturally occurring nociceptive peptide. J Biol Chem 271:23642-23645.

Sim LJ , Childers SR. 1997. Anatomical distribution of mu, delta, and kappa opioid- and nociceptin/orphanin FQ-stimulated [ $\left.{ }^{35} \mathrm{~S}\right] \mathrm{Guanylyl}-5^{\prime}$-O( $\gamma$-thio)-triphosphate binding in guinea pig brain. J Comp Neurol 386:562-572

Sim LJ , Xiao R, Childers SR. 1996. Identification of opioid receptor-like (ORL 1) peptide-stimulated [35S]GTP gamma $\mathrm{S}$ binding in rat brain. Neuroreport 7:729-733.

Simerly RB. 1995. Anatomical substrates of hypothalamic integration. In: Paxinos G, editor. The rat nervous system. Sydney, Australia: Academic Press, Inc. p 353-376.
Simerly RB, McCall LD, Watson SJ . 1988. Distribution of opioid peptides in the preoptic region: immunohistochemical evidence for a steroidsensitive enkephalin sexual dimorphism. J Comp Neurol 276:442-459.

Sinchak K, Hendricks DG, Baroudi R, Micevych PE. 1997. Orphanin $\mathrm{FQ}$ /nociceptin in the ventromedial nucleus facilitates Iordosis in female rats. Neuroreport 8:3857-3860.

Spencer SE, Sawyer WB, L oewy AD. 1988. L-Glutamate stimulation of the zona incerta in the rat decreases heart rate and blood pressure. Brain Res 458:72-81.

Standifer KM, Cheng J , Brooks AI, Honrado CP, Su W, Visconti L M, Biedler J L, Pasternak GW. 1994. Biochemical and pharmacological characterization of mu, delta and kappa 3 opioid receptors expressed in BE (2)-C neuroblastoma cells. J Pharmacol Exp Ther 270:1246-1255.

Stanfa LC, Chapman V, Kerr N, Dickenson AH. 1996. Inhibitory action of nociceptin on spinal dorsal horn neurons of the rat, in vivo. $\mathrm{Br}$ J Pharmacol 118:1875-1877.

Stratford TR, Holahan MR, Kelly AE. 1997. Injections of nociceptin into nucleus accumbens shell or ventromedial hypothalamic nucleus increase food intake. Neuroreport 8:423-426.

Swanson LW. 1992. Brain maps: structure of the rat brain. New York: Elsevier.

Tian J H, Xu W, Fang Y, Mogil J S, Grisel J E, Grandy DK, Han J S. 1997a. $\mathrm{Bi}$-directional modulatory effect of orphanin $\mathrm{FQ}$ on morphine-induced analgesia: antagonism in brain and potentiation in spinal cord of the rat. Br J Pharmacol 120:676-680.

Tian J H, Xu W, Zhang W, Fang Y, Grisel J E, Mogil J S, Grandy DK, Han J S. 1997b. I nvolvement of endogenous orphanin FQ in electroacupuncture induced analgesia. Neuroreport 8:497-500.

U eda H, Yamaguchi T, Tokuyama S, Inoue M, Nishi M, Takeshima H. 1997. Partial loss of tolerance liability to morphine analgesia in mice lacking the nociceptin receptor gene. Neurosci Lett 237:136-138.

Urban J H, Bauer-Dantoin AC, Levine J E. 1993. Neuropeptide Y gene expression in the arcuate nucleus: sexual dimorphism and modulation by testosterone. Endocrinology 132:139-145.

Vaughan CW, Christie MJ . 1996. Increase by the ORL 1 receptor (opioid receptor-like 1 ) ligand, nociceptin, of inwardly rectifying $\mathrm{K}$ conductance in dorsal raphe nucleus neurons. Br J Pharmacol 117:1609-1611.

Vaughan CW, Ingram SL, Christie MJ . 1997. Actions of the ORL 1 receptor ligand nociceptin on membrane properties of rat periaqueductal gray neurons in vitro. J Neurosci 17:996-1003.

Wagner EJ, Ronnekleiv OK, Grandy DK, Kelly MJ . 1998. The peptide orphanin FO inhibits beta-endorphin neurons and neurosecretory cells in the hypothalamic arcuate nucleus by activating an inwardlyrectifying $\mathrm{K}^{+}$conductance. Neuroendocrinology 67:73-82.

Wang J B, J ohnson PS, I mai Y, PersicoAM, Ozenberger BA, E ppler CM, Uhl GR. 1994. CDNA cloning of an orphan opiate receptor gene family member and its splice variant. FEBS Lett 348:75-79.

Wang XM, Zhang KM, Mokha SS. 1996. Nociceptin (orphanin FQ), an endogenous ligand for the QRL 1 (opioid-receptor-like1) receptor; modulates responses of trigeminal neurons evoked by excitatory amino acids and somatosensory stimuli. J Neurophysiol 76:3568-3572.

Watson RE, Hoffmann GE, Wiegand SJ . 1986. Sexually dimorphic opioid distribution in the preoptic area: manipulation by gonadal steroids. Brain Res 398:157-163.

Wick MJ , Minnerath SR, Liana X, Elde R, Law PY, L oh HH. 1994. I solation of a novel cDNA encoding a putative membrane receptor with high homol ogy to the cloned mu, delta, and kappa receptors opioid. Brain Res Mol Brain Res 27:37-44

Wu YL, Pu L, Ling K, Zhao J, Cheng ZJ , Ma L, Pei G. 1997. Molecular characterization and functional expression of opioid receptor-like 1 receptor. Cell Res 7:69-77.

Xu XJ , Hao J X, Wiesenfeld-Hallin Z. 1996. Nociceptin or antinociceptin: potent spinal antinociceptive effect of orphanin $\mathrm{FQ}$ /nociceptin in the rat. Neuroreport 7:2092-2094.

Yamamoto T, Nozaki-Taguchi N, Kimura S. 1997. Analgesic effect of intrathecally administered nociceptin (orphanin FQ), an opioid receptorlike 1 receptor agonist, in therat formalin test. Neuroscience 81:249-254.

Yu TP, Xie CW. 1998. Orphanin FQ/nociceptin inhibits synaptic transmission and long-term potentiation in rat dentate gyrus through postsynaptic mechanisms. J Neurophysiol 80:1277-1284.

Yu TP, Fein J, Phan T, Evans CJ, Xie CW. 1997. Orphanin FQ inhibits synaptic transmission and long-term potentiation in rat hippocampus. Hippocampus 7:88-94.

Zamboni L, DeMartino C. 1967. Buffered picric acid formaldehyde, a rapid new fixative for electron microscopy. J Cell Biol 35:148A.

Zhu CB, Cao XD, Xu SF, Wu GC. 1997. Orphanin FQ potentiates formalininduced pain behavior and antagonizes morphine analgesia in rats. Neurosci Lett 235:37-40. 